\title{
bibliothèques décors
}

\author{
(XVII ${ }^{\mathrm{e}}$-XIX'e SIÈCLE) \\ sous la direction de \\ Frédéric Barbier, István Monok \\ \& Andrea De Pasquale
}

BIBLIOTHÈQUE DE L'ACADÉMIE HONGROISE DES SCIENCES

BIBLIOTHÈQUE NATIONALE CENTRALE DE ROME

\&

ÉDITIONS DES CENDRES 
YANN SORDET

D’un palais (I643) l'autre (I668) : les bibliothèques Mazarine(s) et leur décor ${ }^{1}$

La Bibliothèque Mazarine est aujourd'hui la seule bibliothèque en France à manifester depuis le $\mathrm{XVII}^{\mathrm{e}}$ siècle une continuité non seulement fonctionnelle - son accessibilité et sa vocation publique n'ont été qu'épisodiquement perturbées depuis I643 - mais également architecturale et décorative, puisqu'en dépit de (ou grâce à) quelques mutations qui font l'objet de cette étude, elle a conservé dans toute sa cohérence un cadre expressément conçu pour elle à partir de i646.

Rappelons que, sur le plan documentaire, Mazarin a eu trois bibliothèques : celle qu'il constitue à Rome avant son installation définitive à Paris $\left({ }^{6} 639\right)^{2}$; celle qu'il crée de toutes pièces à partir de I642, que Gabriel Naudé, sans doute recruté dès la fin de l'année I642, développe dans des proportions considérables, et qui est dispersée pendant la Fronde au début de l'année I652 ; celle, enfin, qu'il reconstitue dès son retour au pouvoir, dont la responsabilité est confiée à François de La Poterie, ancien assistant et successeur de Naudé. Des deux bibliothèques parisiennes de Mazarin, la première fut la plus considérable. Développée de manière fulgurante, en huit années elle dépassa les 40000 volumes ${ }^{3}$; un acte récemment découvert la dit même, en juin I650, " composée de cinquante six mille volumes dont la plupart sont rares \& précieux ${ }^{4}$ ». L'évaluation de sa volumétrie, à défaut de source catalographique ,

- I. Cette enquête sur le décor de la Bibliothèque Mazarine et ses vicissitudes a fait l'objet d'une première présentation en 2013, dans le cadre du colloque Ikonographie und Dekoration der Bibliotheken in der Zeit der Barock und Klassizismus, organisé à Eger. Poursuivies au-delà du colloque, les recherches ont donné lieu à un article publié dans le Journal des savants en 2015. C'est le texte de cet article que nous reproduisons ici, avec l'accord bienveillant du comité de rédaction du Journal des savants. $\square$ 2. Doit-on croire le P. Jacob qui estime cette bibliothèque à " plus de cinq mille volumes " (Traité des plus belles bibliothèques publiques et particulières, Paris, Rolet Le Duc, I644, p. 95) ? L'Inventario della biblioteca del card. Mazarino in Roma, conservé avec les papiers de Gabriel Naudé (BnF, ms. it. 478, f. I-18), ne comprend pas plus de 800 titres. La date des éditions les plus récentes (1639) laisse penser que le développement de la collection n'a guère été poursuivi après l'installation de Mazarin à Paris, mais cette bibliothèque semble avoir été maintenue à Rome au moins jusqu'en I648, date du dernier accroissement repéré : «mandata da S. E. in $9^{\text {bre }} \mathrm{I} 648$ " (" Bibliotheca

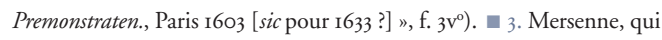
l'a vue en mars 1646, considère qu'elle " a desja 23 mille volumes ", et qu'une fois augmentée des " IO5 bales de livres " que Naudé vient tout juste de rapporter d'Italie, elle en comptera " 32 milles " (lettre à André Rivet, du 20 mars 1646, Leyde, Bibl. de l'université, BPL Lat. . 85-86, éd. dans Correspondance du P. Marin Mersenne, éd. Cornélis de Waard et al., XIV, Paris, CNRS, 1980, p. I52). Un an plus tard le même Mersenne l'estime à 30 ooo volumes " quorum sunt to ooo folio " (lettre à Samuel Sorbière du 2I mars I647, Bnf, Mss, n.a.f. 6204, f. 294,
Correspondance du P. Marin Mersenne..., ouvr. cité, XV, 1983, p. I40). En février I65I Naudé avance le chiffre de 40000 volumes : "à mon advis elle passoit les 40000 vol. dont il y en avoit plus de I2 000 fol. ", Aujourd'huy I4. fevrier I65I [" Mazarinade " consacrée au procès-verbal de visite de la bibliothèque à la requête du président Tubeuf, rédigé par Naudé], [s.l., s.n., s.d.], p. 4, Bibliothèque Mazarine (désormais BM), M Io 056 (Célestin Moreau, Bibliographie des mazarinades, Paris, Renouard, I851, $\mathrm{n}^{\circ}$ 3289). ${ }^{4}$. Archives nationales (désormais AN), S/6505. Il s'agit d'un brevet royal du 6 juin I650, par lequel le jeune Louis XIV entérine la "donation faite au publiqc par Monsieur le cardinal Mazarini en datte de ce jourd'huy de sa bibliothecq[ue] ", en la plaçant sous sa protection. Il convient alors de montrer que la taille de la bibliothèque renforce à la fois le bénéfice et la légitimité du geste, et partant devrait la prémunir contre la dispersion voulue par la Fronde parlementaire. Voir Yann Sordet, "Le premier acte de donation au public de la bibliothèque de Mazarin (1650) ", Histoire et civilisation du livre, $\mathrm{X}, 20 \mathrm{I} 4, \mathrm{p} .93-\mathrm{III}$. $\quad 5$. De la première bibliothèque parisienne il ne fut pas fait d'inventaire ; on dispose de sources fragmentaires, comme le catalogue publié par Naudé de la bibliothèque de Jean Descordes, acquise en bloc en I643, et que la tradition imposée par Naudé considère comme le noyau de la bibliothèque de Mazarin (Catalogus bibliothecae Cordesianae, Paris, Vitray, 1643), ou des listes de dons, d'acquisitions et de reliure à finalité comptable, remises par le bibliothécaire au cardinal (BnF, Mss, n.a.f. 5764-5765). Une partie de la première bibliothèque fut récupérée après la Fronde : les volumes concernés peuvent être repérés à partir de listes de récupérations 
repose nécessairement sur les estimations contemporaines, vraisemblablement toutes fournies par Naudé, soit directement soit qu'il les ait inspirées à ses visiteurs (Mersenne y compris). Ce chiffre la place, avec sans doute la bibliothèque ducale de Wolfenbüttel, au premier rang des collections européennes de son temps. Le contenu de la seconde bibliothèque parisienne de Mazarin est mieux identifié, principalement par l'inventaire que les exécuteurs testamentaires du cardinal en font dresser en I66I et I662 ${ }^{6}$. Il signale un peu moins de 26800 volumes imprimés et 2400 manuscrits, soit un total de 29200 unités matérielles. Amputé des sélections opérées à la demande de Colbert pour la bibliothèque du roi en I668, et notamment des manuscrits, cet ensemble constitue, sans solution de continuité, le noyau de l'actuelle Bibliothèque Mazarine.

Du point de vue architectural - en d'autres termes sur le plan des espaces et de l'organisation matérielle - Mazarin disposa de quatre bibliothèques successives : celle de son palais romain du Quirinal (aujourd'hui Palazzo Rospigliosi), laconiquement décrite par le Père $\mathrm{Jacob}^{7}$; celle de l'hôtel de Clèves, qui ne fut peut-être qu'un entrepôt provisoire de livres où furent stockées les premières acquisitions de Naudé ; celle qui fut organisée dans son nouvel hôtel parisien à partir de $\mathrm{I} 643$ en l'attente d'un espace $a d$ hoc, et que nous nous proposons aujourd'hui de localiser très précisément ; et celle qui fut installée dans l'aile que les architectes Pierre Le Muet et Maurizio Valperga, dont les responsabilités respectives sont encore mal définies, ont édifiée à partir de I646 le long de la rue Royale (qui deviendra bientôt la rue de Richelieu).

Cette nouvelle bibliothèque constitua pendant vingt ans l'écrin des deux collections parisiennes successives du cardinal. Devenue l'une des curiosités de Paris, que visitaient savants et amateurs, elle fut aussi un objet de fantasmes révélés par les discours de la Fronde. On peut en analyser l'organisation et le décor, d'après quelques descriptions contemporaines, grâce

\footnotetext{
dressées par François de La Poterie en I654 (BnF, ms. n.a.f. 5765, f. 4I et suiv.), et de mentions portées sur les plats lors de la vente de 1652, cf. I. de Conihout, "Les reliures de Mazarin ", dans Mazarin, les lettres et les arts, dir. ead. et P. Michel, Paris, Bibliothèque Mazarine ; Monelle Hayot, 2006, p. 278. 6. Bibliothèque Mazarine, ms. 4109-4III (imprimés) et BnF, n.a.f. 5763, f. 143-236 (manuscrits). En cours d'édition par la Bibliothèque Mazarine. $\mathbf{n}$ 7. Les livres y sont " conservez dans des armoires trélissez de fil doré, cizelées et dorées à surface, avec des vases, bustes et autres antiques sur le haut d'icelle ", Louis Jacob, Traité des plus belles bibliothèques..., ouvr. cité, I644, p. 95. 1 8. John Willis Clark, The Care of Books: An Essay on the Development of Libraries and their Fittings, Cambridge, The University Press, 1909, p. 272-274. André Masson, "Mazarin et l'architecture des bibliothèques au XVII ${ }^{\mathrm{e}}$ siècle ", Gazette des Beaux-Arts, 196I, p. 356. — 9. Léon de Laborde, Le palais Mazarin et les grandes habitations de ville et de campagne au dix-septième siècle, Paris, Franck, I846 ; Alfred Franklin, Histoire de la Bibliothèque Mazarine et du Palais de l'Institut, Paris, Welter, I90I ; Louis Battifol, "Les origines du palais Mazarin ", Gazette des Beaux-arts, 39, 1908-I, p. 265-289. Roger-Armand Weigert, « L'Hôtel de Chevry-Tubeuf et les débuts du palais Mazarin ", Bulletin de la Société de l'histoire de l'art français, 1948 (années 1945-46), p. 18-33; id., "Le Palais Mazarin, architectes et décorateurs ", Art de France, II, 1962, p. I47-169 ; id., " Du Palais Mazarin à la Bibliothèque nationale ", Mazarin, homme d'état et collectionneur (I602-I66I), Exposition du troisième centenaire de la mort de Mazarin, Bibliothèque nationale, I96I, p. XIII-XXX. Voir aussi Madeleine Laurain-Portemer, « Le palais Mazarin et l'offensive baroque de 1645-1650 ", Gazette des Beaux-Arts, 8I,

mars 1973, p. 151-168. Io. Claude Dulong, « Du nouveau sur le palais Mazarin ", Bibliothèque de l'École des Chartes, 153, 1995, p. I3I-155; Claude Mignot, « Le palais Mazarin : augmentations I644-1645 ", dans François Mansart, le génie de l'architecture française, Paris, Gallimard, 1998, p. I80-182 ; id., "Première "bibliothèque Mazarine", rue de Richelieu ", dans Les Bibliothèques parisiennes : architecture et décor, dir. Myriam Bacha et Christian Hottin, Paris, 2002, p. 68-70 ; Alexandre Cojannot, «Antonio Maurizio Valperga, architecte du cardinal Mazarin à Paris ", Mémoires publiés par la Fédération des sociétés historiques et archéologiques de Paris et de l'Tlle-de-France, $\mathrm{n}^{\circ}$ 54, 2003, p. 33-60 ; Id., "Le cardinal Mazarin et l'architecture française ", dans Mazarin, les lettres et les arts..., ouvr. cité, p. 93-IIO ; Bénédicte Gady, "Les décors peints du palais Mazarin : réattributions et redécouvertes ", Revue de la $B N F, \mathrm{n}^{\circ}$ 44, 2013, p. 65-68. II. La construction de l'hôtel de Chevry fut confiée à l'architecte et entrepreneur Jean Thiriot, collaborateur de Jacques Lemercier, comme l'a montré Roger-Armand Weigert en découvrant le marché passé en avril I635 (AN, MC/CXI/I44, fol. 317), "L'Hôtel de Chevry-Tubeuf et les débuts du palais Mazarin ", art. cit., I948, p. 20 ; Mazarin, homme d'état et collectionneur..., ouvr. cité, I96I, $\mathrm{n}^{\circ}$ 650. I2. Lequel agit sans doute déjà au nom et sur l'ordre de Mazarin, cf. Claude Dulong, " Du nouveau... ", art. cit., 1995, p. 137I38. C'est seulement à l'été I649, le 30 août, qu'un véritable acte de vente sera signé devant notaire, faisant passer Mazarin du statut de « locataire » à celui de propriétaire (AN, MC/CXII/54 ; l'acte est accompagné de l'inventaire de l'ensemble des titres de propriété établis depuis I64I, que Tubeuf transmet alors à Mazarin). I3. Claude Dulong, "Du nouveau... ", art. cit., 1995, p. 136.
} 
à un petit ensemble de dessins identifiés en 1908 dans les collections de la Bibliothèque royale du Danemark, et, par extrapolation rétrospective, à partir des éléments que l'actuelle Bibliothèque Mazarine en a conservés. En effet, par le fait d'une singulière continuité, qui s'explique à la fois par un souci d'économie et une interprétation plutôt rigoureuse des intentions testamentaires du cardinal, non seulement les livres mais le schéma d'organisation et la menuiserie de sa bibliothèque furent transférés, après sa mort, dans le bâtiment édifié par Louis Le Vau à partir de 1662 pour abriter les deux principales entités de sa fondation, à savoir le collège Mazarin et la Bibliothèque Mazarine [ill. 13].

Depuis les travaux de John Willis Clark et d'André Masson, l'historien des bibliothèques et l'historien de l'architecture considèrent que la Mazarine introduisit en France le modèle architectonique de la bibliothèque classique inventé pour l'Escurial au siècle précédent ${ }^{8}$. Celui-ci se révélant parfaitement compatible avec les principes naudéens publiés en I627 dans l'Advis pour dresser une bibliothèque, réimprimé à l'identique en I644, à la veille des travaux de Le Muet et Valperga.

Nous nous proposons de réexaminer ici la question des modèles et des sources qui ont pu déterminer l'organisation et la décoration de la Mazarine, en exploitant des documents qui apportent des précisions inédites sur la chronologie, les principes et les acteurs de ces aménagements.

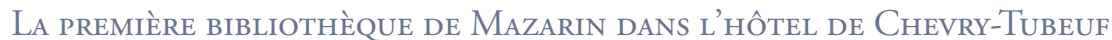

Depuis les travaux pionniers de Léon de Laborde et d'Alfred Franklin, la connaissance du palais Mazarin a été renouvelée de manière décisive par Roger-Armand Weigert ${ }^{9}$ et, au cours des vingt dernières années, plusieurs contributions ont permis d'en préciser le détail de la construction et des aménagements ${ }^{\mathrm{IO}}$. Claude Dulong a montré que dès I64I Mazarin, qui souhaitait résider dans la proximité du palais de Richelieu, avait jeté son dévolu sur l'hôtel de Chevry-Tubeuf, dans ce quartier des Petits-Champs où justement financiers et robins proches du premier cardinal-ministre s'étaient installés dans des hôtels nouvellement édifiés. Initialement construit pour le contrôleur général des Finances Charles Duret de Chevry sur une parcelle acquise en octobre I634 ${ }^{\text {II }}$, à l'intersection des récentes rues Neuve-des-PetitsChamps et Vivien, l'hôtel avait été revendu en I64I au président de la chambre des comptes Jacques Tubeuf ${ }^{\mathrm{I}}$. Celui-ci étendit la propriété vers l'ouest par l'achat de terrains vacants donnant sur les rues Neuve-des-Petits-Champs et Royale/Richelieu, sur lesquels il fit élever par l'architecte Pierre Le Muet trois corps de bâtiment parallèles, dans l'intention de les mettre en location. Dès l'été I643 Mazarin, Premier ministre depuis mai, prenait la décision de quitter l'hôtel de Clèves pour l'hôtel de Chevry-Tubeuf, et Anne d'Autriche le Louvre pour le Palais-Royal ${ }^{13}$. L'emménagement se fit en octobre. La croissance des collections du cardinal a de toute évidence joué un rôle fondamental dans la programmation des travaux d'extension du palais. En juin I644 était passé avec François Mansart le marché de construction des deux galeries superposées qui représentent aujourd'hui, après les considérables bouleversements des XVIII et $\mathrm{XIX}^{\mathrm{e}}$ siècles, les seuls vestiges cohérents du palais Mazarin : la galerie basse, qui accueillit une part importante des collections d'antiques du cardinal, et la galerie haute, décorée 
par Giovanni Francesco Romanelli dans les années I646-I647 d'après les Métamorphoses d'Ovide, constituent en effet aujourd'hui les galeries « Mansart » et « Mazarine » de la Bibliothèque nationale de France.

La construction de l'aile de la bibliothèque constitue l'étape suivante de ce vaste et rapide programme d'extension du palais Mazarin, et la dernière d'envergure avant la Fronde.

En exposant en 196I le marché de maçonnerie du bâtiment, qu’il avait récemment découvert, Armand Weigert en a retiré l'attribution à Mansart pour révéler qu'il fut confié à Pierre Le Muet, l'architecte qui avait déjà élevé les trois petits hôtels perpendiculaires à la rue Neuvedes-Petits-Champs, ainsi qu’à « Maurice Valpergue ». L’un et l'autre " architectes et ingénieurs du roi » étaient associés, dans ce marché du 3 mai 1646, à Nicolas Messier, l'entrepreneur qui avait déjà été chargé de la construction des galeries haute et basse ${ }^{\mathrm{T4}}$. Le Piémontais Antonio Maurizio Valperga, architecte préféré de Mazarin comme l'a montré Alexandre Cojannot, était arrivé à Paris en 1645 et avait aussitôt été commis à la direction des travaux du palais ; mais du fait de missions en Italie entre l'automne I646 et le printemps I647, c'est Le Muet qui conduisit seul la première partie du chantier. Valperga reprit sans doute la direction des travaux à son retour en I647, et jusqu’à son emprisonnement par les Espagnols en 1650. Aussi est vraisemblable l'hypothèse qui lui attribue le dessin de l'aile de la Traverse, qui en I647-I648 joint

- I4. AN, MC/CXII/47. Le document a été révélé et exposé par RogerArmand Weigert, Mazarin, homme d'état et collectionneur..., cat. cit., I96I, n 650. Et sa cote précisée dans $I d$., "Le Palais Mazarin, architectes et décorateurs ", art. cit., I962, p. 167 nI23. Le choix de ces architectes a été interprété comme un évincement de Mansart, Claude Mignot, « Le palais Mazarin : augmentations I644-I645 », art. cit., I998, p. I80-I8I. Claude Mignot a signalé deux autres séries de pièces qui documentent la construction : deux marchés de taille de pierre relatifs à l'écurie (MC/XLII/IO8, I9 avril et 2I mai 1646), et une liasse de mémoires quittancés par Tubeuf (MC/CXII/6I, I ${ }^{\text {er }}$ mars I653), Pierre Le Muet architecte (I59I-1669), Thèse de doctorat, Université Paris IV, t. I, p. 350-35I. I5. A. Cojannot, "Antonio Maurizio Valperga... ", art. cit., 2003, p. 39. Voir aussi : Claude Dulong, "Un entrepreneur de Mazarin : Nicolas Messier ", Bulletin de la Société de l'histoire de Paris et de lîle de France, 1992-1994 (1997), p. 48-50. 1 16. Ces dimensions sont confirmées par le mémoire du couvreur de 1649, qui évoque 75 toises un pied de couverture d'ardoise ( $c f$. infra), ainsi que par un procès-verbal de toisé exécuté par Louis Le Vau le $\mathrm{I}^{\mathrm{er}}$ juin I66I, au moment de la division du palais Mazarin, qui décrit un bâtiment de 76 toises un pied, y compris l'épaisseur des murs ; ce dernier document a été retrouvé par Henri Lacaille dans les Archives de Monaco, il devait accompagner un plan levé par Le Vau, aujourd'hui non localisé, H. Lacaille, "Le partage du palais Mazarin à la mort du cardinal ", Correspondance historique et archéologique, VII, I900, p. 336. I7. I toise = I,949 m. Les dimensions intérieures de la grande galerie, d'après le toisé du maçon Nicolas Messier ( $c f$. infra), sont de 32 toises, confirmées par l'échelle du plan partiel conservé à Copenhague ; à quoi il convient d'ajouter 6 toises et 6 pieds pour les pièces (vestibule, cabinet et salon) et l'épaisseur des murs de la partie nord, visible sur le plan de Copenhague ; dans la partie sud, il faut compter encore avec une salle de 6 toises et 6 pieds de long, partie intégrante de la bibliothèque (le toisé de maçonnerie de I648 la désigne comme « chambre proche la bibliothèque ", des marchés d'entretien des vitres de I654 et de I657 ( $c f$. infra) comme la "salle avant que d'entrer à la bibliothèque »). Dans une lettre à Grémonville de juin 1646, alors que le bâtiment n'est pas encore élevé,
Naudé, désignant la seule grande galerie, évoquait une bibliothèque de 30 toises ; il donna plus tard les chiffres erronés de " neuf ou dix toises " puis de " douze thoises" (Aujourd'huy I4. fevrier I65I..., ouvr. cité, p. 3 ; Advis a nosseigneurs de Parlement, sur la vente de la bibliotheque de Mr. le Card. Mazarin, [1652], p. 2, BM, M I0052, cf. Moreau, Bibliographie des mazarinades..., $\mathrm{n}^{\circ}$ 476). Alfred Franklin a relevé cette approximation (Les Anciennes Bibliothèques de Paris..., Paris, Imprimerie nationale, t. III, I873, p. 55, n. 7). L'hypothèse la plus vraisemblable est que Naudé a donné ici les dimensions de la salle principale qu'occupait la bibliothèque de Mazarin dans l'ancien hôtel de ChevryTubeuf, avant son transfert dans la nouvelle aile. I 18 . Les galeries conçues par Mansart ne sont alors pas achevées. Naudé poursuit : «on travaille puissament a la gallerie des statues et a tout le reste du palais, où les maçons et les peintres sont esgalement occupez ", BnF, Mss, n.a.f. 6500, f. 9v ${ }^{\circ}$, éd. par Kathryn Willis Wolfe et Philip J. Wolfe, Lettres de Naudé à Grémonville, Paris ; Seattle ; Tübingen, 1986, p. 32. - I9. Une restitution de la distribution du palais avant 1646 a été proposée par Cl. Mignot ( Le palais Mazarin : augmentations I644I645 ", art. cit., p. I82) sur la base du marché de vitrerie de 1657 publié par Weigert - restitution qui ne localise pas la bibliothèque. 1 20. Le 2 février il est déjà en route pour Paris, d'après une lettre du P. Niceron à Mersenne datée de Rome (Correspondance du P. Marin Mersenne..., ouvr. cité, XI (1642), 1970, p. 32). = 21. D'après Ph. J. Wolfe, entre le 4 décembre 1642 et le Io avril I643, date de rédaction du Mémoire confidentiel adressé au Cardinal Mazarin. On note que dès le 4 avril 1643 Gassendi qualifiait Naudé d' "Eminentissimi Cardinalis Mazarini bibliothecario ", Correspondance du P. Marin Mersenne..., ouvr. cité, XI (1643), p. I24. 22 . Livraison du 30 janvier $1644\left(\mathrm{n}^{\circ} \mathrm{I} 3, \mathrm{p} .80\right)$. 23. Le seul détail un peu précis qu'il donne concerne " quatre cens volumes infolio, couverts de maroquin incarnat, avec des filets d'or ", qui désignent la collection de Brienne, acquise par Richelieu pour le Roi puis sans doute laissée à Mazarin par Anne d'Autriche. Il précise également que " tous les jeudys, depuis le matin jusqu'au soir, elle est commune a tous ceux qui y veulent aller estudier ", L. Jacob, Traicté des plus belles bibliothèques..., ouvr. cité, I644, p. 488 et 487. 
la bibliothèque au corps de logis principal en passant derrière les trois hôtels jadis construits par Le Muet pour Tubeuf ${ }^{15}$.

Le marché de mai I646 évoque un bâtiment de 74 toises de long (soit environ $\mathrm{I} 44 \mathrm{~m}$ ) ${ }^{\mathrm{I}}$, à édifier le long de la rue Royale (de Richelieu), qui comprendra des écuries au rez-de-chaussée et un premier étage distribué en « bibliotheque » et " logement "; la hauteur de la voûte des écuries est déterminée par la nécessité d'établir le plancher des appartement et bibliothèque de plain-pied avec celui des bâtiments déjà existants. La bibliothèque, qu'un toisé de 1648 récemment découvert permet d'évaluer à 46 toises (soit près de $90 \mathrm{~m}$ ), galerie principale et dépendances comprises, n'occupait donc qu'une partie du premier étage du nouveau bâtiment ${ }^{17}$. De cette aile, il ne subsiste aujourd'hui qu'un segment de $13 \mathrm{~m}$ de long sur la rue de Richelieu, correspondant à deux travées originelles (portées à trois travées par l'ouverture postérieure d'une fenêtre supplémentaire sur chaque façade, $c f$. ill. I). Elles constituaient l'extrémité nord de l'aile, et furent partiellement séparées du corps de bâtiment principal au moment du percement en 1683 de la rue Neuve Mazarin (devenue rue Colbert), qui joignit la rue de Richelieu par une arche ménagée sous le bâtiment de Le Muet et Valperga. Leur isolement relatif explique qu'elles aient échappé pour partie aux restructurations effectuées après la mort de Mazarin, successivement pour le duc de Nevers, la marquise de Lambert, la banque de Law, la Bibliothèque royale puis nationale.

Les travaux commencèrent rapidement, comme en témoigne une lettre de Naudé à Grémonville du I9 juin I646 : " [Son Éminence] faict bastir au sien [palais] une escurie pour cent chevaux et une bibliotheque au dessus qui sera longue de 30 toises au lieu que la nostre d'à présent, quoy qu'augmenté depuis vostre depart de deux chambres, n'en a que $3^{18}{ }^{18}$ \%. Avant d'en venir à cette bibliothèque au décor et à l'organisation inédits en France, reconnaissons que nous sommes mal renseignés sur le sort des livres de Mazarin avant leur implantation dans la galerie de Le Muet-Valperga, la connaissance approximative que nous avons de l'organisation de l'hôtel de Chevry-Tubeuf sous Mazarin n'ayant pas permis jusqu' ici leur localisation ${ }^{19}$.

Naudé était rentré d'Italie à la fin de l'hiver $1642^{20}$. Mazarin - la correspondance entre les deux hommes en témoigne - avait manifesté dès I64I son intention de le prendre à son service. Le recrutement fut vraisemblablement conclu en décembre $1642^{21}$. Les documents comptables laissés par Naudé prouvent que, dès le mois d'octobre I643, la bibliothèque en gestation, qui compte déjà la collection de Jean Descordes acquise en bloc durant l'été, est transportée dans l'hôtel de Chevry-Tubeuf depuis l'hôtel de Clèves, que Mazarin occupait depuis son installation définitive à Paris. Sans doute est-elle implantée dès cette époque dans l'aile gauche de l'hôtel de Chevry-Tubeuf, dans un espace que nous pensons avoir précisément localisé. Elle est en tout cas accessible aux chercheurs, au plus tard au tout début de l'année i644. En témoigne la Gazette de France, qui annonce en janvier I644 que Mazarin accueille dans son hôtel une "Académie pour tous les doctes \& curieux, qui y vont en foule tous les jeudis depuis le matin jusques au soir feuilleter sa belle bibliothèque, ornée d'environ neuf mille volumes, en toutes sciences, dont le nombre croist encor de jour en jour par les soins que prend Son Éminence de satisfaire aussi bien en ce point les gens de lettres comme il fait tous les autres ${ }^{22}{ }^{2}$. On ne sait rien de son organisation, de son ameublement et de sa décoration. Le P. Jacob, qui fréquente la bibliothèque de Mazarin dans son premier local, dans une notice aussi floue que flagorneuse, n'en fournit aucune description ${ }^{23}$. Le P. Mersenne, qui la vit en mars I646,

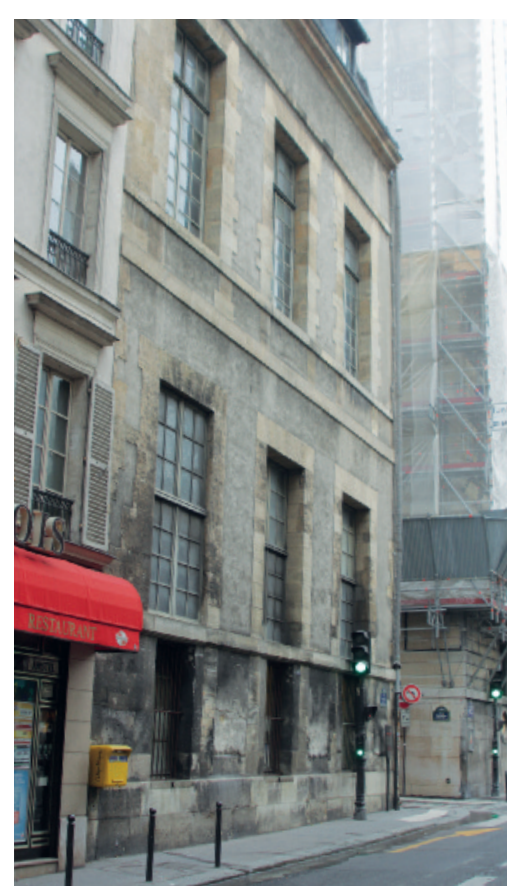

I. Partie conservée de l'aile de la bibliothèque du palais Mazarin édifiée entre I646 et I648 (58, bis rue de Richelieu. 2013). 
ne nous éclaire pas davantage ${ }^{24}$. Tout au plus des notes comptables découvertes dans les papiers de Gabriel Naudé à sa mort, et remises à Colbert, fournissent-elles quelques précisions sur la chronologie et la nature des prestations : en octobre I643 Mazarin rétribua ainsi l'ouvrage de dix compagnons menuisiers "qui travailloient à la biblioteque chez Mr. Tubeuf ${ }^{25}$ ".

Les travaux de construction de la nouvelle bibliothèque, initiés au printemps I646, ont dû se poursuivre jusqu'en I648. On avait jusqu' ici peu de renseignements sur leur chronologie, comme sur l'implantation de la collection de livres une fois le bâtiment livré, aménagé et décoré. La correspondance de Naudé et de Mazarin entre I643 et I648 est naturellement lacunaire, puisque les seuls échanges conservés correspondent à l'éloignement de Naudé lors de ses campagnes de prospection de livres en France, en Italie ou en Allemagne. On peut le regretter : l'élaboration de la bibliothèque, le choix de son implantation, de son organisation, de sa décoration, les étapes de sa conception, ont sans doute fait l'objet d'échanges entre les deux hommes dont le témoignage écrit n'a pas été conservé ${ }^{26}$. Or l'analyse de documents encore insuffisamment exploités apporte des précisions inédites sur les travaux conduits dans le palais Mazarin entre I646 et I653. Il s'agit d'un ensemble de mémoires de divers ouvrages, pour la plupart visés et arrêtés par Pierre Le Muet et Maurizio Valperga en I648 et I649, acquittés par Tubeuf et déposés auprès de son notaire le $\mathrm{I}^{\mathrm{er}}$ mars $\mathrm{I} 653^{27}$. Les travaux concernent principalement deux ailes du palais, celle des écuries et bibliothèque, et celle de la Traverse. Cette dernière était édifiée parallèlement à la rue Neuve-des-Petits-Champs, joignant à l'est l'ancien hôtel de Chevry-Tubeuf et les galeries de Mansart, à l'ouest le sud de l'aile de la bibliothèque ; nouveau centre de gravité du palais, elle accueillera l'appartement « neuf » ou « d'hiver » du cardinal ${ }^{28}$.

24. "Je veis dernierement la bibliotheque du Cardinal Mazarin, qui a desja 23 mille volumes. Le Sr Naudé qui vient d'arriver d'Italie avec Ios bales de livres, la fera, dit-on, monter à 32 mille ; s'ils poursuivent, ce sera la plus nombreuse de l'Europe ", lettre à André Rivet, du 20 mars I646, doc. cit. supra, note 3. 25. Diverses observations tirées de quatre livres ou registres... trouvés dans les papiers de feu Mr. Naudé, BnF, ms. italien 478 ( ${ }^{\mathrm{e}}$ pièce), f. $24 \mathrm{v}^{\circ}$. Également : " Despences pour les meubles, fournitures et entretennement de lad. bibliotheque du mercredi 9 septembre 1643 ", BnF, Mss, n.a.f. 5764 , f. I2 et suiv., notamment : " pour la serrure et clés du cabinet de chez Mr. Tuboeuf [...], pour apporter de l'hostel de Cleves les coffres et livres qui sont au mesme cabinet ». Les dépenses de transport de livres, menuiserie, tapisserie, fournitures courantes, meubles, reliure et frais de mission, se poursuivent en I644. Franklin est le premier à avoir cité ces comptes rendus comptables (La Bibliothèque Mazarine..., ouvr. cité, p. I4), dont

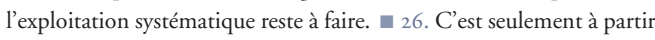
de la Fronde des Princes (I65I-I652), comme l'a noté Philip Wolfe, que leur correspondance devient régulière. Elle concerne alors, assez fréquemment, le sort de la bibliothèque, devenue un objet d'inquiétude. 27 . AN, MC/CXII, 6I ( $\mathrm{I}^{\mathrm{er}}$ mars I653). Tubeuf entendait recouvrer les sommes concernées auprès de Mazarin, conformément au contrat de vente du 30 août I649. Cette liasse a été signalée par Claude Mignot (Pierre Le Muet..., thèse cit., p. 350), et les données relatives à Valperga exploitées par Alexandre Cojannot, "Antonio Maurizio Valperga... ", art. cit., 2003, p. 38. Elle apporte pour l'histoire de la construction et des aménagements du palais Mazarin à la veille de la Fronde des données inédites considérables, et la plupart des éléments que
Claude Dulong regrettait en 1995 de n'avoir pas trouvés, " Du nouveau... ", art. cit., I995, p. I44. $=28$. Sur le décor des pièces de l'appartement d'hiver, voir les hypothèses récentes de B. Gady, «Les décors peints du palais Mazarin... ", art. cit., p. 65-68. 129. Parties des ouvrages de serrurerie faicts et fournys pour les bastimens et grande escurye de Monseigneur Eminentissime cardinal Mazarini par $\mathrm{Mr}$ Anthoine Le Maistre, arrêté le I8 septembre I648 par Valperga (AN, MC/CXII, 6I, $\mathrm{I}^{\mathrm{er}}$ mars 1653 ). 130 . Jugement de tout ce qui a esté imprimé contre le cardinal Mazarin depuis le sixième janvier jusques à la declaration du premier avril mil six cens quarante neuf [Mascurat, $\mathrm{I}^{\mathrm{re}}$ éd.], [Paris, I649], p. I89 et I76. 3I. Ibid., p. I90. Naudé dit avoir fait imprimer cette inscription, datée de 1648 , "de la façon qu'elle devoit estre gravée ". Nous ne connaissions qu'un seul exemplaire de cette impression figurée (BnF, ms. fr. 22592), avant que l'apparition d'un second en décembre 2013 nous permette d'en faire l'acquisition pour la Bibliothèque Mazarine $\left(2^{\circ}\right.$-I0924 Rés). Voir Y. Sordet, « Le premier acte de donation... ", art. cit., 20I4, p. IO5. " 32. "Une grande porte brisée qui est sur la rue pour entrer dans la bibliotecque avec la grille de fer dessus, faicte de gris à deux couches ", Autre mémoire d'ouvrages de peinture gris faictes au bastiment neuf de son éminence $\left(2^{\mathrm{e}}\right.$ partie $\mathrm{du}$ Mémoire des ouvrages de peinture faictes par Thomas Boudan dans le vieil logis de Monseigneur le cardinal par commandement de Monsieur de Valpergue, commencées en mai $\mathrm{I} 648, \mathrm{AN}, \mathrm{MC} / \mathrm{CXII} / 6 \mathrm{I} ; \mathrm{I}^{\mathrm{er}}$ mars 1653). Cette porte sur rue est peut être la deuxième (en partant de la droite, i.e. du sud) que montre l'élévation de Gomboust de 1652 [ill. 2]. 
Les livraisons de serrurerie, effectuées en fonction des besoins des corps de métiers (essentiellement maçons et charpentiers), dans leur échelonnement, nous laissent supposer que l'essentiel des structures maçonnées a été élevé avant avril I647, qu'entre avril et octobre I647 on a travaillé à la charpente de l'aile de la bibliothèque, et à partir du 22 octobre à sa couverture $^{29}$. Le 7 février 1648 , on note encore la livraison de « chesneaux et bavettes pour la charpenterye de l'appartement de Monsieur Naudé ", qui occupait trois chambres situées au-dessus des pièces faisant suite à la bibliothèque. Les aménagements et la décoration occupent l'année I648. L'essentiel des travaux de maçonnerie intérieure (cloisonnement, établissement des plafonds, planchers et cheminées, pavage) fut exécuté par l'entrepreneur désigné par le marché de I646, Nicolas Messier, entre le 30 janvier et le 20 septembre. Les travaux de peinture de la bibliothèque, de ses accès et de l'appartement de Naudé, confiés au peintre en bâtiment Thomas Boudan et supervisés par Valperga, ont commencé en mai I648, et seront visés par Le Muet en novembre 1649. Le garnissage des vitres a été effectué par le vitrier Simon Rallus avant le 29 septembre I648, date à laquelle son mémoire est arrêté par Valperga. Portes et fenêtres de la bibliothèque ont été ferrées et équipées de serrurerie avant le 20 décembre 1648 (mémoire arrêté par Valperga).

Les travaux de menuiserie dans l'aile de la bibliothèque et celle de la Traverse ont été exécutés dans le courant de l'année I648, sans doute assez tôt pour la bibliothèque, du moins avant l'intervention du peintre ( $c f$. infra). La plupart des mémoires en sont arrêtés à l'automne ; le 20 décembre notamment est visée par Valperga la réalisation d'une grande porte sculptée " pour aller a la bibliotecque ». Le mémoire général du maçon Nicolas Messier est arrêté le 26 septembre 1648 , et celui du charpentier le 2 octobre, tous deux par Valperga. Le mémoire des ouvrages de couverture d'ardoise, qui fait état pour l'aile de la bibliothèque d'une toiture très exactement de 75 toises, I pied 3/4 de long, est arrêté seulement le 29 septembre 1649.

À la fin de l'année I648, à la veille de la radicalisation de la Fronde (en janvier suivant la cour fuit Paris pour Saint-Germain et le Parlement décrète Mazarin «perturbateur du repos public »), le mobilier de la bibliothèque est donc en place et son décor achevé. Mais l'installation complète des livres n'a pu se faire, ni les derniers aménagements que la vocation publique de la bibliothèque requérait. Celle-ci n’a pas recouvré, à cette date, la " publicité » qui était la sienne dans l'ancien hôtel de Chevry-Tubeuf. C'est ce qui apparait dans la correspondance qu'entretiennent Naudé et son maitre pendant la Fronde, et dans le Mascurat (I649). Le bibliothécaire y évoque de manière récurrente un projet en devenir imminent mais non réalisé : « sans luy, Paris ne seroit pas à la veille $\mathrm{d}$ 'avoir une bibliothèque publique la plus belle qui soit au monde..." ; " elle sera ouverte pour tout le monde sans excepter ame vivante ". À Saint-Ange, qui cherche deux livres, Naudé fait encore répondre par Mascurat : «Ils seront peut-estre dans cette grande bibliotheque de plus de quarante mille volumes, que le cardinal Mazarin auroit desja donnée au public sans les troubles de ces deux dernieres années ${ }^{30}$ ". On a prévu pour le public « une entrée particulière, qui sera dans la rue de la porte de Richelieu, $\&$ la chose estoit desja si advancée, que lors de la sortie du Roy [i.e. le 6 janvier I649], on gravoit en marbre noir \& lettres d'or, l'inscription qui devoit estre sur ladite porte, pour advertir tous les passans d'y entrer ${ }^{31}$. Cette porte sur la rue, dispositif essentiel du projet de bibliothèque publique, a sans doute été mise en place au début de l'année I648 ; sa mise en peinture grise fait partie des travaux réalisés par le peintre Thomas Boudan à partir de mai ${ }^{32}$. 
Il est un autre document qui révèle cet inachèvement, et que nous considérons désormais comme décisif pour localiser la première bibliothèque de Mazarin. Il s'agit du Procès-verbal de la visite de la bibliothèque effectuée le I4 février I65I, à la requête du président Tubeuf, et dont Naudé assura la rédaction et la publication ${ }^{33}$. Plusieurs fois cité, ce document n’a jamais été analysé sérieusement dans une perspective topographique. Les livres y apparaissent répartis grossièrement par matières, dans cinq espaces principaux : «la grande salle du petit corps de logis qui joint au grand ", trois " entresols [...] qui sont sur la montée de la garderobe ", et " la grande Bibliothèque ", elle même composée de la "grande gallerie " précédée de deux " chambres " ${ }^{34}$. Rien n'autorise à penser que la "grande salle du petit corps de logis » et les trois entresols se trouvent dans la proximité de la nouvelle bibliothèque (ici « la grande Bibliothèque »). Je considère pour ma part que la topographie sur laquelle repose la description de Naudé est fort éclatée et localiserais volontiers ces salles dans l'ancien hôtel de Chevry-Tubeuf, précisément dans son aile gauche. Les « trois entresols " correspondent très exactement à trois entresols contigus décrits dans un état général des vitres de février 1654. Celui-ci évoque successivement la salle dite des Suisses, celle des gentilshommes, et un office, chacune de ces pièces disposant d'un entresol au-dessus, et faisant partie de «l'appartement ou estoit l'ancienne bibliotèque à l'aisle gauche en entrant ${ }^{35}$. Ces trois pièces apparaissent à nouveau en 1657 , dans un autre état général des vitres, mais sans plus aucune référence à l' " ancienne bibliothèque ", dont le souvenir est sans doute moins immédiat ${ }^{36}$. Quant au " petit corps de logis ", où se trouve la salle principale de cette première bibliothèque, il désigne vraisemblablement un corps de bâtiment édifié sur l'arrière du premier des trois petits hôtels jadis construits par Le Muet, à l'ouest de l'aile gauche de l'hôtel de Chevry-Tubeuf, et assurant son articulation avec les deux galeries superposées plus récemment édifiées par Mansart. Les marchés de vitrerie de 1654 et de I657 le désignent comme " corps de logis du milieu ", " où est la monstre de l'horloge ». Il est visible sur le plan de Jacques Gomboust publié en I652 ${ }^{37}$ [ill. 2]. Nous savons de Naudé (cf. supra n. I7) que cette salle principale mesurait entre 9 et I2 toises de long (soit

2. Jacques Gomboust, [Plan de Paris], vers 1652 (Bibliothèque de l'Institut de France).

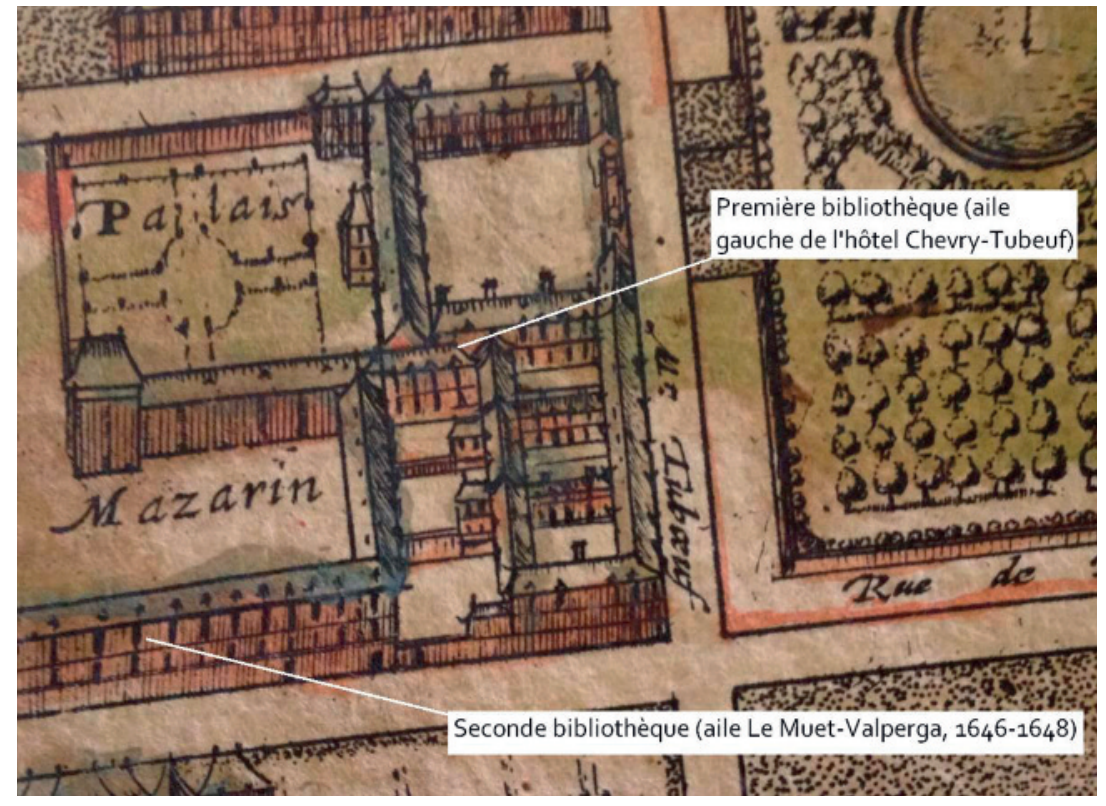


entre 17 et $24 \mathrm{~m}$ ) ; les trois entresols de l'aile gauche de l'hôtel de Chevry-Tubeuf, avec lesquels elle communiquait sans doute, servaient de toute évidence de magasins. Nous avons l'assurance d'avoir trouvé ici la localisation primitive de la bibliothèque de Mazarin dans le palais.

La répartition des collections révélée par le procès-verbal de visite de I65I laisse entendre que l'ensemble des volumes, au moment de la Fronde, n’a pas encore été transféré dans la nouvelle bibliothèque. D'autres éléments viennent à l'appui d'un aménagement inachevé : l'organisation systématique des collections n'y est pas d'une grande rigueur ; et dans trois espaces au moins se trouvent des livres entreposés sur le sol " faute de place sur les tablettes », dans l'ancienne bibliothèque (premier entresol) comme dans la nouvelle (seconde chambre avant la galerie, et grande galerie elle-même $)^{38}$. La vente publique des livres organisée aux mois de janvier et février I652 vida la totalité de ces espaces, aussi bien la nouvelle bibliothèque, dont l'installation n'était pas achevée, que l'ancienne, dont on ignore encore l'aménagement et le décor.

Les seules sources dont on dispose en la matière correspondent à la seconde bibliothèque de Mazarin, reconstituée après la Fronde dans la galerie de l'aile Le Muet-Valperga, dont elle n'occupera sans doute jamais la totalité de la menuiserie. On connaît la description de Sauval, publiée en 1724 seulement mais sans doute rédigée vers 1655 :

cette illustre bibliothèque est dans une gallerie longue de trente toises ou environ, large de quatre \& demi, couverte d'une voute haute de plus de cinq, éclairée de huit croisées, $\&$ environnée de deux ordonnances de tablettes. Les premières sont pleines de livres in-quarto $\mho$ in-folio, $\mho$ de plus accompagnées d'un grand pupitre à hauteur d'appui qui règne tout autour, $\&$ de cinquante colonnes corinthiennes de bois, fort hautes \& travaillées

- 33. Ouvr. cité, supra, n. 3. Ce procès-verbal fut imprimé à 300 exemplaires, d'après le compte que nous avons retrouvé dans les papiers laissés par Naudé, Diverses observations tirées de quatre livres ou registres... trouvés dans les papiers de feu Mr. Naudé, BnF, ms. italien 478 ( $2^{\mathrm{e}}$ pièce), f. $3 \mathrm{Ov}^{\mathrm{o}}$. 134 . Le nombre de pièces est conforme à celui que Naudé donne en 1652, en évoquant " tous les thresors ramassez dans l'enclos de sept chambres remplies de bas en haut, \& dont la Gallerie de douze [sic] thoises n'est comptée que pour une " (Advis a nosseigneurs de Parlement, sur la vente de la bibliotheque..., ouvr. cité). I 35 . Estat general de touttes les vitres et chassis de verre qui sont dans le palais de monseigneur le cardinal, quil convient entretenir en bon et suffizant estat... (I8 février I654), BnF, Mss, n.a.f. 21194, f. 3V $\mathrm{V}^{\circ}$. Le document a été signalé par R.-A. Weigert en 1962 ( "Le Palais Mazarin, architectes et décorateurs ", art. cit., p. 160). $=36$. Estat general de touttes les vitres et chassis de verre qui sont dans le pallais de Monseigr le Cardinal, quill convient entretenir en bon et suffisant estat de grosses et menues réparations (20 mai 1657), AN, MC/XVC/25, éd. par R.-A. Weigert, "Le palais Mazarin en 1657 ", Humanisme actif: Mélanges d'art et de littérature offerts à Julien Cain, Paris, Hermann, I968, I, p. 385-398 (spécialement p. 394). En janvier 1654 François de La Poterie avait encore fait transporter dans la nouvelle bibliothèque une centaine de volumes doubles ou dépareillés qui étaient restés " dans la chambre des livres doubles audessous de la vieille bibliothecque ", BnF, Mss., n.a.f. 5765, f. 64-65. - 37. Jacques Gomboust, Lutetia, Paris, I652. 10. Dans la "grande salle du petit corps de logis qui joint au grand ", se trouvent les livres de droit civil et philosophie in-folio, ainsi que de théologie in-quarto ; dans le " $\mathrm{I}^{\mathrm{er}}$ entresol ", « livres en médecine, chymie, \& histoire naturelle de toute sorte de volumes "; le " second entresol " est "plein de bibles en toutes langues... jusqu'au nombre avec les autres MSS \& 6 . d'environ 200 comme aussi de commentateurs sur la bible en toute sorte de volumes "; le « troisieme entresol » est " plein de livres MSS... de toute sorte, tant pour les matieres, que pour les volumes "; dans la "premiere chambre " de la nouvelle bibliothèque, "livres en droit canon, politique, \& autres matieres mélées en diverses sciences "; dans la seconde, "livres lutheriens, calvinistes, sociniens, $\&$ autres heretiques en toutes langues, comme aussi [...] livres hebreux, syriaques, arabes, ethiopiens, $\&$ semblables orientaux de toutes les sortes, avec beaucoup qui estoient à terre faute de place sur les tablettes \& pulpitres "; dans la " grande gallerie ", enfin, " toute l'histoire tant ecclesiastique que profane, tant universelle que particuliere de toutes les nations avec les 350 vol. MSS in fol. reliez en maroquin incarnat, \& recueillis par Monsieur de Lomenie : la mathematique au nombre d'environ 3500 vol. les Peres, la scholastique, la controverse, les sermonaires, les livres de l'imprimerie du Louvre, \& quasi toutes les humanitez, avec plus de livres couchez par terre, qu'il n'en pourroit tenir dans trois chambres de juste grandeur, \& beaucoup de grands volumes de chartes, stampes, voyages, entrées, \&... ", Aujourd'huy I4. fevrier I65I..., ouvr. cité, p. 2-3. Une lettre de Naudé du 9 janvier 1652 confirme non seulement la contiguïté des trois entresols, mais le principe général de répartition documentaire dans la première bibliothèque du palais Mazarin : «Messieurs Portail, Pithou et Petau estoient dans la chambre de medecine [ $=\mathrm{I}^{\text {er }}$ entresol] d'où après avoir veu ce qui y estoit ils passerent en celle des Bibles $\left[2^{\mathrm{c}}\right]$ et de là aux Mss $\left[3^{\mathrm{c}}\right]$, et puis à la grande bibliothecque ", MAE, Mémoires et documents, France, 88I, f. $39 v^{\circ}$, éd. dans Considérations politiques sur la Fronde..., ouvr. cité, I99I, p. I05. Les livres du second entresol furent les premiers dispersés lors de la vente forcée de janvierfévrier 1652 ( " l’on commença après la chambre des bibles a entamer la grande galerie "), qui s'acheva par la cession du contenu du troisième entresol : « aujourd'huy i7me de febvrier l'on a achevé de vendre entierement la bibliothecque de Vostre Eminence par l'adjudication qui a 
avec bien de la propreté. Les balustres sont placés au-dessus, où l'on monte par quatre escaliers pratiqués, \& cachés dans les quatre angles des premières tablettes. Cette seconde ordonnance occupe tout l'espace qui, depuis la première, va jusqu'à la naissance de la voûte, \& est destinée pour les volumes, tant in-octavo que pour les autres petits livres. \& pour plus d'enrichissement \& de commodité, une petite galerie la borne, portée sur la corniche \& l'entablement des colonnes corinthiennes, \& fermées [sic] d'un balustre de fer verni, à hauteur d'appui. Pour remplir de livres ce grand espace, \& les bien choisîr, le Cardinal fit choix de Gabriel Naudé, consommé en cette sorte de connoissance, \& qui a laissé bien loin derrière lui les plus grands Bibliothécaires... ${ }^{39}$.

Il n'existe en revanche pas de représentation de la bibliothèque du temps de Mazarin. Parmi les portraits du cardinal, le seul à le présenter au sein de ses collections est le célèbre cuivre gravé par Robert Nanteuil et Pierre Van Schuppen d'après François Chauveau, qui illustre en 1659 la thèse de Charles-Maurice Le Tellier : le cardinal y figure dans la galerie Haute du palais, laquelle laisse voir plusieurs pièces de sa collection d'antiques et de peintures. Il ne se trouve ainsi jamais représenté, de son vivant, au sein de sa bibliothèque ${ }^{40}$. Trois documents figurés, décisifs pour la connaissance de la galerie de la rue de Richelieu, sont postérieurs à sa mort : ils ont été identifiés dans les collections de la Bibliothèque royale du Danemark à partir d'une découverte faite en 1908 par l'historien de l'architecture Fr. Schiøtt : il s'agit d'une élévation longitudinale et d'un plan de la moitié de la galerie, et d'une élévation en coupe

3, 4 et 5 (CI-CONTRE ET

CI-DESSOUS DE GAUCHE À DROITE)

Galerie de la bibliothèque

de Mazarin, entre 1662

et I664, plan partiel, coupe transversale et élévation partielle (Copenhague, Bibliothèque royale, Kortsamlingen).
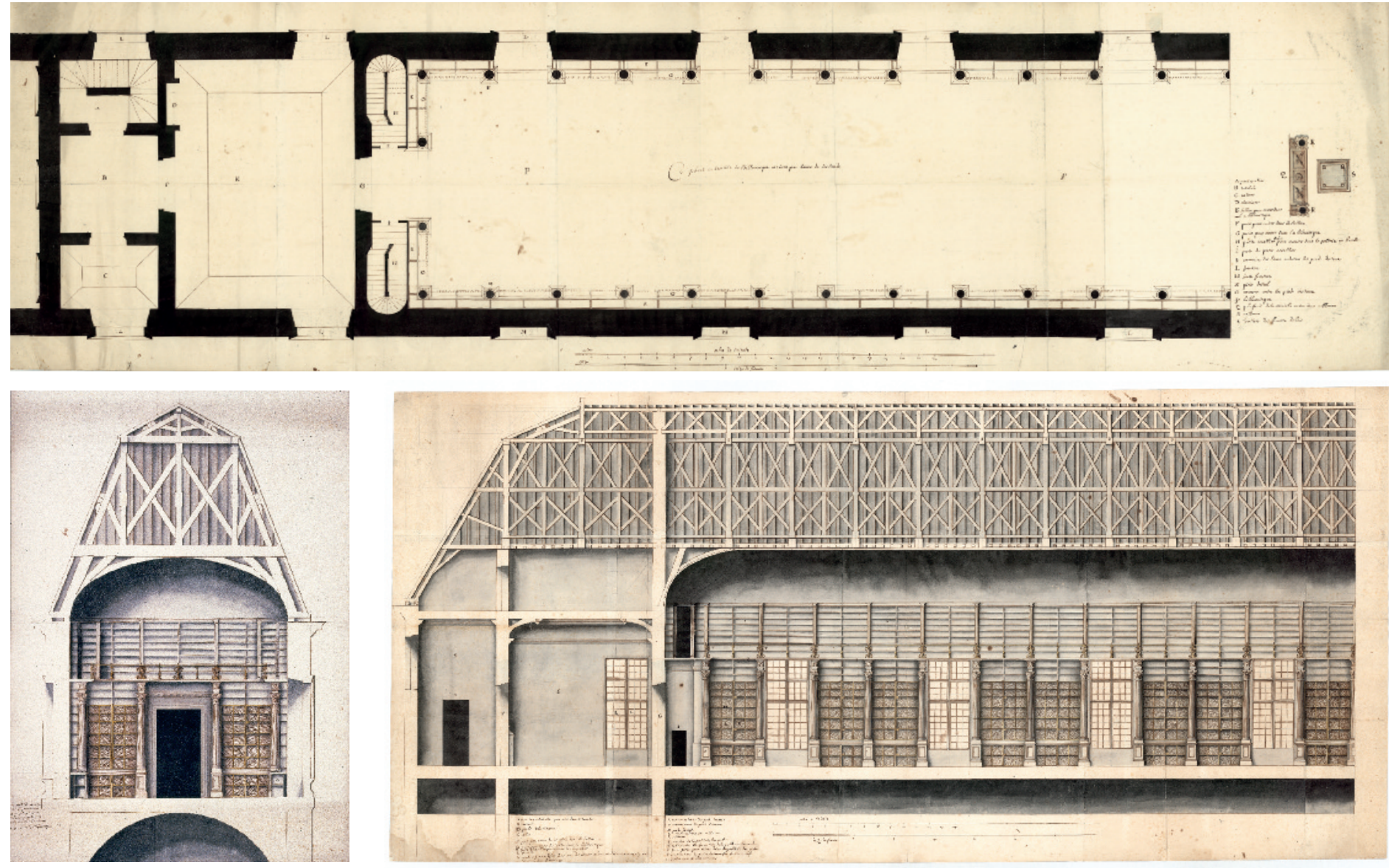
transversale [ill. 3 à 5$]^{41}$. Les marges du plan portent également un relevé du décor de bois sculpté qui orne le revers du balcon et les "vollets des fenest $[\mathrm{r}]$ e de bois ». La localisation de ces dessins, le fait que leur échelle soit rapportée à la fois à la toise de France et à l' " aulne de Seelande ", ont permis de les mettre en rapport avec le projet de bibliothèque voulue par Frédéric III de Danemark, dont la conception fut directement inspirée par celle de Mazarin, comme le signalait dès le XviI ${ }^{e}$ siècle Charles Le Maire : "le roy d'Angleterre, \& celui de Danemarc la virent avec admiration lors qu'elle estoit au palais Mazarin, d'où elle fut transportée dans ce college [i.e. des Quatre-Nations]. Sa majesté danoise a fait faire la sienne sur le modèle de celle-cy ${ }^{42}{ }^{2}$. Ce n'est sans doute pas Frédéric III lui-même, comme l'a montré Knud Bøgh, mais son fils - futur Christian V - qui effectua cette visite ; le prince a séjourné à Paris entre décembre 1662 et mai I663, et a fréquenté le duc de Mazarin, l'un des héritiers du cardinal ; il est vraisemblable qu'il ordonna lui-même ces relevés ${ }^{43}$.

Ils constituent le témoignage le plus proche de la réalité de la bibliothèque au temps de Mazarin. Le plan fait apparaître les 54 colonnes que nous retrouvons aujourd'hui à la Bibliothèque Mazarine, alors que la description de Sauval, approximative sur ce point, n'en signalait que cinquante ${ }^{44}$. Il convient cependant de relativiser la valeur documentaire des relevés de Copenhague. Les armoires en partie basse, qui correspondent aux deux tablettes des avantcorps formant pupitre et aux six premières tablettes de l'entrecolonnement, y apparaissent fermées par des portes grillagées, ce qui est confirmé par les sources. Une lettre à Colbert du I3 août I66I, signalée par Laborde ${ }^{45}$, révélait dès cette date le dessein de placer au-devant de chaque travée deux portes grillagées (l'une au-dessous du pupitre, l'autre au-dessus), fermant par une serrure. L'analyse des comptes et délibérations de la succession de Mazarin nous permet aujourd'hui de dater la pose de ces grilles entre le 2 septembre I662 et le I5 septembre $1664^{46}$. Par ailleurs, les dessins des élévations ont été mis en couleur : non seulement les grilles y sont

esté faicte de tous les MSS qui estoient dans l'un des entresolles " du Cardinal Mazarin et son architecte Pierre Le Muet ", Bulletin des (lettres de Naudé à Mazarin du I2 janvier et du I7 février I652, bibliothèques de France, 1970, nº 5, p. 235-242. " 42. Charles Le Maire, éd. ibid., p. II3 et II9). Nous reviendrons ailleurs sur la question du Paris ancien et nouveau, Paris, I685, t. II, p. 560. 13 . La construction classement de la bibliothèque de Mazarin avant I66I. - 39. L’ordre de la Bibliothèque royale du Danemark fut commencée en I665; achede finalité doit être inversé : la croissance de la collection et le projet vée en 1673, elle a en effet été conçue comme une longue galerie Naudé ont commandé et déterminé le bâtiment, pas l'inverse. Henri rectiligne, au-dessus d'un rez-de-chaussée, disposant d'un balcon périSauval, Histoire et recherches des antiquités de la ville de Paris, Paris, 1724, phérique porté par 66 colonnes et accessible par des escaliers tournants

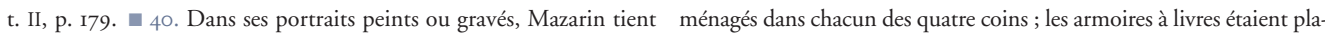
en général la barrette cardinalice, ou un billet qui désigne son autorité cées le long des quatre murs. 14 . Comme l’a supposé Bøgh, Sauval ministérielle, très rarement un livre ; tout au plus quelques volumes a pu oublier les deux paires de colonnes qui encadraient les deux accès d'apparence modeste peuvent être posés sur la table de travail auprès de la grande galerie, à chacune de ses extrémités. ■ 45. L. de Laborde, de laquelle il est assis. La galerie de la bibliothèque ne sera du reste par- Le Palais Mazarin..., ouvr. cité, p. 369, n573; A. Franklin, Histoire de faitement installée qu’après I652, et Joëlle Garcia a interprété comme la Bibliothèque Mazarine..., ouvr. cité, I90I, p. 208-209. Lettre par la une volonté de discrétion et de prudence politique la quasi-absence suite convoquée par Bøgh pour fixer un terminus ante quem à la réalid'évocation des goûts de collectionneur de Mazarin après la Fronde, sation des dessins. Les Représentations gravées du cardinal Mazarin au XVII siècle, Paris, l'exécution de la fondation du college Mazarin, AN, MM/46I, f. 47v -48 Klincksieck, 2000, p. 95. 4I. Copenhague, Det Kongelige Bibliotek, (5 août I662 : décision prise de passer le marché), f. 72 (II février I663: Kortsamlingen, Armoire 2, Tiroir BI (anciennement Ny Kgl. Samling "il y en a une partie payée, et mise en place »), f. $163 \mathrm{v}^{\circ}$ (I5 septembre 37 r c, fol., $\mathrm{n}^{\circ}$ I2-I et n I2-2) ; Kortsamlingen, Gr. fol., Topographie, I664 : "Anthoine Le Maistre $\mathrm{M}^{\mathrm{e}}$ serrurier a Paris et François Joumel Paris. Lélévation longitudinale a été signalée par Fr. Schiøtt, "Kong [Jumel d’après d'autres sources] $\mathrm{M}^{e}$ espinglier sont entrez en l’assemblée Frederik III's Biblioteks- og Kunstkammer-Bygning ", Sartryk af Archi- qui ont dict que suivant les marchés faits avec eux ils ont fait touttes les tekten, X, 1908, p. I2. En 1965, les deux autres dessins, conservés travées garnies de fer et de fil de laton servant de fermeture aux livres de séparément, ont été rapprochés du premier par Knud Bøgh, "Kardinal la biblioteque de feu son Eminence »), f. I88v (16 décembre 1664 : visite Mazarin og Frederik IIIs Bibliotekssal, en arkitektonisk forbindelse ", des travaux par Le Vau). AN, H/2822, f. 80-83 et H/2824, f. 57 (Comptes Fund og Forskning $i$ Det Kongelige Biblioteks samlinger, XII, 1965, du collège Mazarin, Registre des dépenses, ordre de paiement du p. 7-30 et I59-166 (résumé dans : « La première salle de bibliothèque 5 décembre 1664, en référence au marché du 2 septembre I662). 
dorées (ce qui est conforme au marché de septembre 1662 puisque les fils de laiton devaient être peints), mais les colonnes sont rehaussées de blanc et les tablettes apparaissent en gris clair. Ce point a fait, nous le verrons, l'objet d'intenses débats entre 1966 et 1972, au moment de la programmation d'un vaste chantier de restauration. Mais il apparait aujourd'hui que cette mise en couleur relevait de pures conventions graphiques, propres notamment à restituer des volumes sur un dessin d'architecte. L'ensemble des boiseries de la bibliothèque, même unifié par un enduit, conservait du temps de Mazarin et de Naudé la couleur du bois. Le mémoire du peintre Thomas Boudan de I648, jamais signalé encore, le révèle aujourd'hui. L'essentiel de ses interventions dans les deux ailes de la Traverse et de l'écurie-bibliothèque (murs, menuiseries, grilles et croisée) a consisté en une mise en peinture grise, comme dans les « trois chambres du logement de Mons ${ }^{\mathrm{r}}$ Naudé faictes en gris qui contiennent six travées \& demie avec les frises ». Parmi les rares exceptions à ce principe de mise en peinture grise, on note " deux portes en couleur de bois » dans l'aile de la Traverse et, surtout, la grande galerie de la bibliothèque, dont la menuiserie, qui recouvre l'intégralité des murs, a été recouverte d'un vernis neutre : « tout le bois de l'architecture mis en huile». Les éléments de serrurerie qui composent la galerie haute conservent également la neutralité du métal, puisqu’ils sont recouverts d'une peinture à base de carbonate de cuivre ("vert de montagne ») : «Plus pour les balustrades de lad. bibliotecque blanchies deux fois a blanc de plomb a huile \& la trois ${ }^{e}$ couche faicte de verd de montagne ${ }^{47}$." À la voûte de la grande galerie, ni fresque ni mise en peinture, mais un simple blanchissage à la chaux ${ }^{48}$. On sait par ailleurs que le sol de la galerie était "pavé de grand carreau ${ }^{49}$ ".

Pouvons-nous restituer l'organisation interne de l'étage de la bibliothèque ? Les plans et dessins de Copenhague, qui ne donnent à voir qu'une moitié de l'espace, sont les seuls documents figurés de quelque précision aujourd'hui repérés pour le XVII ${ }^{\mathrm{e}}$ siècle. Pour être parfaitement lus, ils doivent être "orientés ", et rapprochés des éléments dont nous disposons pour appréhender la topographie générale du palais Mazarin. Trois sont connus, l'état général des vitres de 1654 et sa réactualisation en I657, ainsi que le procès-verbal de toisé réalisé par Le Vau en juin 166I $^{50}$. Nous en signalons un quatrième, plus précieux à la fois par son détail et par son antériorité : il s'agit du toisé des ouvrages réalisés par le maçon Nicolas Messier entre janvier et septembre 1648, qui couvre l'ensemble des aménagements intérieurs effectués dans l'aile de la bibliothèque et dans l'aile de la Traverse, et qui méritera par ailleurs d'être entièrement

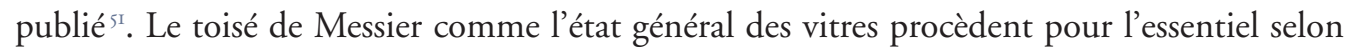
un itinéraire continu, et nous font pénétrer dans la bibliothèque par le sud. Létage noble de la Traverse, qui accueille l'« Appartement neuf » de Mazarin, est de plain pied avec le premier

17. Autre ouvrage de peinture faictes dans la bibliotecque de monseigneur le cardinal par command de monsieur de Valpergue, $3^{\mathrm{e}}$ partie du Mémoire des ouvrages de peinture faictes par Thomas Boudan..., doc. cit., I648, AN, MC/CXII/6I ( $\mathrm{I}^{\text {er }}$ mars I653). " 48. "Le blanchissage faict avec chaux de la voulte de la gallerie et biblioteque ", Mémoires des ouvrages de maçonnerie exécutés à l'intérieur des ailes de la bibliothèque et de la Traverse par l'entrepreneur Nicolas Messier, entre le 30 janvier et le 20 septembre I648, AN, MC/CXII/6I ( $\mathrm{I}^{\text {er }}$ mars I653). 14 49. D'après le mémoire du maçon Nicolas Messier, cf. supra. Ce que confirme un rapport de Robert de Cotte établi en 1717 dans la perspective d'aménagements pour la Bibliothèque royale, qui fait état de dallages de pierres blanches et noires (BnF, dép. des Estampes et de la Photogra-

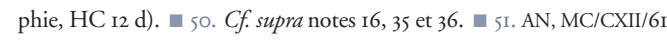

$\left(\mathrm{I}^{\mathrm{er}}\right.$ mars I653). 152 . Claude Mignot suppose à tort que cet appartement fut "occupé un temps par M. Naudé ", Pierre Le Muet..., ouvr. cité, p. 356. 13 . En omettant les petites pièces situées au nord de la grande galerie (salle, cabinet, vestibule et palier). Notre lecture permet par ailleurs d'affirmer que la chapelle neuve - la deuxième du palais Mazarin - que Weigert localisait dans l'Appartement neuf ( Le Palais Mazarin en 1657 ", art. cit. p. 397) se trouve en fait dans l'aile de la bibliothèque. 154 . Les galeries "servent à beaucoup de commoditez, comme à se promener, à manger, et autres divertissemens ", P. Le Muet, Traicté des galleries, entrées, salles, antichambres \& chambres, publié avec sa traduction du Traicté des cinq ordres de Palladio, Paris, François Langlois, 1645 , p. II7. 
étage de l'aile de la bibliothèque. Au point d'articulation entre ces deux ailes, se trouve un grand salon ("Grand sallon à l'Italienne » dit le marché de vitrerie de 1657), prenant le jour à la fois, au sud, sur le jardin du président Tubeuf (qui occupe l'un des hôtels jadis construits par Le Muet sur la rue Neuve-des-Petits-Champs) et à l'ouest sur la rue de Richelieu. En progressant de là dans l'aile de la bibliothèque, on traverse, successivement, un " petit passage comme vestibule " puis " une salle " et deux chambres, ce premier ensemble étant désigné en 1657 comme " appartement de la bibliothèque " ${ }^{22}$ (du seul fait de sa localisation dans l'aile Le Muet-Valperga, car le logement du bibliothécaire se trouve ailleurs, à l'étage supérieur) ; on accède ensuite à une chapelle, puis à un " passage " qui correspond peut-être à la montée de l'escalier, accessible depuis la porte "publique » ouverte sur la rue de Richelieu. Les espaces de la bibliothèque proprement dite viennent ensuite, composés d'une « salle avant que d'entrer dans la bibliothèque ", de la grande galerie, d'une "salle après la bibliothèque " puis, à l'extrémité de l'aile, de trois espaces conçus dans la largeur du bâtiment, un " cabinet ", un "vestibule » et le palier d'un escalier.

Le procès-verbal de Le Vau confirme cette distribution en juin I66I : du sud au nord, " cinq chambres de plein pied, vestibulle et petite chappelle, le tout peinct et enrichi, et grande bibliothèque au bout " ${ }^{53}$. Le plan et l'élévation de Copenhague montrent donc la partie nord de l'aile de la bibliothèque. Partant, le segment aujourd'hui conservé au nord de la rue Colbert correspond à l'ensemble des salles qui faisaient suite à la grande galerie, à savoir : une salle comportant deux croisées (sur rue et sur jardin) ; le cabinet de travail de Gabriel Naudé, comportant une fenêtre côté rue ; le vestibule au centre; le palier de l'escalier, côté jardin. Cette extrémité est désignée par Nicolas Messier comme " costé de Monsieur Naudet »; de fait, à l'étage supérieur, fut installé le logement, composé de trois chambres, qu'occuperont les deux bibliothécaires du palais Mazarin, Gabriel Naudé dès 1648 puis François de La Poterie jusqu'en I668. Cet étage supérieur - le troisième de l'aile - n’a pu être ménagé qu’au dessus des pièces qui précèdent et suivent la grande galerie de la bibliothèque, du fait de la grande hauteur - à l'italienne - de celle-ci. On vérifie encore sur le plan de Copenhague que dans la galerie, seules les fenêtres donnant sur jardin (en fait sur la cour des écuries, à l'est) sont ouvertes, les fenêtres donnant sur la rue de Richelieu étant obstruées, et légendées comme « fausses fenestres» [ill. 6.]

\section{LA GRANDE GALERIE ET SES MODÈLES}

Au cœur de la nouvelle bibliothèque, et concentrant l'essentiel de son programme décoratif, se trouve une galerie. L'espace de la galerie était devenu au cours du Xvi siècle un composant presque obligé de la distribution privée ou palatiale en France, à partir d'une certaine taille de la demeure. À l'origine élément de liaison purement fonctionnel, en se développant elle devint un espace de déambulation dédié à la promenade intérieure, tout en intégrant de manière croissante, à partir des années I640, des fonctions de réception et de représentation (la galerie d'Anet, qui jouait le rôle de grande salle dès le milieu du Xvi ${ }^{\mathrm{e}}$ siècle, constitue à ce titre une exception). Cette diversification, que nota Pierre Le Muet lui-même en $1645^{54}$, modifiait sensiblement son statut en la faisant passer d'espace privé à pièce d'apparat. Claude Mignot, 


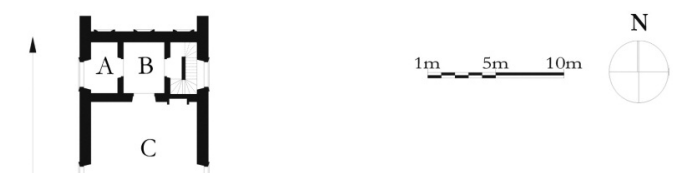

6. L'aile de la bibliothèque dans le palais Mazarin : hypothèse de distribution correspondant aux années I648-I668 (agence Loup-Menigoz, sur les indications de Yann Sordet).

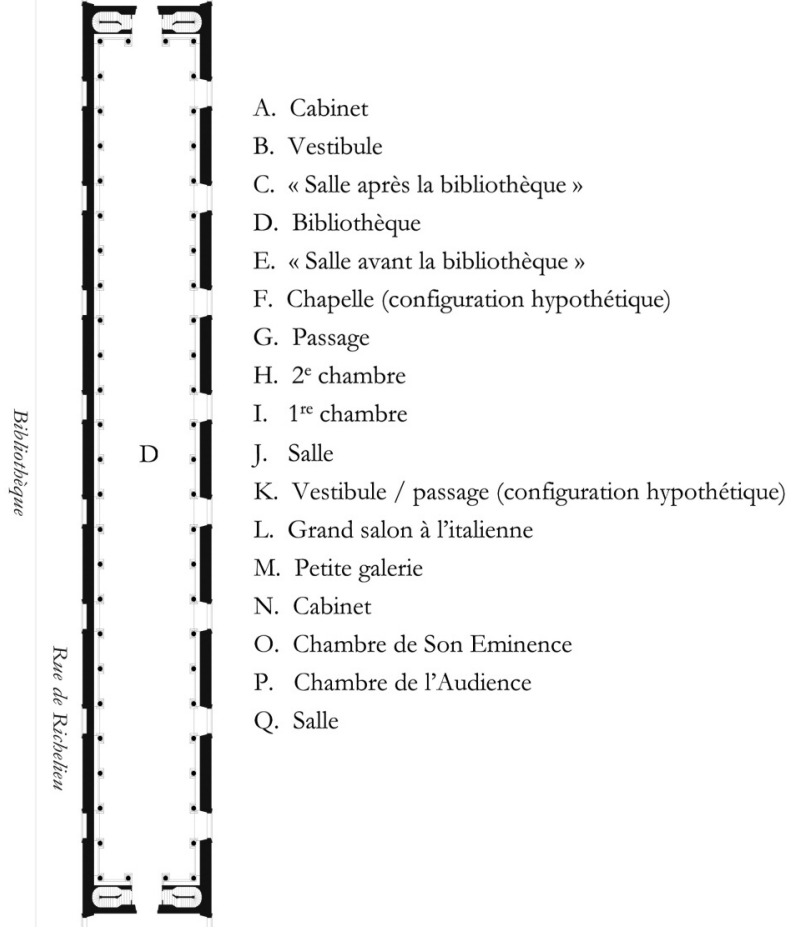

$\mathrm{E}$
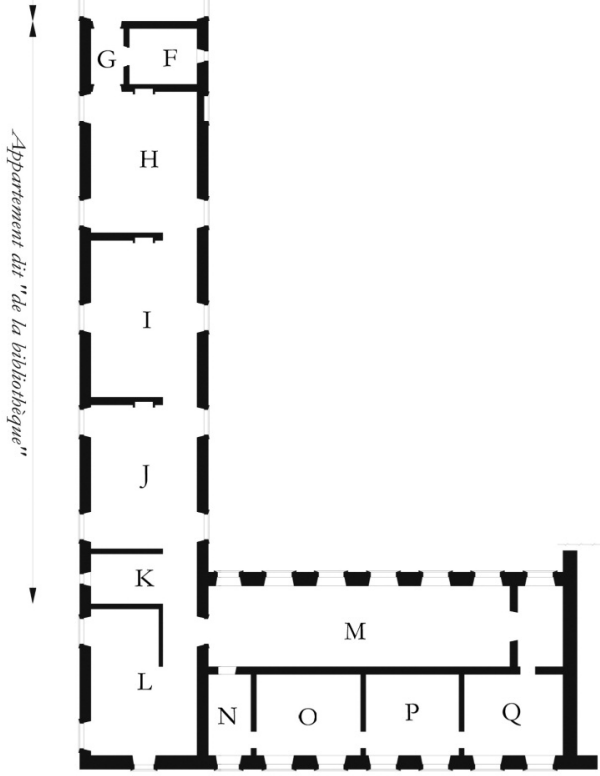

Aile de la Traverse

(appartement d'biver de Maqarin) 
examinant sa localisation dans les schémas de distribution au milieu du XVII ${ }^{\mathrm{e}}$ siècle, a noté que la galerie tend à se greffer sur les pièces les plus publiques des demeures (vestibules, grands escaliers, antichambres) ${ }^{s}$. Espace idoine à la publicité et à la représentation, tout naturellement elle se trouve affectée aux collections et remplace en cela la Kunstkammer. Mais on observera que les galeries sont généralement prétextes à de grands programmes peints ${ }^{56}$ et que, lorsqu'elles sont dévolues aux collections, à partir du XviI ${ }^{\mathrm{e}}$ siècle en France, elles accueillent généralement des collections d'antique et/ou de peinture, non des livres. Les deux galeries parisiennes qui ont constitué pour Mazarin un modèle immédiat, celles décorées par Simon Vouet et Philippe de Champaigne pour Richelieu au Palais cardinal, étaient destinées l'une aux collections d'art et l'autre aux portraits des « hommes illustres».

La bibliothèque de Mazarin inaugure donc cette disposition en France, où les bibliothèques s'organisent désormais selon deux modèles : le cabinet, renvoyant à l'espace privé, et la galerie, impliquant une dimension "publique » dans l'usage ou la représentation. Ainsi le schématise Augustin-Charles d'Aviler dans son Dictionnaire d'architecture au milieu du XvIII ${ }^{\mathrm{e}}$ siècle : "BIBLIOTHEQUE, s. f. Lieu en forme de grand cabinet ou de galerie, où des livres sont rangés sur des tablettes avec ordre \& décoration... ${ }^{57}$. "

Revenons rapidement sur les éléments, bien connus, de l'évolution des bibliothèques à l'âge moderne pour réexaminer la place qu'y occupe la Mazarine. Le principe médiéval d'une organisation segmentée de l'espace, avec des rangs de pupitres aux fonctions de conservation et de consultation qui forment autant d'épis transversaux, est resté inchangé au XVI siècle. C'est le cas même dans les bibliothèques qui ont intégré le vocabulaire ornemental et l'équilibre des proportions de la Renaissance, comme à la Malatestiana de Cesena, construite de I447 à I452, comme encore à la Laurenziana, où les Médicis firent intervenir Michel-Ange. L'innovation déterminante, rappelée par les travaux de John Willis Clark et Walter Schürmayer ${ }^{58}$ puis André Masson, a consisté à " repousser » les livres à la périphérie de l'espace, sur les murs, ce qui aura plusieurs conséquences, notamment sur la reliure et le « titrage » des volumes. La première bibliothèque à mettre en œuvre ce principe est celle conçue par l'architecte Juan de Herrera pour Philippe II à l'Escurial (1563-1584). Les armoires de bois, divisées en sections par des colonnes cannelées, sont placées le long des murs et laissent libre le plancher, permettant un aperçu global et immédiat de l'ensemble de l'espace; les voûtes accueillent par ailleurs une imposante décoration peinte à "programme ». À l'Ambrosiana (I609), les tablettes sont également implantées le long des murs, cette fois sur deux niveaux, une galerie étroite desservant l'étage supérieur ; la voûte en est décorée et une galerie de portraits occupe le haut des murs, comme en témoigne l'élévation gravée qui accompagne la Descrizione di Milano de Serviliano Latuada (I737-I738). La bibliothèque romaine d'Antonio Barberini, dont l'installation est achevée vers I630, constitue en quelque sorte la troisième étape de cette évolution qui conduirait à la Mazarine. Réunissant les deux caractéristiques fondamentales de l’implantation des livres sur les murs et de la galerie à deux niveaux, elle était, comme l'Ambrosienne,

\footnotetext{
- 55. Claude Mignot, «La galerie dans les traités ", Les grandes galeries 1646) ne s’écarte pas de ce principe. I 57. Dictionnaire d'architecture européennes, XVII -XIX siècles, dir. Claire Constans et Mathieu da Vinha, civile et hydraulique, et des arts qui en dépendent, Paris, Jombert, 1755 , Versailles, Centre de recherche du château de Versailles; Éditions de la p. 62. D’Aviler donne par ailleurs la définition du " cabinet " comme Maison des sciences de l'homme, 20I0, p. 44. " 56. La galerie Fran- " Petite pièce d'un appartement, consacrée à l'étude ", ibid., p. 74. çois Ir de Fontainebleau, décorée par Le Primatice, en représente en $\square$. Walter Schürmeyer, Bibliotheksräume aus fünf Jahrbunderten, France un puissant modèle, et la galerie Haute du palais Mazarin (I644- Frankfurt am Main, Englert und Schlosser, 1929, p. 15.
} 
familière à Naudésø. John Willis Clark avait considéré que la Mazarine dérivait directement de l'Escurial ; pour Masson les modèles intermédiaires italiens, fréquentés par Naudé et Mazarin, et notamment la bibliothèque des Barberini, furent plus déterminants ${ }^{60}$. Madeleine Laurain-Portemer a par la suite signalé que Mazarin avait obtenu des Barberini un plan, non retrouvé, de leur bibliothèque ${ }^{61}$. Étant donnée la date de la requête (I64I), ce plan aurait-il été destiné à éclairer l'aménagement de la bibliothèque de Richelieu, ce qui conférerait à celle-ci un statut de relais dans la lignée des modèles de la Mazarine? Autrement dit la Mazarine, bibliothèque-galerie, espace ouvert et continu, ne doit-elle cette primauté en France qu'à l'inachèvement de la bibliothèque de Richelieu ${ }^{62}$ ? Il ne le semble pas. Si la bibliothèque de son prédécesseur a bien été pensée, déjà, dans un bâtiment structurellement indépendant du corps de logis principal (elle constituait une aile reliant le palais cardinal, plus exactement la galerie des Hommes illustres, à la rue de Richelieu), si de ce fait elle promettait d'être directement accessible depuis la rue, si elle était déjà conçue comme un vaisseau sous comble édifié sur un rez-de-chaussée voûté, l'aménagement interne programmé relevait d'un schéma d'implantation

-19. À la Vaticane, c'est en 1645 seulement que les armoires murales remplacent définitivement les anciens pupitres, Pierre Petitmengin, "Recherches sur l'organisation de la bibliothèque vaticane à l'époque des Ranaldi (1547-1645) ", MEFR, 1963, p. 625. — 60. J. W. Clark, The Care of books..., ouvr. cité, p. 273 ; André Masson, « Mazarin et l'architecture des bibliothèques... ", art. cit., p. 356. 16 6r. Les Barberini ne fournirent pas le plan général de leur palais romain à Mazarin, qui l'avait demandé à son agent Benedetti, mais le 9 avril I64I ce dernier adressait au cardinal le dessin de leur bibliothèque, vraisemblablement un plan et une élévation : "Qui annesso mando il disegno della libreria del s. card. Barberino fatto di pianta et di prospettiva", MAE, Correspondance politique, Rome 74, f. 4I, cit. par M. Laurain-Portemer, "Mazarin et l'art baroque au temps de Richelieu (I634-1642)", dans Études mazarines, Paris, De Boccard, 1981, p. I88-189 et 359. 1 62. Pour sa propre bibliothèque, infiniment plus réduite en volume que celle de Mazarin (l'inventaire de I643 signale 250 ouvrages conservés au château de Rueil, et 6 I35 au Palais cardinal, BM, ms. 4270-427I), Richelieu avait fait construire un bâtiment par Jacques Lemercier, responsable par ailleurs de l'essentiel des aménagements et agrandissements de son palais. D'après la correspondance du cardinal, les travaux de fondation auraient commencé en I640, mais le marché de maçonnerie fut signé en avril 1642 seulement. Françoise Bercé a retrouvé et édité ce marché, passé avec l'entrepreneur Jean Thiriot le Is avril 1642 (AN, MC/LXXXVI/3II, $\mathrm{n}^{\circ} 24$, " Marchés pour le Palais cardinal de 1628 à 1642 ", Archives de l'art français, 26, 1984, p. 65-68; voir aussi Alexandre Gady, "Bibliothèque de Richelieu au Palais cardinal ", dans Les Bibliothèques parisiennes..., ouvr. cité, 2002, p. 66-67). Un programme de 58 portraits d'hommes illustres fut spécifiquement commandé pour le décor de la bibliothèque ; ils sont aujourd'hui conservés au musée de Versailles (Christiane Chardigny, "Les portraits de la bibliothèque de Richelieu au Palais Cardinal ", dans Richelieu et le monde de l'esprit, Paris, I985, p. I49-I54). À la mort de Richelieu, le 4 décembre I642, il ne semble pas que le décor ait été achevé, ni les livres installés dans le nouveau bâtiment. = 63. Henri Sauval, Histoire et recherches..., ouvr. cité, t. II, p. I72. $=64$. On sait cependant que Pierre de Cortone a été sollicité au printemps 1647 par le cardinal Francesco Barberini pour intervenir dans la nouvelle bibliothèque de Mazarin, alors en cours de construction. Les éléments de correspondance conservés (deux lettres, citées infra) sont trop évasifs pour qu'on puisse deviner une plus ferme intention derrière la simple suggestion de Barberini ; et Pierre de
Cortone n’ayant pas donné suite, autant qu’on le sache Mazarin n’a pas sollicité d'autre artiste pour un tel programme, ni avant ni après la Fronde. "Quando Vostra Eminenza risolvesse di qualche luogo dove occupare il s.r Pietro, bisognarebbe che egli sapesse li lumi, il campo da riempire e le historie, mentre vorrebbe esser non solo opera per se bella ma che servisse alli virtuosi di Francia per impararvi et avanzarsi nella pittura, come la biblioteca insigna di Vostra Eminenza la somministra alli litterati» (lettre de F. Barberini à Mazarin, du 17 avril I647, éd. par Madeleine LaurainPortemer, "Le palais Mazarin à Paris et l'offensive baroque... ", art. cit., 1973, p. 163, n. 14). "Il raguaglio che V.E. mi dà della publicha libreria che fa fabrichare il Sig.r cardinale Mazzarino sia della grandezza de quella de V. E., mi persuado che sia per essere opra de molta considerazione, e mentre mi acenna che al mese de febraro io possi essere sbrigato dal opera della Ciesa nova [i.e. Saint-Luc et Saint-Martin, à Rome], in questo conoscendo la mia pocha abilità nel operare, mi rende impossibile il poterla finire, e trovandoci io più dificoltà che non si persuade V.E., si per la qualità e grandezza del opera comme ancho per la pocha sanità cagionatomi da catarri, che quest'anno o patiti..." (lettre de P. de Cortone à F. Barberini, du 14 juin 1647 , éd. dans Karl Noelhes, La chiesa dei SS. Luca e Martina nell'opera di Pietro da Cortona, Rome, I970, doc. 85, p. 348349). $=65$. «Donne et legue aussy a la Couronne tous les tableaux qui sont a present dans ma bibliothecque ", testament du 6 mars I66I, copie (original disparu), BnF, ms. français II453, f. $9 \mathrm{v}^{\circ}$. a 66. Antoine Schnapper, Curieux du Grand Siècle, Paris, Flammarion, 1994, t. II, p. 273. Un visiteur du palais en 1664 , Sébastiano Locatelli, a également vu dans la bibliothèque " divers instruments de mathématique montés en or ", Voyage de France, éd. Adolphe Vautier, Paris, 1905, p. I34, cit. par Patrick Michel, Mazarin, prince des collectionneurs : les collections et l'ameublement du cardinal Mazarin (1602-166I) : histoire et analyse, Paris, Réunion des musées nationaux, 1999, p. 500. On ne sait rien, par ailleurs, de l'ameublement fonctionnel de la bibliothèque, hormis les quelques informations sur les meubles et instruments de travail que font apparaître les comptes déjà cités de Naudé - relatifs à la première bibliothèque, dans le palais de Chevry-Tubeuf - ou une lettre du bibliothécaire à son maître de I65I : «le sieur Petit m’ouvrit les 3 entresols et la grande bibliotheque d'où j'ai tiré quatre ou cinq placets [siège sans dossier] garnis de serge violette et qui faisoient partie d'un petit emmeublement semblable ", Lettre du 3 juin I65I, MAE, Mémoires et documents, France, 875, f. I47, éd. dans Considérations politiques sur la Fronde..., ouvr. cité, I99I, p. I3. 
des livres assez traditionnel. Sauval fut le premier à comparer les deux bibliothèques, qu'il a toutes deux visitées : il n'évoque du reste pas la bibliothèque de Richelieu dans le chapitre consacré au palais cardinal, mais, brièvement, à propos du palais Mazarin, lorsqu'il compare l'un et l'autre. Et pour témoigner de l'ampleur du second, c'est sur la bibliothèque qu'il se fonde, convoquant des arguments de volumétrie et, nous semble-t-il, de structure : «non seulement le vaisseau de sa bibliotheque est tout autre que celui du Palais cardinal, mais encore les livres \& les manuscrits qu'il a ramassés, sont \& beaucoup plus curieux, \& et en bien plus grand nombre ${ }^{63}$ ». Le peu que nous savons de la conception de la bibliothèque de Richelieu est fourni par le marché d'avril I642, qui confirme une organisation encore traditionnelle des collections : la galerie (6o x Io m) doit être entrecoupée de murets latéraux, formant des petits cabinets sur les parois desquelles les livres sont appelés à prendre place, conformément au modèle des stalles et des pupitres transversaux. Cette structure devait elle-même porter la galerie haute.

Revenons au modèle de l'Escurial, alors inédit par ses dimensions (près de $55 \mathrm{~m}$ de long, Io $\mathrm{m}$ de large et autant de haut). Quelques différences majeures avec la bibliothèque réalisée entre I646 et I648 au palais Mazarin sautent aux yeux : la proportion des voûtes de Juan de Herrera et leur décor d'une part, et d'autre part la manière dont le mobilier de bibliothèque a été conçu et appliqué aux parois, donnent une prépondérance visuelle écrasante aux éléments architectoniques et décoratifs. Suivant un programme défini par le frère José de Sigüenza (I544I606), bibliothécaire de Philippe II, chacun des sept compartiments de la voûte a accueilli l'un des arts du trivium ou du quadrivium, représenté par le peintre bolonais Pellegrino Tibaldi (I527-I596), dans une organisation générale qui exprime, pour reprendre les termes de Sigüenza, " le parallèle entre la Théologie et la Philosophie, entre la Révélation et la Loi naturelle ". Par son ampleur et son iconographie ce décor marque certes une révérence, mais d'une certaine manière il préexiste aux livres, leur reste visuellement indépendant, et pourrait exister sans leur présence. Dans ce cadre qui manifeste à la fois la puissance de la stéréotomie et la capacité rhétorique de la peinture, les éléments de la bibliothèque (menuiserie et livres) viennent se placer comme autant de " meubles » dont la mobilité - si l'on peut dire - reste possible. Les colonnes font intégralement partie de cet élément mobilier : elles n'ont aucune fonction architectonique, ne supportent ni imposte ni entablement ni départ de voûte ; elles servent seulement de séparateur décoratif entre les travées. On n’y appréhende pas la solidarité particulière entre structure architecturale et livres qui caractérisera la bibliothèque Barberini et, plus encore, la Mazarine. Dans cette dernière en effet, l'architecture n'est pas visible, on ne voit pas d'autres murs que ceux "formés " par les livres; et le décor y est exclusivement dévolu aux éléments d'organisation bibliothécaire, essentiellement menuisés. Contrairement à l'Escurial, à l'Ambrosienne, et à la plupart des bibliothèques romaines conçues par Borromini dans les années I630 et I640 (bibliothèques de l'église de San Carlo alle Quattro Fontane, Vallicelliana, Innoncenziana au palais Pamphili), ni plafond décoré, ni voûte peinte ${ }^{64}$. Aucun espace libre au-dessus des régimes de tablettes qui puisse accueillir, comme à l'Ambrosienne, une suite de tableaux ou une décoration peinte. À la mort de Mazarin cependant se trouvait localisé dans la bibliothèque un nombre important de tableaux italiens, que le cardinal dans son testament du 6 mars I66I léguerait à la couronne ${ }^{65}$. Mais, objet d'une transaction en cours avec le grand marchand Everhard Jabach, ils n'y étaient que momentanément entreposés, et ne participaient pas à son décor ${ }^{66}$. 
Cette sobriété, qui marque une évidente différence dans le palais avec les galeries haute et basse, et cette dévolution intégrale des surfaces verticales aux livres, asservissent l'espace tout entier, architecture et décor, à la fonction bibliothécaire. La Mazarine ne peut pas exister sans ses livres : la galerie n'envisage pas d'emploi alternatif à la bibliothèque. Une lettre de Naudé à Mazarin en témoigne directement, au mois de février 1652, alors que l'espace vient d'être pour la première fois entièrement vidé de ses livres : « [Votre Eminence] doit songer au retablissement de ladite bibliothecque [...] et d'autant aussy qu'a moins d'avoir cette volonté et bonté, je ne scay pas ce qu'elle pourra faire dorennavant de la bibliothecque neuve et cette belle menuiserie qui ne peut servir a autre chose qu'à mettre des livres ${ }^{67}$. "

Cet espace est, par nécessité, une bibliothèque. Il n'accueille pas d'autre décor que celui des structures de conditionnement et d'organisation matérielle des livres. Sans livre, c'est une aberration architecturale. L'évidence fonctionnelle et la bibliothéconomie surpassent l'apparat architectural et décoratif ou, plus exactement, tiennent lieu pour le visiteur de l'un et de l'autre. Les tablettes étant implantées du sol jusqu’à la naissance de la voûte, et les menuiseries n'étant pas fermées ${ }^{68}$, les livres constituent pour l'œil la structure à la fois porteuse et décorative du bâtiment. La formulation du peintre Thomas Boudan dans son mémoire déjà cité de I648, est à ce titre aussi exceptionnelle que significative : pour désigner la menuiserie de la grande galerie, il évoquait " tout le bois de l'architecture".

C'est sans doute à l'Ambrosienne que songeait Naudé en I627 quand il écrivait : « Les livres ne se mettent plus sur des pulpitres à la mode ancienne, mais sur des tablettes qui cachent toutes les murailles ${ }^{69}$. " Mais seule la Mazarine réalisera pleinement cette conception.

- 67. Lettre du I7 février I652, éd. dans Considérations politiques sur la Fronde..., ouvr. cité,1991, p. I20. Depuis I652, les armoires de la Mazarine n'ont été vidées entièrement de leurs livres qu’à trois reprises, en 1668 lors du transfert au collège des Quatre-Nations, en 1739, puis en I968 à la veille d'importants travaux de restauration. 188 . Contrairement à la Barberiniana, où la partie basse des armoires est fermée par des portes ouvragées. À la Mazarine, les seules éléments fermés ont été conçus - dans une logique d'optimisation des capacités - dans les piédestaux des colonnes : ces "guichets ", comme les désignent les sources, sont visibles sur les dessins de Copenhague. Ils existent toujours, l'essentiel de leur serrurerie d'origine ayant été remplacé en I668. Ils ont en revanche perdu toute utilité au début du XIX ${ }^{\mathrm{e}}$ siècle, lorsque Leblond a implanté au-devant d'eux les socles des 54 bustes dont il a souhaité orner la salle de lecture. 169 . Advis pour dresser une bibliothèque, Paris, François Targa, I627, p. II2 (chapitre VIII : « L'ornement \& la décoration que l'on y doit apporter »). $\square 70$. Sur le balcon, au centre des volutes de ferronnerie qui portent la main-courante, alternent le $\mathrm{C}$, le $\mathrm{M}$, et deux haches en sautoir (provenant du faisceau de licteur), surmontés d'une fleur de lys. Les élévations de Copenhague ne figurent pourtant que la seule lettre " $M$ », par le fait sans doute d'une simplification du dessinateur, car la réalisation de ces trois motifs, aujourd'hui préservés, semble contemporaine. 1 7I. La lame figurant la puissance et les verges liées la capacité de rassemblement. Nous renvoyons, sur l'héraldique Mazarine, au travail fondamental de I. Loskoutoff, Rome des Césars, Rome des papes : la propagande du cardinal Mazarin, Paris, Champion, 2007 (notamment p. 204 et suiv.) et à E. Coquery, " Mazarin et Errard : du faisceau au trophée ", dans Mazarin, les lettres et les arts..., ouvr. cité, p. 258. On observera que les armes du cardinal se retrouvent par ailleurs très peu sur les livres eux-mêmes, l'essentiel des reliures aux armes de Mazarin avant I661 correspondant à des exemplaires offerts et/ou de dédicace. $\quad 72$. Non pas dans la description qu'il consacre au palais Mazarin, mais dans un petit chapitre qui traite des bibliothèques parisiennes : "La Mazarine n'est pas seulement la plus longue \& la plus large de toutes, mais encore enrichie d'une ordonnance de colonnes corinthiennes si hautes \& si bien travaillées, qu'on l'appelle quelquefois la Bibliothèque des colonnes. Enfin je n'en ai point vu qui lui puisse être comparée, non pas même la Vaticane ni l'Ambroisienne ", Henri Sauval, Histoire et recherches..., ouvr. cité, I724, t. III, p. 52. 19 73. Pierre Couleau, De librorum et scientiarum optimo usu paraenetica oratio ad literos ut publicam Mazarinaeam bibliothecam frequentius invisant..., Paris, Jean Boudot, I696, p. 3. La représentation des disciplines qui constitue le sujet de ce bandeau a été commentée par Patrick Latour, "Entre humanisme et Lumières : la bibliothèque du collège Mazarin et ses fonds scientifiques au XvIII ${ }^{\mathrm{e}}$ siècle ", Recherches sur Diderot et sur l'Encyclopédie, $\mathrm{n}^{\circ} 38$, avril 2005, p. 51-69. 
Le décor y est exclusivement constitué de deux éléments, l'ordre des colonnes et l'héraldique Mazarine, qui ont justement frappé les contemporains. Les caissons du "plafond de la corniche ", qui montrent successivement le faisceau de licteur et les trois étoiles, ont été précisément relevés entre I662 et I664 par l'auteur des dessins de Copenhague. Les meubles des armes du cardinal sculptés au revers du balcon, et les lettres de son chiffre ${ }^{70}$, rythment comme un ostinato l'ensemble de l'espace. Seuls éléments figurés de la bibliothèque, associés à la masse des livres sans le recours à la moindre représentation peinte ou plastique des artes liberales, ni à une quelconque allégorie du savoir, ils permettent de clarifier la fonction de représentation dévolue à cette galerie. Les meubles du cardinal sont souvent associés, dans les devises et allégories, aux deux vertus de prudence (les trois astres) et de force (le faisceau de licteur) ${ }^{71}$. Aussi la bibliothèque, dans une conception qui est celle de l'humanisme tardif, manifeste-t-elle directement, sans la médiation d'un programme iconographique, sa vocation d'éclairer l'exercice du pouvoir en procurant sans concurrence les moyens de la sagesse et du discernement.

Les 54 colonnes, cannelées et légèrement fuselées, ont plus fortement encore que les armes de Mazarin marqué l'identité visuelle de la bibliothèque, signe, comme on le verra, que leur emploi n'allait pas forcément de soi. L'appellation contemporaine de "bibliothèque des colonnes " est attestée par Sauval ${ }^{72}$. Au point que la seule association d'une colonne et de travées de livres suffit désormais à désigner la Mazarine : on le voit à un bandeau gravé par Henri-Simon Thomassin vers I694, à une époque où la bibliothèque a quitté le palais Mazarin et occupe déjà le bâtiment qui est le sien aujourd'hui : la gravure ne représente pas précisément la Mazarine - pas de pupitres, pas de piédestaux, arrière-plan approximatif -, elle la suggère par la seule présence des colonnes [ill. 7 ${ }^{73}$.

Les sources décisives permettant d'attribuer le dessin et l'exécution de la menuiserie de la bibliothèque ne sont pas encore mises au jour. Cet élément majeur, de même que la serrurerie des balustres du balcon, sont étrangement absents des minutes du notaire de Tubeuf, que nous avons intégralement dépouillées sur la période I646-I653. À croire qu'ils ont fait l'objet de

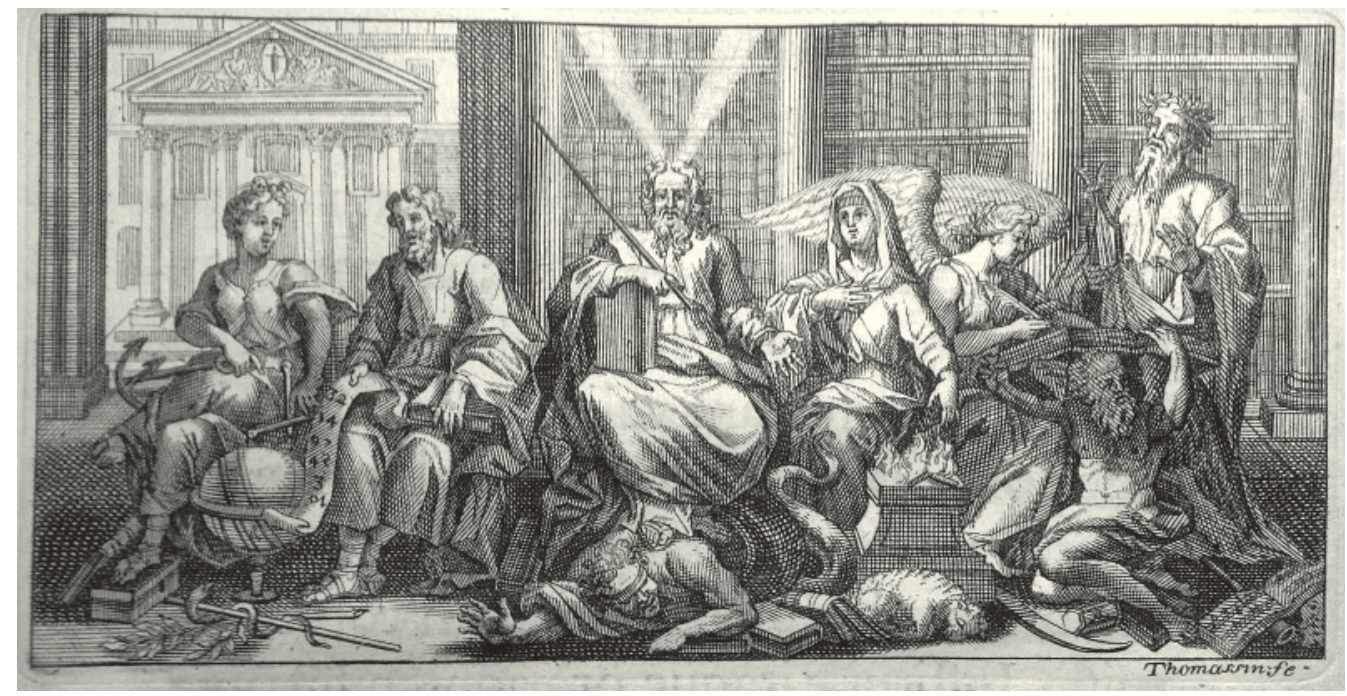

7. Vignette gravée par Henri-Simon Thomassin, vers 1694 . 
procédures d'ordonnancement et de comptabilité distinctes des autres travaux conduits dans l'aile Le Muet-Valperga. Les mémoires et quittances d'ouvrages retrouvés pour le palais ne permettent de documenter précisément que des interventions secondaires (porte d'accès, mise en huile des boiseries et peinture postérieure de la serrurerie).

Qui est précisément à l'origine de ce décor, exclusivement sculpté et confié à la seule menuiserie ? Le Muet ? Valperga ? Un décorateur particulièrement attentif à la théorie des ordres comme Charles Errard ${ }^{74}$ ? L'un des menuisiers de talent dont les interventions sont par ailleurs attestées dans le palais Mazarin ? La conception éminemment architecturale de ces colonnes, de par leur fonction, leur taille et les canons qu'elles respectent, inciterait plutôt à en attribuer le dessin à l'un des deux architectes associés par le marché de maçonnerie de I646. Faut-il dans ce cas considérer, pour des raisons de chronologie, que Le Muet aurait livré les écuries - soit le rez-de-chaussée du bâtiment - mais que Valperga, revenu à Paris au printemps I647, considéré alors comme l'architecte personnel de Mazarin, aurait suivi seul la poursuite des travaux et notamment tout l'aménagement intérieur ${ }^{75}$ ?

On notera cependant que Le Muet (I59I-I669) était un amateur d'ordres (ce qui n'était pas le cas de Mansart). En I63I-I632 il avait traduit les Regles des cinq ordres d'architecture de Vignole ; un an avant la signature du marché de l'aile de la bibliothèque, il avait dédié au président Tubeuf sa traduction du traité de Palladio, dont il donnera une nouvelle édition dès $1647^{76}$. C'est alors l'un des meilleurs spécialistes de la théorie des ordres, de la grammaire et des proportions de l'ornementation classique, et partant de la conception des colonnes ${ }^{77}$. On observera également que les colonnes de la Mazarine ne sont pas corinthiennes comme il a toujours été dit, mais " composites ". Il s'agit du cinquième ordre de Palladio, dont la précellence et la " romanité " purent ne pas déplaire à Mazarin : "l'ordre composite, qui s'appelle aussy latin, pource qu'il est de l'invention des anciens Romains, est ainsy nommé parce qu'il participe aux deux ordres susdicts [i.e. l'ionique et le corinthien], \& le plus beau $\&$ le plus regulier est celuy qui est composé de l'Ionique et du Corinthien ${ }^{78}$."

- 74. Errard a fourni les dessins d'ordre pour l'ouvrage de Fréart de Chambray, Parallele de l'architecture antique et moderne, Paris, I650. Il envisagea par la suite de donner son propre Parallèle, dont les planches seront rassemblées et publiées après sa mort. Emmanuel Coquery, Charles Errard: la noblesse du décor, Paris, Arthena, 2013, p. 36I-379. - 75. A. Cojannot, "Antonio Maurizio Valperga... ", art. cit., 2003, p. 39. 76. P. Le Muet, Traicté des cinq ordres d'architecture, desquels se sont seruy les Anciens. Traduit du Palladio augmenté de nouuelles inuentions pour l'art de bien bastir..., Paris, François Langlois, I645; Ibid., Pierre II Mariette, I647. L'architecte avait donné en I623 la première édition de sa Manière de bastir pour toutes sortes de personnes; les rééditions qu'il en donne à partir de 1647 sont suivies des Augmentations de nouveaux bastimens faicts en France par les ordres \& desseins du Sieur Le Muet : il y publie notamment les plans et élévations des corps de logis qu'il a édifiés pour le président Tubeuf sur la rue Neuvedes-Petits-Champs, mais aucun élément relatif à l'aile de la bibliothèque pourtant commencée dès I646. On ne saurait trouver là un argument pour lui en retirer la réalisation, car la Maniere de bastir est essentiellement consacrée à la maison individuelle et aux problématiques de distribution. 177 . F. Lemerle, "À l'origine du palladianisme européen : Pierre Le Muet et Roland Fréart de Chambray ", Revue de l'art, 178, 2012-4, p. 43-47. 18 . Andrea Palladio, Traicté des cinq ordres d'architecture, dans la traduction de Pierre Le Muet, ouvr. cité 1645, p. 89. " 79. "Mémoire de menuyseries faictes pour Monseigneur le Cardinal Mazarin en son Pallays par l'ordre de Monsieur de Vallepergue architecque de Mon dit seigneur fournys par Dionys Menuysier ", arrêté par Valperga le 3 septembre I648, AN, MC/CXII/6I $\left(\mathrm{I}^{\mathrm{er}}\right.$ mars 1653$)$. 180 . Autre mémoire, visé par Valperga le 20 décembre I648, ibid. $\square$ 8I. La plus importante prestation de menuiserie semblet-il de l'aile de la Traverse ( 5509 livres), Mémoire des ouvrages de menuiserie faits par Adrian Pignon, arrêté par Le Muet le 20 novembre I649 (biffé : 1648), ibid. C'est dans cette petite galerie de l'aile de la Traverse (voir ill. 6, M) que se situe la scène rapportée par le comte de Brienne, qui vit Mazarin à quelques jours de la mort prononcer, à la vue de ses collections : « il faut quitter tout cela ", Claude Dulong, « Du nouveau... ", art. cit., 1995, p. 144. 10 82. Errard est intervenu à Fontainebleau vers 1645, dans la scénographie de l'Orfeo de Luigi Rossi en 1647, puis à partir de I653 au Louvre dans l'appartement du cardinal ; il a livré plusieurs travaux, notamment de bois peint, dans l'hôtel de Chevry-Tubeuf. Pierre Dionys a travaillé avec lui au palais Mazarin et au Louvre (Emmanuel Coquery, Charles Errard..., ouvr. cité, 2013, p. $62-65,100$, n. $429,249-250$ ). 
Une de ses particularités, fixée par Palladio, est que le piédestal est, en proportion, le plus haut de tous les cinq ordres, ce qui en fait le plus " esguayé " (Palladio écrit «svelto " dans l'édition originale de 1570) : " et d'autant que, comme j'ay dict, cet ordre se doit faire plus esguayé que le corinthien, son piedestal est du tiers de la hauteur de la colonne » (contre un quart seulement pour le corinthien). Ces proportions, vérifiées sur les élévations de Copenhague comme dans l'actuelle salle de lecture de la Mazarine, procurèrent trois avantages : elles permirent d'intégrer, sur toute la hauteur du piédestal, un corps inférieur à deux niveaux de tablettes pour les in-folio, surmonté d'un pupitre qui s'est partant trouvé à hauteur d'appui ; les piédestaux ont pu ainsi rythmer exactement les armoires basses, et les colonnes rythmer exactement les armoires hautes, établies entre le sommet du pupitre et l'entablement ; la hauteur des piédestaux a également permis l'intégration de petits placards fermant à clés.

Plusieurs menuisiers sont intervenus dans le palais Mazarin, dont les sources comptables et notariales nous transmettent les noms. Les quittances délivrées par Tubeuf entre I649 et 1652 pour travaux dans l'Appartement neuf et dans l'aile des écuries-bibliothèque en signalent quatre : Pierre Dionys, Adrien Pignon, Jean Selincourt et Pierre Cotton. Les montants des sommes quittancées aux deux premiers sont de loin les plus importants, et la nature de leurs interventions révèle des talents évidents dans le domaine de la décoration. Pour l'Appartement neuf, Dionys déclare avoir livré plusieurs cadres de tableaux, « fait tailler les armes de Monseigneur ", " sur la chemynee de la grande salle hautte avoyr fait une figure d'enfans pareil a celuy quy estoit faict quy sont asseiz desseus la cornyche de la dite chemynee quy tiennent ung cartouche ou sont taillez les chiffre de monseigneur ${ }^{79} \ldots »$. Cette description pourrait s'appliquer au décor héraldique de bois sculpté qui orne aujourd'hui l'imposte de la porte de la grande galerie de la Mazarine [ill. 8]. Il a également livré « une grande porte pareille a une quy estoi faicte pour entrer au grand departement [i.e. l'appartement neuf ?] pour aller a la bibliotecque de dix piezd de haut [3,24 $\mathrm{m}$ ] et six piezd de large [I,94 $\mathrm{m}$ ] brysee en deux avec double cadre et table d'atente ornez de cartouche masque et coquille ${ }^{80}$ ». Ces dimensions ne sont pas éloignées de celles de la porte citée précédement, qui fut installée dans le collège des Quatre-Nations pour servir d'accès principal à la nouvelle Mazarine, et qui sépare aujourd'hui la Mazarine de l'Institut de France (avec le bâti : 3,30 × I,80 m). L'hypothèse d'un transfert de ces panneau et porte, à l'occasion du grand déménagement qui aura lieu en 1668 , n'est pas improbable. Pignon, de son côté, a exécuté dans la petite galerie de l'appartement d'hiver " un plafon suivant le dessin que Monsieur Valpergue arquite [i.e. architecte] de son Éminence ma donné faict d'arquitecture avec ormemens sclutur \& enfoncement avecq une corniche corinte au pourtour ${ }^{8 \mathrm{I}}$ ».

Des deux hommes, Pierre Dionys a plus particulièrement retenu notre attention : il travaille avec le grand décorateur Charles Errard, dont Emmanuel Coquery a récemment montré qu'il avait les faveurs de Mazarin, ayant abondamment servi l' « imagerie Mazarine » à partir de 1646, et conduit plusieurs chantiers de décoration en intégrant le vocabulaire de son héraldique $^{82}$. Rien ne permet pour l'heure de l'associer en tout certitude à la sculpture et à l'installation du décor de la bibliothèque en I648, mais nous l'avons retrouvé en I668, au moment où ce singulier décor de boiseries est démonté de sa galerie d'origine pour rejoindre la nouvelle Mazarine transférée au collège des Quatre-Nations, et y être ajusté. Dans le registre des comptes du collège, il apparaît en qualité d'expert, requis pour superviser les interventions 


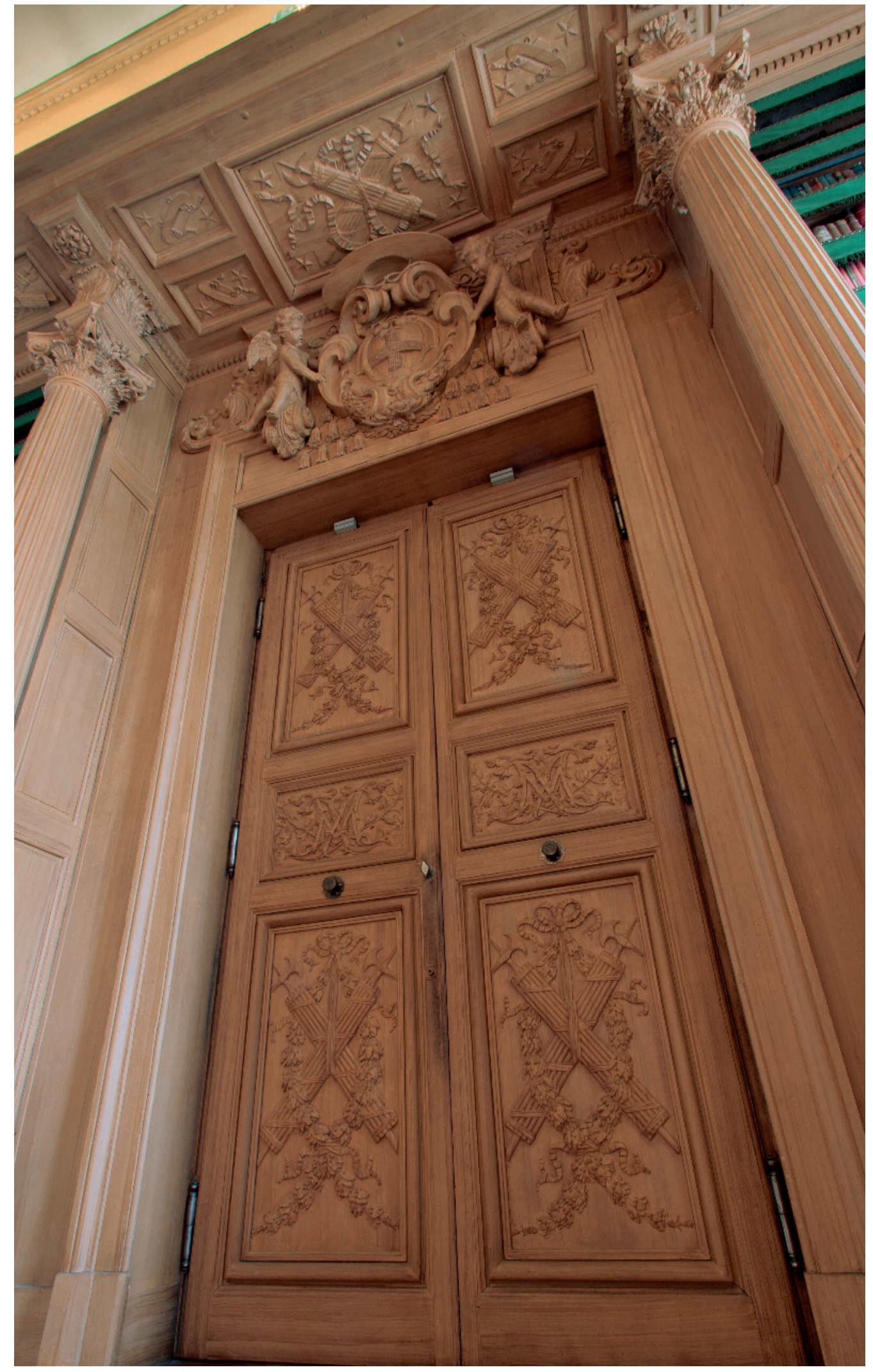


des charpentiers et menuisiers, et notamment de l'artisan Jean Charon (I6.. - av. I673), qui a précisément effectué la dépose, le transport et la réinstallation de la menuiserie de la bibliothèque ${ }^{8_{3}}$. Devons-nous interpréter cette implication comme le signe d'une parfaite connaissance de ce décor, et de sa responsabilité sur son exécution ?

Pour la réalisation de la balustre de ferronnerie, le nom d'Antoine Lemaistre constitue l'hypothèse la plus vraisemblable : il s'agit du principal serrurier à l'œuvre dans le palais, dont d'importants mémoires sont quittancés entre décembre I649 et août I652, et à qui sera confié en 1662 le soin de placer les grilles aux armoires de la bibliothèque ${ }^{84}$. Nous connaissons déjà le peintre chargé des finitions de la galerie (sur le bois comme sur les ferronneries), Thomas Boudan.

\section{«Bibliotheca Mazarino Naudaea »}

Le Père Mersenne, dans une lettre à Samuel Sorbière du 2I mars I647 - publiée en 1983 mais que personne à notre connaissance n’a relevée - a employé la formule significative de «Bibliotheca Mazarino Naudaea ${ }^{85}$ ». La part de Naudé dans la conception et l'organisation de la collection semble en effet déterminante, non seulement par l'exercice particulièrement actif de la charge bibliothécaire qu'il occupe depuis I642-I643, mais aussi parce que le cadre conçu entre 1646 et 1648 apparaît comme une réalisation du programme fixé dès I 627 dans l'Advis pour dresser une bibliothèque. Le projet Mazarino naudaeus du reste n'a pas conduit le bibliothécaire à modifier ou réactualiser son texte pour la réédition de 1644 : la mention « seconde édition, reveue, corrigée \& augmentée " est largement abusive, sauf à désigner l'adjonction du traité du P. Jacob, avec lequel cette réédition de l'Advis est publiée.

Parmi les règles que Naudé avait lui-même fixées en matière de construction et d'aménagement, se trouvent en effet respectées trois recommandations majeures :

- celle de placer la bibliothèque "dans des estages du milieu ", ce qui à la fois la prémunit du « remugle » engendré par la "fraicheur de la terre », et garantit contre les « intempéries de l'air » (chapitre VI : «la disposition des lieux où on les [livres] doit garder »);

- celle de faire en sorte que « les principales ouvertures soient tousjours vers l'Orient, tant à cause du jour que la bibliotheque en pourra recevoir de bon matin, qu'à l'occasion des vents qui soufflent de ce costé, lesquels estans chauds $\&$ secs de leur nature rendent l'air grandement tempéré... \& pour dire en un mot sont tres-sains \& salubres ». Dans le bâtiment de la rue de Richelieu, le plan de Copenhague confronté aux états des vitres de i654 et I657 en témoigne, la galerie, contrairement aux salles qui la précèdent et la suivent, ne prend le jour que vers l'est ;

- celle de ne point « rechercher \& entasser dans une bibliotheque toutes ces pieces \& fragments des vieilles statues... encore moins faut il employer l'or à ses lambris, l'yvoire \& le verre à ses parois, le cedre à ses tablettes, \& le marbre à ses fonds \& planchers, puis que telle façon de

[ 83. Son nom apparaît en marge des relevés de comptes des travaux de de sculpture. = 84. Cf. supra, note 46. 1 85. "Bibliotheca Mazarino menuiserie ("le sieur Dionis menuisier est l'expert nommé »), Registre Naudaea jam 30 ooo voluminibus constat, quorum sunt Io ooo folio ", cumulatif des dépenses pour le collège Mazarin (1662-1674), AN, H/2845. Bnf, n.a.f. 6204, f. 294, éd. dans Correspondance du P. Marin Girardon exerce alors les mêmes fonctions d'expert pour les ouvrages Mersenne..., ouvr. cité, XV (I647), I983, p. I40. 
paroistre n'est plus en usage, que les livres ne se mettent plus sur des pulpitres à la mode ancienne, mais sur des tablettes qui cachent toutes les murailles » (chapitre vIII : «L'ornementation \&la decoration que l'on y doit apporter »). On comparera cette injonction de sobriété à la longue liste des ornements de bibliothèques que relève un Claude Clément dans son Musei sive bibliothecae... instructio (1635), en les classant selon une typologie sans doute déjà assez anachronique. Naudé, surtout, lie étroitement disposition verticale et périphérique des livres d'un côté, absence de décoration de l'autre. Et de fait le principe mural, si pleinement développé (" toutes les murailles »), entraîne nécessairement l'exclusion de la fresque ou du tableau ${ }^{86}$. Le mobilier bibliothécaire, étendu à l'ensemble de l'espace vertical, escamote le décor tout en en tenant lieu.

Ajoutons, à ces principes issus du programme naudéen, trois caractéristiques qui me paraissent importantes pour qualifier l'identité de la Mazarine et la situer précisément dans une histoire générale de l'architecture et du décor des bibliothèques :

$\left.I^{\circ}\right)$ Si la galerie des livres de Mazarin n'est pas autonome du point de vue architectural (elle reste l'élément d'un complexe palatial, auquel elle est articulée, édifiée sur un rez-dechaussée dont la fonction lui reste étrangère), elle n'en constitue pas moins une aile dédiée, et construite $a d h o c$, ce qui n'était le cas ni à l'Escurial ni au palais Barberini, où la bibliothèque se trouvait enclavée dans le bâti. Ce caractère est commun au projet défini pour la bibliothèque de Richelieu. Appendice, orientée en direction de la rue (chez Richelieu) ou le long de celleci (chez Mazarin), la bibliothèque constitue déjà un élément d'extériorité, en partie déterminé par une vocation publique. En cela l'une et l'autre représentent une étape importante dans le processus d'individuation de la bibliothèque dans l'espace urbain ${ }^{87}$.

$2^{\circ}$ ) Les " murailles " garnies de livres conservent leur parfaite linéarité, le regard ne s'en trouve pas interrompu. Ce n'est pas le cas à la Bodleian Library (I6I2), où le rayonnage est certes mural, mais précédé de structures en applique intégrant l'escalier d'accès à la galerie supérieure, ainsi que des bancs et pupitres placés face aux tablettes [ill. 9 $]^{88}$.

9. Oxonia Illustrata, 1675.

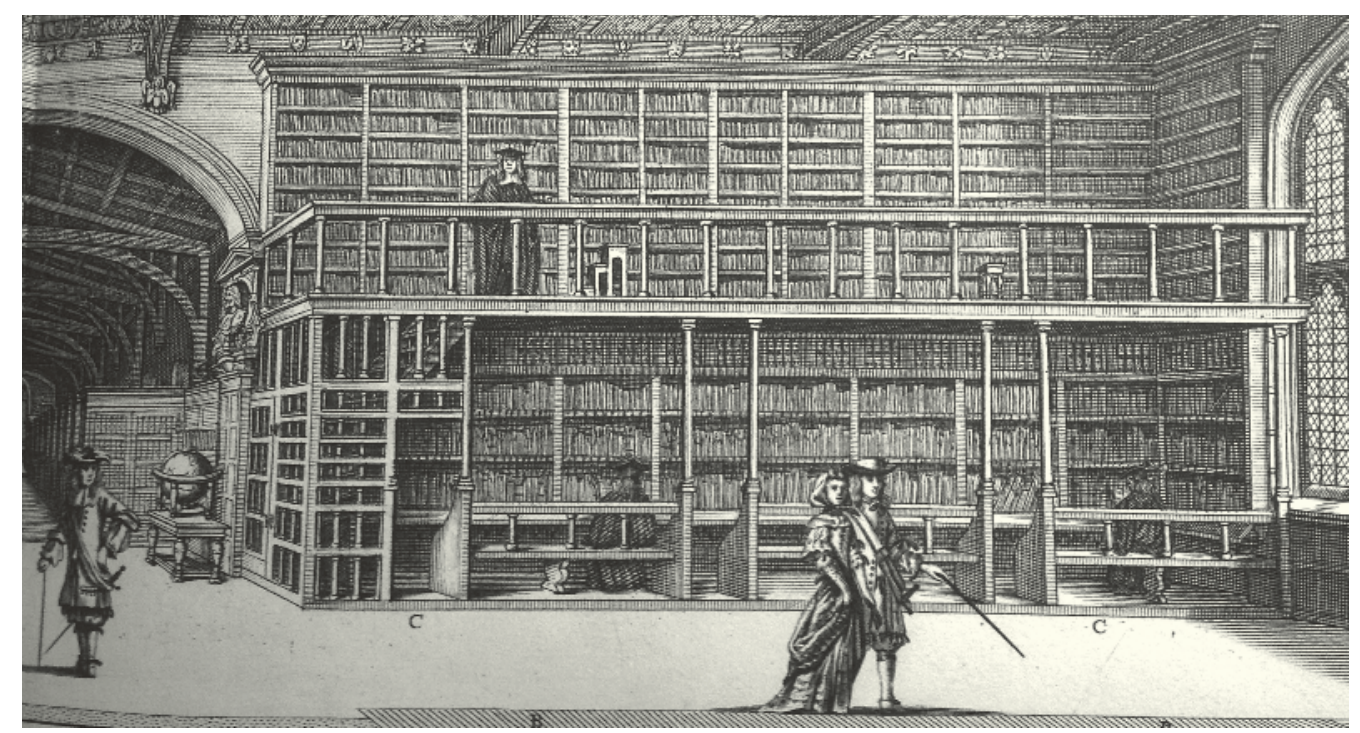
Gravure de David Loggan. 
Cette unité de l'espace, qui tire pleinement profit de la disposition en galerie, sera très favorablement appréciée au moment des discussions qui prépareront l'aménagement de la nouvelle Mazarine en I668, tant pour des raisons de solennité que pour des motifs de sécurité des collections.

$3^{\circ}$ ) Une des particularités du décor menuisé de la Mazarine tient au fait que la couleur du bois lui a été conservée, même si le sujet a fait l'objet d'interprétations contradictoires au $\mathrm{xx}^{\mathrm{e}}$ siècle. Cette nudité ajoute à la sévérité et à l'unité du décor, et achève d'exclure toute dimension picturale. Elle n’allait pourtant pas de soi : les décors de bois étaient alors généralement peints et dorés, comme du reste dans tous les autres espaces du palais Mazarin aménagés dans les années 1640 et $1650^{89}$.

Pour résumer, la bibliothèque de Mazarin n'expose pas de décor, si ce n'est celui offert par la seule menuiserie nécessaire à l'organisation des livres, affichant par l'absence de tout apport pictural la nature de son matériau ; son silence visuel (pas d'inscription, pas d'iconographie peinte, aucune référence explicite en matière d'érudition ou de science) confere à la seule masse des livres, dans sa disponibilité, son pouvoir de démonstration ; livres et menuiserie ensemble, paraissent au visiteur porter seuls le bâtiment. Économie de moyens et primauté de la fonction qualifient donc sa conception.

\section{D’un PALAIS L'AUTRE : UNE CONTINUITÉ SANS SERVILITÉ (I66I-I668)}

Les mesures prises par Mazarin quelques jours avant sa mort pour assurer l'unité et la pérennité de sa bibliothèque sont exceptionnelles à l'aune de l'ensemble de ses ultimes dispositions. Par son testament (6 mars I66I) en effet, il a lui même programmé la dispersion de ses collections d'art, de mobilier et d'antiques ${ }^{90}$, et consacré la division du palais. Celui-ci était partagé entre ses deux héritiers : sa nièce Hortense, épouse de Charles Armand de La Porte de La Meilleraye, devenu duc de Mazarin ; son neveu le marquis de Mancini, récemment fait duc de Nevers, à qui échut le lot occidental côté rue de Richelieu, comprenant entre autres l'aile Le Muet-Valperga ${ }^{91}$. À partir de I698 le « Nivernais » loua à la marquise de Lambert (I647-I733) la partie nord de l'aile, correspondant justement aux espaces visibles sur les dessins de Copenhague (trois travées de la grande galerie, puis les salles lui faisant suite), et dont l'étage supérieur avait été l'appartement de Gabriel Naudé. Elle y tint dans le premier tiers du XviII siècle le fameux salon que nous connaissons. Le reste de l'hôtel de Nevers, c'est à dire la partie sud,

\footnotetext{
n 86. À la bibliothèque de Leyde, qui conserve au XVII ${ }^{\mathrm{e}}$ siècle sa dispo- par Borromini dans les années I630 à I650, les menuiseries ont conservé sition par pupitres transversaux, des tableaux ornent les murs ainsi la couleur du bois (généralement du noyer), mais elles sont intégrées laissés libres, comme en témoigne la planche gravée par Woudanus en dans des espaces très décorés. Voir la contribution de Fiammetta Sabba, I6IO, qui illustre le Stedeboeck der Nederlanden (Amsterdam, Willem "I saloni librari Borrominiani di Roma ", dans le présent volume. Blaeu, I649) ; à l'Ambrosiana, entre les dernières tablettes et la naissance $\quad 90$. Les bâtiments et les bustes devaient revenir par moitié à ses deux de la voûte, les murs accueillent une galerie de portraits. 187 . La héritiers. En outre, plusieurs legs particuliers comprenaient des œuvres pleine autonomie sera réalisée à Oxford au XviII ${ }^{e}$ siècle avec la biblio- d'art, et une somme de 300 ooo livres, destinée à divers legs, était thèque Radcliffe (édifiée par James Gibbs à partir de 1737), puis à Paris à prendre sur les " meubles meublant, pierreries, bagues et joyaux ", avec la Bibliothèque Sainte-Geneviève achevée par Henri Labrouste en ce qui supposait une vente préalable. Voir P. Michel, Mazarin, prince 1850. 18 . Le dispositif, visible sur les planches gravées par David des collectionneurs..., ouvr. cité, I999, p. 310 et suiv. @ 91. H. Lacaille, Loggan pour le recueil Oxonia Illustrata (1675), a été conservé. @ 89. "Le partage du palais Mazarin... à la mort du cardinal ", art. cit., On précisera toutefois que dans les bibliothèques romaines dessinées $\quad$ p. 330-34I.
} 
occupée par Mancini puis son fils, est cédé en I719 au financier John Law, qui en fait le siège de sa Banque générale de I719 à $172 \mathrm{I}^{92}$. L'ensemble des bâtiments se trouve ensuite à nouveau " réuni " en étant dévolu à la Bibliothèque royale, qui y déploie ses collections à partir de I724. Cette affectation entraîne d'importants bouleversements, conduits par les architectes Robert de Cotte au XVIII ${ }^{\mathrm{e}}$ siècle et surtout Henri Labrouste au XIX ${ }^{\mathrm{e}}$, responsable de la disparition presque intégrale de l'aile Le Muet-Valperga ${ }^{93}$. Mais entre temps la bibliothèque de Mazarin avait quitté les lieux.

Le testament du cardinal avait décidé la fondation du collège des Quatre-Nations, de la Bibliothèque Mazarine, administrativement soumise au collège mais conservant une vocation publique, ainsi que d'une académie équestre qui ne verra pas le jour. Le collège serait rattaché à l'Université de Paris, et placé sous l'autorité de la Sorbonne. Citons la disposition la plus explicite relative au sort de la collection :

Le bibliothecaire sera tenu se charger des livres de la bibliotheque, dont il fera inventaire, ou recollement de celuy qui en aura esté fait [...]. Sera aussi fait un memoire des tablettes, tables, armoires, bancs \& sieges servans a ladite bibliothèque, que son eminence donne encore par ces présentes [nous soulignons]. Veut Son Éminence que ladite bibliotheque soit ouverte a tous les gens de lettres deux fois par chacune semaine, à tel jour qu'il sera advisé par les quatre inspecteurs, \& par le grand maistre dudit college ${ }^{94}$.

La solidarité de la collection et de son cadre de menuiserie était posée en principe, ce qui imposa nécessairement quelques contraintes aux exécuteurs de la fondation. Cela n’empêcha pas Louis Le Vau, l'architecte retenu pour le collège Mazarin et qui en conduira le chantier jusqu'à sa mort en octobre I670, de concevoir pour la bibliothèque une galerie non pas continue comme dans le bâtiment de Le Muet-Valperga, mais en forme de L, le plus court segment formant retour sur le quai, face au Louvre ${ }^{95}$. Cela n'empêcha pas non plus, au sein du conseil de fondation, de vifs débats sur la pertinence de respecter tel ou tel élément du décor menuisé et de son organisation générale.

92. Une partie de la grande galerie de la bibliothèque de Mazarin (à savoir les cinq travées restées au duc de Nevers et non intégrées dans l'appartement de Madame de Lambert) accueille alors la galerie des Mississippiens, dont la décoration du plafond est confiée au vénitien Gianantonio Pellegrini en 1720-I72I. Sur les aménagements et la décoration dus à John Law, voir la contribution récente de Valentine Toutain-Quittelier, " John Law et le décor de la Banque royale : un programme unique ?", dans Le Système de Law : Représentations, discours et fantasmes $d u$ XVIII ${ }^{\mathrm{e}}$ siècle à nos jours, Actes du Colloque international de Montpellier, 4-5 octobre 2013, dir. Florence MagnotOgilvy, à paraître aux Presses universitaires de Rennes sous le titre "Gagnons sans savoir comment! " Le Système de Law, une chimère française. 93. A l'exception, rappelons-le, de son extrémité septentrionale, partie de l'hôtel de Nevers louée à la marquise de Lambert, qui sera occupée de la fin du XIx ${ }^{\mathrm{e}}$ siècle et jusqu'en 1917 par le département des Médailles de la Bibliothèque nationale, puis, à partir de 1928, par le Centre national de synthèse. Cet ultime témoin de la grande bibliothèque de Mazarin est aujourd'hui vide. Malgré les transformations opérées depuis I66I, de l'étage de la bibliothèque subsistent deux espaces correspondant à la volumétrie originelle : le petit cabinet de travail de Gabriel Naudé donnant sur la rue de Richelieu, et la « salle après la bibliothèque ", qui faisait suite à la grande galerie, et qu'une mention de Robert de Cotte sur un plan de 1725 nous dit avoir constitué la salle à manger de la marquise de Lambert. La principale modification a été le percement, dans cette dernière salle, de deux ouvertures supplémentaires (à l'est et à l'ouest) ; ouvertures pratiquées après 1717 , car les relevés de Robert de Cotte sont sur ce point conformes au plan de Copenhague et aux marchés de vitrerie de 1654 et I657 (voir ill. 6, A et C). Nous remercions Jacqueline Sanson, directrice générale de la BnF, de nous avoir permis de pénétrer pour les besoins de cette enquête dans le vestige de l'hôtel de Nevers. a 94. Testament de Mazarin ( $c f$. supra, note 65), que le collège fera imprimer pour servir d'acte de fondation, La Fondation du collège Mazarin, [Paris, vers I680], I6 p., in- $4^{\circ}$, p. II (AN, M/I74, $\mathrm{n}^{\circ} 70$ ). 195 . Plans datés entre I 662 et I664, AN, MM/I76. À la mort de Le Vau l'aile de la bibliothèque est achevée et en cours d'équipement. François d'Orbay, son successeur sur le chantier, dont l'intervention fut notamment déterminante pour le dessin des parties hautes de la chapelle, n'est à notre connaissance pas intervenu dans le pavillon de la bibliothèque. a 96. "C'est a scavoir de bastir le college proche la porte de Nesle vis-à-vis le Louvre auquel lieu on pourroit faire une place publique qui serviroit d'ornement à l'aspect du Louvre ", Registre de l'assemblée des exécuteurs 
La proposition de Le Vau de bâtir le collège face au Louvre, à l'emplacement de la porte de Nesle, fut formulée entre le 24 et le 31 décembre $166 \mathrm{I}^{96}$. D'autres lieux avaient été proposés, entre autres les bâtiments du collège du Cardinal-Lemoine, le jardin des Plantes, l'hôtel de Nemours, l'hôtel d'Orléans (actuel palais du Luxembourg), ainsi qu'une solution restée jusqu'ici inaperçue, et sur laquelle nous reviendrons. Le site de la porte de Nesles fut en tout cas préféré par Colbert dès janvier $1662^{97}$, et définitivement retenu par le roi avant le $\mathrm{I}^{\mathrm{er}}$ juillet $1662^{98}$. On notera la présence de Valperga à plusieurs séances de l'assemblée des exécuteurs testamentaires en I66I et I662, signe d'une volonté de continuité architecturale entre le palais Mazarin et le collège en devenir.

Comme Mazarin l'avait souhaité, et non sans hésitations, le décor sera transféré avec les livres. La date et les modalités du transfert sont jusqu’à aujourd'hui demeurées imprécises. Franklin était resté fort évasif : il a, par un raccourci de formulation, suggéré à plusieurs auteurs la date de I688 ${ }^{\circ}$. En 196I, à l'occasion des manifestations qui accompagnent le quatrième centenaire de la mort de Mazarin, sans doute induit en erreur par Franklin, Weigert retient cette date de 1688 , se ravisant l'année suivante en faveur de l'année $1685^{100}$. L'architecte André Gutton, qui suit les travaux de rénovation en 1968-1970, considère que le transport s'est fait en $1670-1672^{101}$. Maurice Piquard le situe après la mort de Le Vau (1670), et en attribue sans justification le contrôle à François d'Orbay, qui succéda à son beau-père dans la direction du chantier ${ }^{102}$. Pierre Gasnault a supposé un temps que le transfert avait été effectué entre I677 et I680, avant de se rallier à l'année I668 ${ }^{\mathrm{I0}}$. Celle-ci avait été proposée dès I96I, mais sans justification, par André Masson, qui supposait à tort que l'opération avait été effectuée en novembre ${ }^{104}$.

testamentaires du cardinal Mazarin, délibération du $3 \mathrm{I}$ décembre I66I, AN, MM/46I, f. 22v $\mathrm{v}^{\circ}$, et MM/462, f. 38. La suggestion géniale de Le Vau est traditionnellement datée du dernier jour de l'année (voir Hilary Ballon, Louis Le Vau: Mazarin's College, Colbert's revenge, Princeton, University Press, 1999, p. 4I-42 ; et Jean-Pierre Babelon, Le Palais de l'Institut, Paris, Chaudun, 2005, p. 24). Mais elle doit selon nous être avancée de quelques jours, et Colbert dut en avoir la primeur : en témoigne une observation de l'avocat Gomont à la date du 3I décembre, qui précise en avoir " desja conféré avec Monsieur de Colbert qui a trouvé cette proposition fort agréable ", AN, MM/46I, f. 23. L'hypothèse Nesle était totalement absente des échanges du 24 décembre, où toutes les propositions furent passées en revue. Sur l'histoire du site de Nesle, on se reportera à La Tour de Nesle : de pierre, d'encre et de fiction [Exposition, Bibliothèque Mazarine, septembre-décembre 2014], dir. Jocelyn Bouquillard, Patrick Latour et Valentine Weiss, Paris, Bibliothèque Mazarine ; Éditions des Cendres, 20I4. 97. Entre le 3I décembre et le I8 janvier suivant, l'avocat Jean de Gomont, qui assure le secrétariat du conseil de fondation, a réévoqué cette proposition avec Colbert, lequel a «fort approuvé ce dessein ", AN, MM/462, f. 38 et suiv. 98. AN, MM/46I, fol. 40. n 99. «La Poterie se chargea de surveiller leur [i.e. les livres] transport, et ils abandonnèrent enfin le palais Mazarin. C'est le dernier service que La Poterie rendit à la bibliothèque ; dès I688, ses I 200 liv. d'appointements furent changés en une pension... ", Les Anciennes Bibliothèques..., ouvr. cité, t. III, I873, p. II4; formulation à l'identique dans Id., La Bibliothèque Mazarine..., ouvr. cité, I9oI, p. 215. I I00. R.-A. Weigert : « Le transfert, vers I688 sans doute, de la bibliothèque au collège des Quatre-Nations... laisse vide l'immense local ", Mazarin, homme d'État et collectionneur, ouvr. cité, I96I, p. XXIV ; id., « Le Palais Mazarin, architectes et décorateurs ", art. cit., 1962, p. I68. La date de I685 n'est pas justifiée par Weigert ; elle a pu lui être inspirée par la lecture de Charles Le Maire, qui signale à cette date que le transfert au collège Mazarin a eu lieu ( le roy d'Angleterre et celui du Danemark la virent avec admiration, lorsqu'elle était au palais Mazarin, d'où elle fut transportée dans ce college ", Le Maire, Paris ancien et nouveau..., I685, t. II, p. 560). IOI. Lettre à Jacques Renoult du 3 juillet 1968 ; Rapport sur les travaux du Io février 1970, Archives de la BM (inventaire en cours). IO2. Maurice Piquard, «La bibliothèque de Mazarin et la Bibliothèque Mazarine, 1643-1804 ", CRAI, 1975, p. I30. I103. La bibliothèque Mazarine et ses collections jansénistes, conférence du 20 janvier 1984 à la Société des amis de Port-Royal ; id., "Collège des Quatre-Nations : la Bibliothèque Mazarine ", dans Les bibliothèques parisiennes..., ouvr. cité, 2002, p. 88. Isabelle de Conihout et Christian Péligry l'ont quant à eux daté " vers I670 ", "Trésors méconnus de la Bibliothèque Mazarine ", L'Estampille / L'Objet d'art, $\mathrm{n}^{\circ}$ 334, I999, p. 26-39. I04. André Masson, « Mazarin et l'architecture des bibliothèques au XVII ${ }^{e}$ siècle ", art. cit., 196I, p. 360 ; id., Le Décor des bibliothèques..., Genève, Droz, 1972, p. I02. Date de déménagement reprise par Alexandre Cojannot, «La création du collège des QuatreNations ", Art et métiers du livre, $\mathrm{n}^{\circ}$ 222, décembre 2000-février 200I, p. 23 ; et par Claude Mignot, qui a avancé qu'armoires et livres furent réinstallés dans le nouveau bâtiment en I668, ce qui est inexact (les livres ne le seront qu'en 1673), "Première Bibliothèque Mazarine rue de Richelieu ", dans Les Bibliothèques parisiennes..., 2002, p. 70. 
On a conservé un "plan de la première cour du collège Mazarin " qui pourrait dater de I665-1666 et donne à voir la distribution quasi définitive de la bibliothèque au premier étage du pavillon oriental du collège : il est complété d'un profil de la voûte, et s'y trouve esquissée au carbone, sur certaines travées, peut-être de la main même de Le Vau, l'implantation des menuiseries et des colonnes [ill. Io] ${ }^{\text {105. }}$.

À l'automne I665, alors même que le pavillon de la bibliothèque est élevé mais pas encore couvert, et que les exécuteurs de la fondation ont programmé l'ouverture du collège et de la bibliothèque pour le $\mathrm{I}^{\text {er }}$ octobre $\mathrm{I} 667$, des discussions naissent sur le parti architectonique et décoratif qui sera celui de la bibliothèque. Le sujet de préoccupation principal est celui du plan général : galerie rectiligne comme rue de Richelieu, ou bien « L » comme le propose Le Vau ? L'avocat Jean de Gomont, ancien chargé d'affaires de Mazarin devenu rapporteur du conseil de fondation, semble alors le plus attaché au principe de la galerie unique, pour des raisons fonctionnelles mais aussi sans doute par souci de conformité au modèle conçu pour Mazarin :

Monsieur Gomont a dit qu'il falloit adviser de quelle façons l'on disposeroit la biblioteque, soit pour la seureté des livres et pour la gayeté, et s'il y avoit un retour adjoustant qu'il n'estoit point d'advis qu'il y eust un retour d'autant que la Biblioteque estoit de sa longueur et seroit plus belle et donneroit moyen au $\mathrm{M}^{e}$ et sous $\mathrm{M}^{e}$ de la Biblioteque de voir d'un bout à l'autre et observer ceux qui feroient lecture des livres affin afin [sic] que l'on n'y puisse rien soustraire ny alterer, au lieu que s'il y avoit un retour il seroit absolument necessaire qu'il y eust un homme en cet endroit pour faire les mesmes observations ce qui estoit d'autant plus a considérer que lad. Biblioteque estoit deposée au public ou il y auroit tousjours grand monde aux jours qu'elle seroit ouverte; que mesme il estoit necessaire que l'escallier par ou monteroit fut dans le Colege, sur quoy Monsieur Le Vau a dit que le retour qui estoit disposé pour la biblioteque luy donneroit plus de gayeté et plus d'estendue, que neanmoins s'il causoit ses inconveniens [sic], qu'il pouroit tousjours servir d'un lieu de reserve pour y mettre les personnes de condition, qu'a legard de l'escallier il demeuroit d'accord qu'il seroit mieux a l'autre bout de la biblioteque ${ }^{106}$.

Dès le mois de janvier suivant, la question du transfert et de l'installation de la bibliothèque est posée. Surgit alors un débat qu'on retrouvera après l'ouverture, celui de l'accès le plus propre à servir la solennité du bâtiment et l'appréhension de son décor, et le plus pratique pour le fonctionnement conjoint d'une bibliothèque publique et d'un collège. Le II janvier I666, dans une séance à la laquelle la Sorbonne est représentée, Gomont rapporte que :

Dans le premier projet qui en avoit esté faict, l'on avoit résolu de mettre dans la place l'entrée de l'escalier par où le publique devoit monter a la biblioteque mais que depuis luy avoit vu qu'il seroit plus a propos de mettre led. escalier dans le college, pour deux raisons, la premiere qu'on verroit ceux qui entreroient et qui sortiroient, la $2^{\mathrm{e}}$ que l'autre estant estant $[s i c]$ au bout de la biblioteque, a mesure que l'on advanceroit on descouvriroit le retour de la beauté des veues, et qu'a la veue on trouveroit le retour accompagné d'un salon, ou l'on pouvoit mettre des cartes et globes et d'autres curiosités mesme s'en servir comme une espece de cabinet pour y travailler en particulier ${ }^{107}$.

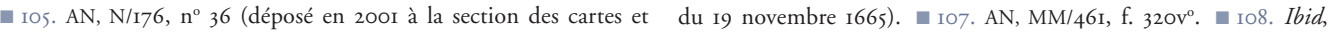
plans), $560 \times 705 \mathrm{~mm}$. IO6. AN, MM/46I, f. 313vº-314 (délibérations f. 322. 


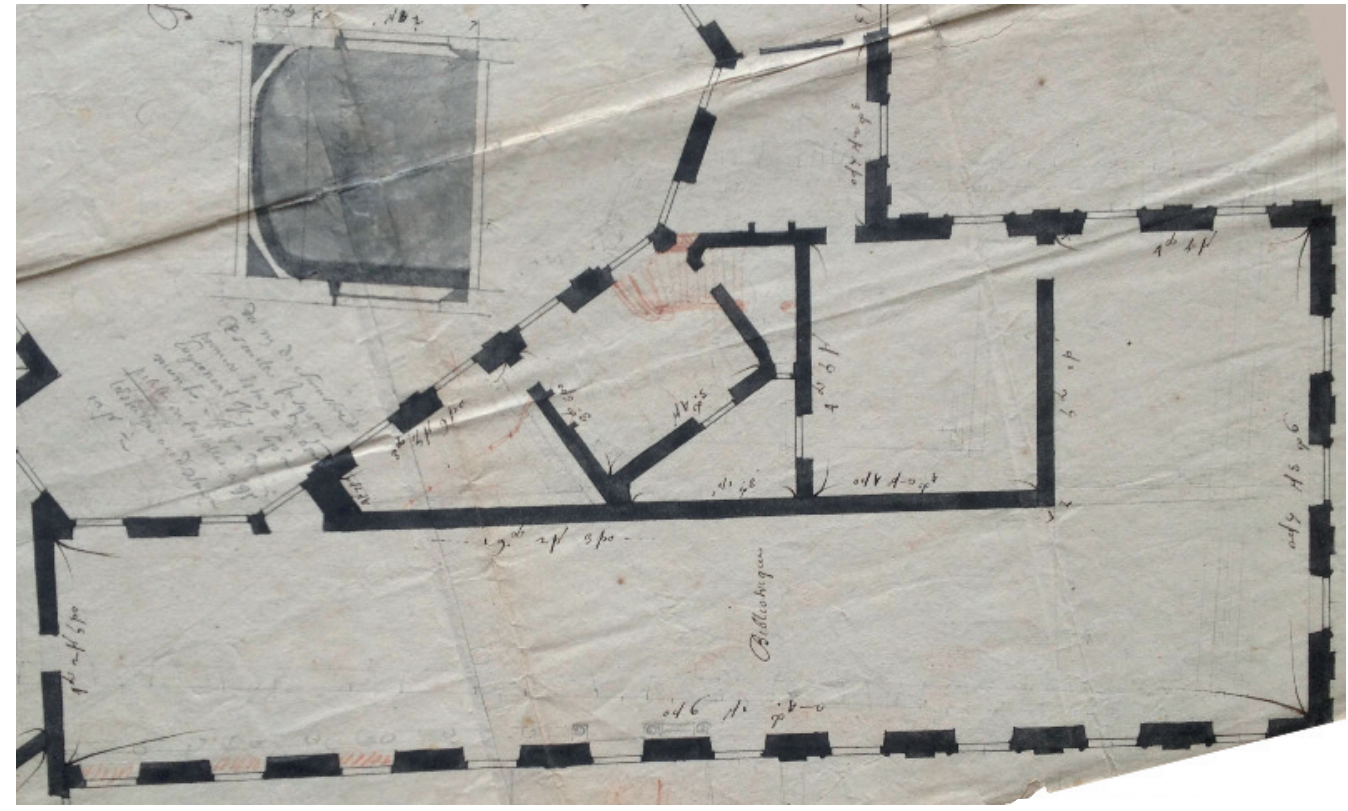

On discute également de la pertinence de conserver le décor de colonnes, et de son adéquation avec les nécessités bibliothécaires. On compare les avantages des différents matériaux pour la couverture du sol, "savoir s'il sera plancheté ou parqueté ou quarelé et de quelle sorte le carreau ou petit ou grand, ou carreau de Caen ou du carreau de marbre ". Le Vau préfere le carreau de Caen, « attendu que s'estoit une biblioteque qui devoit estre ouverte au publique ", mais la majorité se prononce pour le parquet "plus propre $\&$ de plus commode pour les hommes et pour les livres d'autant que le pavé de pierre seroit trop frais pour les estudians et susceptible de l'humidité pour les livres ». Pour mieux asseoir ses décisions, le conseil de fondation effectue même une visite de la bibliothèque de Colbert, récemment aménagée, sous la conduite de Carcavi (le 20 janvier 1666) : on y constate que le sol est pavé de pierre de Caen, et que comme à la bibliothèque de Mazarin, et comme dans les bâtiments qui lui sont destinés dans le collège Mazarin, «ses veues estoient tournées a lorient qui est le soleil qu'on estime le meilleur et le plus favorable ${ }^{108}$ ». Et en effet dans le nouveau bâtiment, dans un premier temps du moins, alors que la petite galerie prend le jour à l'est, au nord et à l'ouest, la grande galerie ne sera ouverte qu'à l'est.

LE TRANSFERT : LES LIVRES (AVRIL I668) PUIS LE DÉCOR (MAI-AOÛT I668)

En mars 1666, la décision de transférer non seulement les livres mais également le décor de menuiserie est confirmée. On évalue la faisabilité, les contraintes et le coût de l'opération. Deux experts sont sollicités, un serrurier, Simon Pottier (l'entablement supporte une balustre de ferronnerie ouvragée, et on se souvient que depuis 1664 la partie inférieure des armoires est équipée de portes grillagées), et surtout un menuisier, Jean Charon. Cet artisan effectuera l'ensemble des interventions de démontage, de transfert, de réinstallation, ainsi que les restaurations et compléments d'ouvrage imposés par le réajustement dans les nouveaux lieux. Charon,
IO. Le pavillon de la bibliothèque au collège Mazarin, vers I665/1666 (Archives nationales). 
qui conduit un diagnostic de la galerie rue de Richelieu, trouve quelques tablettes affectées par des galeries de vers et recommande - on devine aisément pourquoi - une reprise à neuf de la structure des armoires, précisant que « la nature du sappin qui est a la biblioteque qui vient du Norvege est tousjours humide et plain de nœuds, qu'il seroit bien plus a propos d'en faire venir de meilleur du costé d'Auvergne ». L'avocat Gomont, responsable des comptes de la fondation, plaide de son côté pour l'économie. Cet argument a sans doute été décisif pour la conservation de l'intégralité de la menuiserie de la rue de Richelieu ${ }^{109}$, plus peut-être que le devoir de continuité et de fidélité aux intentions du fondateur, qui est formulé pour la première fois en relation avec le décor de la bibliothèque au mois de mai 1666 :

Monsieur de Gomont a dit qu'il estoit necessaire de resoudre de quelles maniere seroient faictes les tablettes de la biblioteque sans rien changer aux ornemens qui les accompagnent, que c'estoit un respect qu'on devoit rendre a sa memoire et une deference aux advis qu'il avoit pri de touttes parts pour la forme \& embellissement de lad. Biblioteque car mesme qu'en se servant de lad. menuiserie on feroit epargne considerable pour le colege, sauf neanmoins a y ajouster ou diminuer ce que l'on jugeoit de plus convenable a l'estat et disposition des lieux, \& pour cet effet monsieur de Gomont a prié Msr Le Vau d'examiner le tout affin qu’au premier conseil il en soit délibéré "ro.

L'été suivant, l'aménagement du pavillon de la bibliothèque se poursuit. On envisage un temps, au moment de la préparation des marchés de vitrerie et de peinture, d'ajouter au décor de la bibliothèque des vitres peintes aux armes du cardinal, qui ne paraissent pas avoir été réalisées ${ }^{\text {III. }}$. Mais c'est seulement le lundi 2I février I667, lors d'une séance particulièrement décisive puisque sont présents Colbert (chez qui se réunit pour l'occasion le conseil) et Le Vau, que les principes de l'aménagement intérieur sont définitivement fixés : «il a esté arresté qu’elle sera parquetée et que l'on y mettra les tablettes \& colonnes qui sont maintenant en la biblioteque de feu son eminence en les faisant adjuster et cadrer aux lieux et endroitz de la biblioteque du college ${ }^{\mathrm{II} 2} »$.

= 109. «Sur quoy Monsieur de Gomont a dit qu'il est tres important de mesnager et employer l'antien bois de lad. biblioteque a cause de la despance ", AN, MM/46I, f. $324 v^{\circ}-325$ (I4 mars I666). IIO. AN,

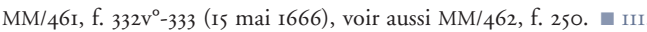
Ce décor de verre peint aurait été réservé aux trois principaux lieux de prestige et de représentation du nouveau collège, à savoir, outre la bibliothèque, la chapelle et la salle des actes : « il falloit faire le choix d'un vitrier qui sceut bien peindre sur le verre pour les lieux ou il seroit necessaire de mettre les armes de feu son Emin ${ }^{\text {ce }}$ avecq autre decoration, savoir en l'eglise en la biblioteque et en la salle des actes; seulement \& non ailleurs ", MM/46I, f. $336 \mathrm{v}^{\circ}$ (6 juillet 1666). Seuls certains " vitreaux » de la chapelle ont, de façon sûre, été peints avec les armes ou le chiffre du cardinal, Registre des délibérations du conseil de fondation du collège Mazarin, 1673-1680, Bibliothèque de l'Institut de France (désormais BIF), ms. 368, f. 5 : séance du 16 janvier I673. NB : Ce registre, identifié comme le troisième, couvre les années 1673 à 1680 ; il a été dissocié de la série principale - aujourd'hui conservée aux Archives nationales dans la série $\mathrm{MM}$ - dès le XVII ${ }^{\mathrm{e}}$ siècle puisqu'il est entré dans la bibliothèque de Nicolas-Joseph Foucauld (I643-172I). D'autres volumes ont été distraits de la série, notamment le deuxième, censé couvrir la période 1669-1672, que nous n'avons pas pu localiser.
- II2. On décide également un premier report de l'ouverture - la date du $\mathrm{I}^{\text {er }}$ octobre $\mathrm{I} 667$ n'est plus tenable au vu du retard pris par les travaux, AN, MM/46I, f. 350v'-35I. II3. MM/46I, f. 356 v (26 février I667), et MM/462, f. $267-267 \mathrm{v}^{\circ}$. II 14 . MM/462, f. $27 \mathrm{Iv}^{\circ}-272$ (I7 juin 1667). III5. " Il ne faut pas panser a faire transporter les livres ceste année, que ce seroit les perdre que de les faire porter dans un bastiment neuf et qui ne seroit occuppé par personne, que neantmoins il estoit a propos d'adviser de donner quelque satisfaction sur ce sujet a $\mathrm{M}$. de Nevers, que luy sieur de Gomont avoit remarqué que le quart des tablettes de la bibliotecque au palais Mazarin estoit vuide, et qu'il n'y avoit aucun livre dans tout le coulidor d'en haut, qu'en pressant les livres dans les tablettes, et en mettant des livres dans celles du coulidor, on laisseroit libre a monsieur de Nevers es lieu ou une moitié du lieu pour y loger, en attendant que la bibliotecque du college fut en estat pour y transporter les livres, et que par ce moyen on pouvoit des a present transporter une partie de la menuiserie de la dite bibliotecque et la placer en icelle du college ", MM/462, f. 272 (I7 juin I667). = II6. Ibid., f. 28I-28IV (séance du 2 mars I668). ॥ II7. Ibid., f. 285 (23 avril I668), f. $285 \mathrm{v}^{\circ}$ (27 avril). La Poterie, qui a organisé le déménagement, sera défrayé en septembre de la somme de 277 l., Io s., ibid., f. 296-v' III. Ibid., f. 295 (29 août I668). 
Le déménagement des livres - et donc désormais de la menuiserie - va se trouver quelque peu précipité, alors même que la galerie en $\mathrm{L}$ du collège Mazarin n’a pas reçu toutes les finitions requises. La raison n'en tient pas au calendrier fixé pour l'ouverture, mais à l'impatience du duc de Nevers, qui a hérité des bâtiments de la rue de Richelieu, et qu'embarrasse cette bibliothèque, son mobilier et... son bibliothécaire. En février i667 le duc fait part de son intention de jouir pleinement de ses appartements et de "faire une grande gallerie " (entendons d'agrément et de réception) du "vaisseau de la biblioteque de feu son Eminence ", espérant "quon luy rendra ce lieu vuide dans la fin du mois de juillet prochain ${ }^{\mathrm{Ir} 3}{ }$. L'impatience de Nevers est croissante : en juin, à la veille d'un voyage en Italie, il rappelle sa volonté de voir la galerie libérée à son retour le mois suivant ${ }^{\mathrm{II}}$. L'inachèvement du pavillon de la bibliothèque - les murs intérieurs ne sont pas enduits, et le marché de parquetage n'est pas encore passé - rend impossible le transfert des livres, pour des raisons aussi bien de conservation que de sécurité. On propose alors au Nivernais de libérer une moitié de la galerie, l'ensemble des collections pouvant être resserré dans l'autre. La chose était possible : la collection qu’avait laissée Mazarin à sa mort était en volume bien inférieure à la première bibliothèque, dont on se souvient qu'elle comptait entre 40 ooo et 56000 volumes en I652, à la veille de sa dispersion. La capacité de la grande galerie de la rue de Richelieu, d'après nos calculs, était d'au moins 40000 volumes; la collection, à la mort de Mazarin, comptait un peu plus de 29000 volumes. On découvre en effet qu'en I 667 le quart au moins des tablettes étaient vides, et qu'aucun volume ne se trouvait implanté dans la galerie supérieure ${ }^{\mathrm{II}}$.

Or à la fin de l'hiver 1667-I668 rien n’a avancé. Le 27 février Nevers a fait adresser par son intendant un mémoire - non retrouvé - rappelant qu’il « vouloit avoir la gallerye de la bibliotecque et le corps de logis qui est au bout, et qu'on eut a faire retirer tous les livres, et mesme le sieur de La Potterie bibliotecquaire ${ }^{116}$ ". Gomont tente à nouveau de transiger, ressort la proposition d'une cession par moitié de la galerie - que Nevers sans doute avait refusée - et évoque un transport des livres pour juillet, car « les bastiments ne sont point encore séchés ni achevés ». Mais Colbert exige en mars que satisfaction rapide soit donnée au duc. Les livres sont aussitôt conditionnés en paquets, et l'opération se précipite lorsque, le 23 avril, le duc fait « lever la serrure de la bibliothèque ", et exige son départ comme celui de La Poterie. Le transport

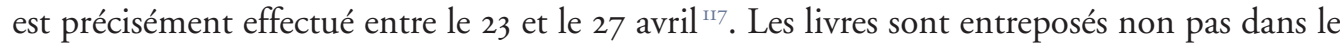
pavillon de la bibliothèque mais dans le collège, très vraisemblablement dans le pavillon principal qui sépare la première de la seconde cour. Le démontage des menuiseries de la rue de Richelieu commence trois jours plus tard, le 30 avril, par la dépose des tablettes de la galerie haute. L'opération est effectuée avec méthode : le menuisier Jean Charon réclame « beaucoup de place dans le college affin de les placer dans l'ordre ou elles sont maintenant et qu'il ny ait point de confusion " puisque " le lieu qui est destiné pour la bibliotecque [...] n’est pas maintenant en l'estat pour y placer les tablettes ». De fait nous avons retrouvé, sur plusieurs éléments verticaux des menuiseries de sapin, des signes à la craie bleue qui constituent autant d'indications d'ordre et de positionnement, renvoyant sans doute au schéma général de remontage qui fut établi. L'opération fut cependant interrompue pendant trois mois, du 5 mai au I3 août, cette fois du fait du duc de Nevers : ayant finalement souhaité conserver une partie de la menuiserie pour son propre usage, il se vexa sans doute du refus des exécuteurs testamentaires, et se montra peu coopératif au point de faire cesser les travaux pour nuisance ${ }^{\mathrm{II} 8}$. 
Dans l'entre-temps, le décor de la bibliothèque eut à subir quelques indélicatesses : à la reprise des travaux, Charon constate que les serrures de près de la moitié des guichets ménagés dans les piédestaux des colonnes ont été ôtées, que d'autres ont été forcées, de même que celles des quatre portes d'accès aux escaliers qui desservent, aux quatre coins de la galerie, le corridor supérieur ${ }^{\text {III. }}$.

Les comptes du collège Mazarin pour les années I662 à I674 font apparaître les noms de tous les entrepreneurs et artisans intervenus sur l'ensemble du chantier. Parmi les menuisiers sollicités, Jean Charon, régulièrement mentionné entre I666 et I674, est le seul qui perçoit des versements en lien avec la réimplantation du décor de la bibliothèque ${ }^{\mathrm{r20}}$, sous l'expertise de Pierre Dionys. Le démontage, le transfert et la pose du décor menuisé de la Mazarine sont sans doute achevés avant la fin de l'année $1668^{121}$. Si le serrurier Simon Pottier est intervenu pour le démontage de la balustre de la galerie haute, les transfert, réajustement et réinstallation des portes grillagées furent confiés à François Jumel, celui-là même qui les avait fournies et installées dans la galerie de la rue de Richelieu entre 1662 et $1664^{\mathrm{I2} 2}$.

En I672 au plus tard, l'ensemble du décor a été mis en place. Les armoires sont alors équipées conformément à l'une des préconisations formulées par Naudé dans l'Advis, celle de garnir les tablettes « de quelque petite serge, bougran ou canevas accomodé à l'ordinaire avec des cloux dorez ou argentez, tant pour conserver les livres de la poudre, que pour donner une grace nompareille à tout le lieu ». En I643, dans la bibliothèque de Richelieu, une partie au moins des tablettes étaient déjà équipées de tels bavolets ${ }^{123}$. On retrouvera ce dispositif de parure et de protection dans la bibliothèque de Charles-Maurice Le Tellier (visible à l'arrière plan du portrait peint par Mignard en I69I, comme dans la gravure qu'en tire Edelinck pour servir de frontispice au catalogue de ses livres en I693) ou dans celle de César d'Estrées (portrait gravé par Giffart, en frontispice de l'édition des Hexaples d'Origène que lui dédie Bernard de Montfaucon en 1713). On suppose que cet aménagement était également présent dans la bibliothèque de Mazarin rue de Richelieu, mais nous ne sommes pas en mesure de le confirmer : les

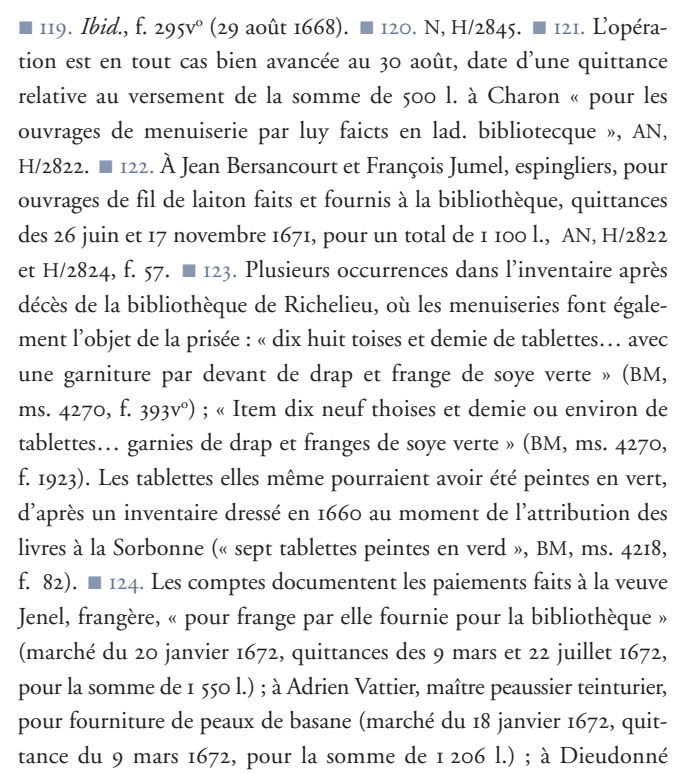

Haroet, marchand tapissier et cuir doré, pour " ouvrages de son mestier " (quittance du 9 mars 1672, pour I80 1.), à Gabriel Coustard et Claude de Berny, marchands drapiers, pour 176 aulnes et demi de "drap de valogne vert guay " (quittance du 24 mars 1672 , pour I 206 1.) ; à Jacques Regnault, maître tapissier, " tant pour son travail que fourniture de cloud doré " (quittance du 28 juin 1672 , pour 800 l.), AN, H/ 2822. I I25. Le 2 janvier, lors d'une visite conduite par François de La Poterie pour les membres du conseil de fondation, on constate que le pavillon de la bibliothèque " a esté trouvé entierement achevé, les armoires posées et fermées et les livres rangez dans leur ordre et prest a estre placez ». Une nouvelle visite, le ro mars, vérifie cette fois que "la bibliotecque estoit rangée comme elle devoit estre, que tous les livres estoient placéz et qu'il n'y avoit plus autre chose a desirer que quelques bureaux pour estudier ", Registre des délibérations du conseil de fondation du collège Mazarin, 1673-1680, BIF, ms. 368 , f. $3 v^{\circ}$ et f. I3. I26. Article $24:$ « la bibliotheque sera ouverte au public deux jours la semaine, le lundy $\&$ le jeudy, depuis huit heures du matin, jusques à dix heures $\&$ demie, \& depuis deux heures après-midy jusques à quatre en hyver, \& jusques à cinq en été ". - I27. La première rentrée du collège s'est faite à l'automne I688, et la bibliothèque ouvrit ses portes au public en avril I689. I28. AN, S/6499A. 
descriptions antérieures à I66I, comme les élévations de Copenhague, sont muettes sur ce point, et jamais, dans les délibérations du conseil d'exécution testamentaire, la perspective de leur dépose ou de leur transfert ne se trouve évoquée. Dans la nouvelle Mazarine ces éléments sont mis en place au cours du premier semestre 1672 : les tablettes sont recouvertes de basane; un bavolet de drap vert, orné d'un galon frangé, est fixé au chant des tablettes par des clous dorés ${ }^{124}$. Rien ne subsiste aujourd'hui des éléments originels de tapisserie et de peausserie qui participaient du décor de la bibliothèque installée dans le collège. Ponctuellement entretenus et renouvelés au XVIII ${ }^{\mathrm{e}}$ et au XIX ${ }^{\mathrm{e}}$ siècles, comme en témoignent les archives comptables, ils ont été entièrement retirés en 1974 , et remplacés.

C'est, forcément, une fois achevées ces ultimes interventions sur les tablettes que les livres purent être disposés dans la nouvelle Bibliothèque Mazarine, au terme d'un séjour temporaire de plus de quatre ans dans le collège. Précisément, les volumes ont été installés sur les tablettes au cours de l'hiver 1673 , entre le 2 janvier et le io mars ${ }^{125}$. On peut donc considérer que dès l'année I673 la bibliothèque était disposée à fonctionner et à ouvrir au public ; cette ouverture attendra cependant le plein achèvement des bâtiments du collège et l'organisation de son fonctionnement. Le 22 octobre 1674 les exécuteurs testamentaires requièrent officiellement son agrégation à l'université de Paris, car « ledit college est maintenant en tel état qu’on y peut faire l'ouverture des classes, \& commencer l'exercice des lettres auquel il est destiné »; mais les lettres patentes portant règlement pour le collège ne sont publiées qu'au mois de mars $1688^{126}$, et le contrat par lequel la Société de Sorbonne accepte sa direction est passé devant notaire le I4 avril de la même année ${ }^{\mathrm{I27}}$. L'acte avait été précédé le 8 avril d'une visite générale dont le procès-verbal a été conservé, en compagnie de François d'Orbay, en charge depuis la mort de Le Vau de la conduite de tous les travaux, de Pierre-Jean Le Chapelier de Moron, grand maître du collège, et de Louis Picques, nouveau bibliothécaire tout récemment désigné : " ensuitte somme descendus au premier estage et entrez dans la salle des globes de laquelle l'on communique dans la biblioteque laquelle salle des globes et biblioteque nous avons trouvé bien parquetée avec armoires, tablettes et colonnes de menuiserie et avons trouvé le tout en tres bon estat » ${ }^{128}$.

\section{LA PERSPECTIVE MAÎTRESSE}

Le groupe est alors entré par la petite galerie du "L ", à laquelle on accède par l'intermédiaire d'un « cabinet " dont la vocation a changé au fil du temps (salle des globes en I688, c'est aujourd'hui l' " atrium " et salle des fichiers). Cette configuration en $\mathrm{L}$ a suscité dès l'époque de Le Vau des interrogations relatives au schéma de circulation et à la manière dont le décor de la bibliothèque devait être appréhendé : en un mot, convenait-il de pénétrer dans la bibliothèque par la petite galerie, accessible depuis la première cour, ou par la grande, accessible depuis l'escalier du collège ? Ces questions ne se posaient pas dans la galerie de la rue de Richelieu, parfaitement rectiligne et ménageant un effet identique par quelque côté qu'on y entrât. En mai I668, alors que le transport des menuiseries venait de commencer, les représentants de la Sorbonne qui suivaient le projet s'interrogèrent sur l'accessibilité de la bibliothèque et souhaitèrent que son entrée fût dissociée de celle du collège, "par ce qu'estant une bibliotecque publique cela feroit du desordre dans la cour des escoliers, surquoy monsieur 
Le Vau a dict qu'il y a deux montées pour monter a la bibliotecque l'une dans le college et l'autre dans la $\mathrm{I}^{\mathrm{re}}$ cour qui n'est point dans le college ${ }^{\mathrm{r} 29}$ ». Le débat reprit au cours des années I690, vraisemblablement en $1694^{130}$, et provoqua les premières divergences entre le collège et la bibliothèque. Le premier souhaitait fermer la porte de communication, au bout de la grande galerie, qui permettait de pénétrer du collège dans la bibliothèque, car elle se trouvait utilisée par les étudiants qui pouvaient passer de la seconde cour à la première et ainsi sortir sans autorisation de l'établissement ; il s'agissait dans le même temps de limiter la fréquentation de l'escalier commun au collège et à la bibliothèque, qui donnait également accès au « trésor » et aux « archives » du premier. Le parti opposé avançait des arguments liés à l'architecture et au décor, imposant le maintien de l'accès principal par le fond de la grande galerie :

Il parroist par la seule inspection du vaisseau de la biblioteque que la veritable porte de celuici et la plus majestueuse est celle du bout, d'où l'ont veoit d'abord la biblioteque dans toute sa longueur, et où la veue part de la partie la plus obscure pour se terminer à la plus eclairée, et non par une porte de coté, où la biblioteque ne paroist avoir aucune longueur, où les voûtes ne sont pas également exhaussées, et d'où etant antré, la biblioteque qui paroist en retour est si obscur dans le fond qu'a peine y peut on decouvrir les objets ${ }^{131}$.

Non seulement l'accès par la petite galerie serait contraire au respect de cette perspective idéale, mais il contreviendrait à la vocation du petit cabinet par lequel on serait alors obligé de passer :

On a destiné ce lieu pour estre fermé quand la biblioteque seroit ouverte, pour y resserer des livres qu'on a jugé ne devoir pas estre meslez et confondus avec les autres, d'où l'on a tout sujet de croire que ce cabinet a esté fait pour y mettre les livres pretieux, les manuscrits et les livres heretiques et deffendus, et peut etre aussy pour y recevoir les personnes de considération et de distinction qui viennent quelque fois a la biblioteque, lesquelles le bibliotecaire jugeroit a propos de distinguer en ne les laissant pas indifferemment avec tout le monde, ainsy qu'il se pratique dans les biblioteques bien regléées, quand elles sont publiques et que tout le monde a droit d'y venir, d'où il s'ensuit que ce cabinet n'est pas propre pour en faire un passage public ou personne ne s'arreste, ou assurement des livres de consequence seroient les plus exposés, etant les plus ecartés et moins en vue des personnes preposées a leur conservation ${ }^{132}$.

I29. AN, MM/462, f. 2938 (délibération du 20 mai I668). I30. Archives de la BM I(2) : " Les Raisons de la maison de Sorbonne pour confirmer la décision faite par les inspecteurs du collège Mazarin avec le grand maître pour changer l'entrée de la bibliothèque " [1694 ?]. - I3I. Ibid. L'extrémité sud de la grande galerie n'est alors éclairée que par les croisées donnant à l'est, car les 3 croisées donnant sur la cour principale du collège, à l'ouest, n'ont pas encore été ouvertes. I I32. Ibid. I I33. Gomont, avec les docteurs de Sorbonne, regrettait alors que l'on " descende " dans la bibliothèque depuis le collège (en effet, la différence de niveau, à étage équivalent, entre le pavillon de la bibliothèque et le pavillon central, a nécessité la mise en place de trois degrés), et demandait à ce que l'architecte abaisse le plancher de la chambre qui précédait la bibliothèque du côté du collège. Le Vau répondit que l'entrée par la première cour [i.e. via le cabinet et la petite galerie] était, lui, de plain pied avec la bibliothèque, et que la vision de ce "grand perron ", au bout de la galerie, "ne sera pas desagreable " AN, MM/462, f. 294 (délibération du 20 mai I668). I34. Dépense en faveur de Jacques Regnault, marchand tapissier " pour le loyer de tapisseries et toiles pour couvrir les livres de lad. biblioteque pendant que l'on a travaillé en icelle aux reparations qui estoient à faire ", AN $\mathrm{H} / 2823$, année 1682 , dépenses. Une malfaçon de la charpente et des faiblesses de maçonnerie avaient été constatées dès septembre 1678 (Registre des délibérations du conseil de fondation du collège Mazarin I673-I680, BIF, ms. 368, f. 220-22I), et plus précisément diagnostiquées le 20 janvier 1679 lors d'une visite à laquelle participait François d'Orbay, AN, H/2845. Les réparations furent sans doute insuffisantes, et seules les transformations de 1739-174I permettront de sécuriser durablement le bâtiment. I I35. AN, MM/464, f. 5 et suiv. I I36. "pou donner un plus grand jour il seroit a propos d'ouvrir les trois croisées fermées qui sont du côté de l'appartement de M. le bibliotecaire ", ibid. - I37. Un plan conservé aux Archives nationale (M/176, n $\left.{ }^{\circ} 3\right)$ montre par des ajouts au crayon de carbone le projet d'implantation des deux escaliers d'accès au couloir haut, l'un dans la petite galerie, à droite de la porte en entrant, et l'autre au fond de la grande, " attenant l'apartement de M. le bibliotecaire" (AN, MM/464, f. $\left.5 v^{\circ}\right)$. I38. AN N/III/Seine/710/5. Dessin retrouvé et reproduit par André Masson, "Mazarin et l'architecture des bibliothèques au XVII ${ }^{\mathrm{e}}$ siècle ", art. cit. I96I, p. 358. 
Cette perspective idéale ne saurait cependant être attribuée au dessein de l'architecte, comme le supposent alors ses défenseurs. Un échange de i668 que le registre de délibérations du conseil de fondation a conservé nous assure que Le Vau était indifférent à cette problématique, et ne voyait lui-même aucun inconvénient à ménager l'accès à la bibliothèque par le cabinet et la petite galerie ${ }^{\mathrm{I} 33}$.

LES INTERVENTIONS SUR LE DÉCOR DE I739-I74I ET I968-I974

Les modifications qui furent apportées depuis la fin du Xvir ${ }^{e}$ siècle aux deux galeries de la bibliothèque ont peu affecté son décor, et pour certaines du reste correspondent à une intention de restitution. Des travaux de réparation de la voûte furent conduits en $1682^{134}$, après quoi la principale intervention date des années 1739-174I. Elle correspondait à une triple nécessité d'urgence, de confort, et d'extension des capacités de conservation. En mai 1739 le bibliothécaire, Pierre Desmarais, faisait état de la nécessité de « réparer le plafond de la bibliothèque qui menace ruine; de donner du jour a lad. bibliotheque en certains endroits et de trouver les moyens de placer les livres actuellement existants et qui existeront dans la suite ${ }^{135}$ ». Le 22 juin Gouffé, maçon du collège, proposa de refaire le plafond en profitant de cette restauration pour créer un étage en attique au-dessus de l'entablement des colonnes, qui accueillerait un nouveau régime de tablettes susceptible d'étendre les capacités de la salle. De fait si Le Vau avait réemployé la balustrade ornée de la rue de Richelieu, celle-ci n’avait dans la bibliothèque du collège qu'une fonction décorative : contrairement au parti originel de la bibliothèque du cardinal, le départ de la voûte juste au dessus de l'imposte avait exclu toute implantation d'une galerie haute.

La faiblesse de l'éclairage au fond de la grande galerie avait plusieurs fois été relevée depuis I668, comme on l'a vu. Il apparait en effet que les trois croisées de la grande galerie donnant à l'ouest, sur la première cour, dont les ouvertures dans la maçonnerie sont bien visibles sur les plans de Le Vau [ill. Io], avaient été conçues comme de fausses fenêtres, et occultées. Le principe fixé par Naudé et mis en œuvre rue de Richelieu, avait donc été jusqu’alors respecté, ce que la connaissance du bâtiment actuel ne révélait pas ${ }^{136}$. Les transformations, conduites entre 1739 et I74I, ont consisté à ouvrir ces trois fenêtres, à transformer la voûte en plafond, et à ajouter une galerie supérieure, ce qui imposa de créer deux escaliers ${ }^{137}$, d'établir un plancher de circulation au-dessus de l'entablement des colonnes et de modifier la balustrade (surhaussée par l'adjonction d'une main courante et complétée de ferronneries ouvragées autour d'un motif en forme d'étoile).

Parmi les plans et relevés du collège Mazarin retrouvés aux Archives nationales, notre attention a été attirée par des dessins qui laissent penser que deux partis ont été successivement envisagés. Trois élévations ont été conservées, qui documentent la préparation des travaux de I739-I74I. La première, seule signalée jusqu'ici, est un relevé de l'existant, qui montre l'extrémité nord de la grande galerie ; on y vérifie le fait que la voûte en anse de panier de Le Vau, partant de l'imposte, ne ménageait aucun espace de stockage au dessus des colonnes ${ }^{138}$. Les deux autres, conservées séparément aux Archives nationales, montrent l'une une coupe transversale de la petite galerie dans sa partie ouest, l'autre une coupe longitudinale intégrale de la grande galerie 

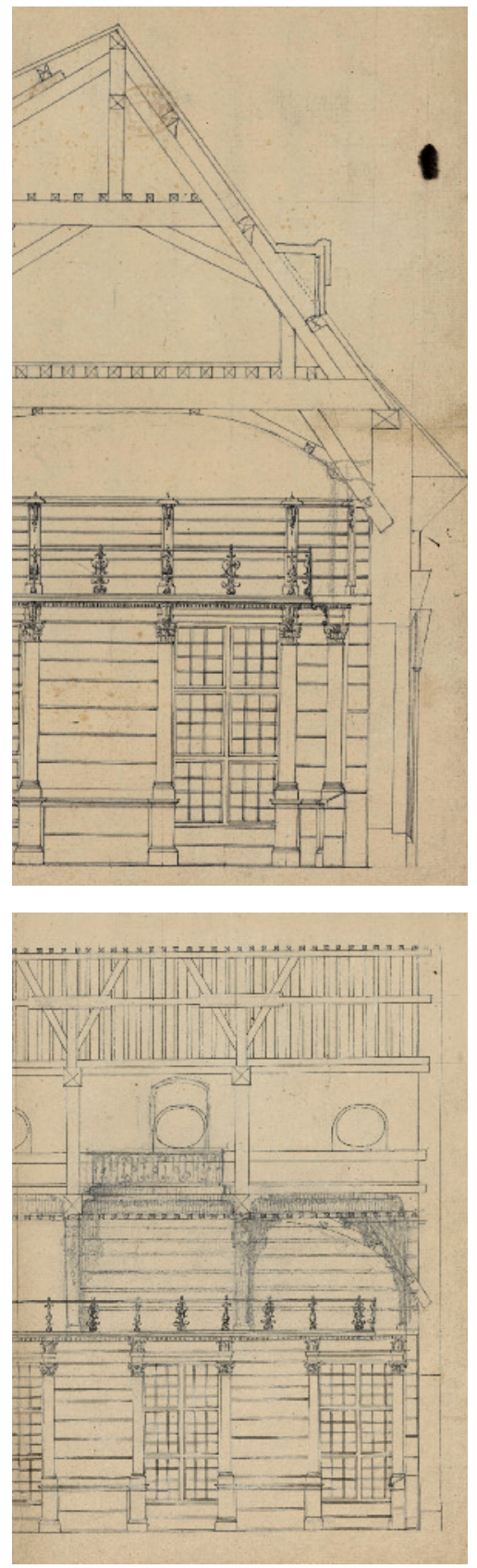

II a-b. Les transformations de I739-I74I. Deux options : surélévation de la voûte ou remplacement par un plafond (Archives nationales).

[ill. II a, b] ${ }^{139}$. La première est une proposition de plafond voûté sous comble, qui maintient le parti de Le Vau, mais dont la surélévation aurait permis d'établir trois à quatre étages de tablettes au-dessus de l'entablement. La seconde représente la situation originelle, sur laquelle une esquisse au crayon de carbone montre comment le remplacement de la voûte par un plafond plat permettra de doubler la capacité du nouvel étage en portant le nombre de tablettes à sept ou huit (sept dans le parti réalisé). Cette hésitation initiale entre un surhaussement de la voûte et son remplacement par un plafond suspendu fut tranchée en faveur de la seconde proposition.

Les devis avaient été présentés au début du mois de septembre 1739 et les travaux exécutés dans la foulée. Dans les archives comptables du collège des Quatre-Nations, un chapitre spécifique est consacré à ces " ouvrages extraordinaires " ${ }^{\mathrm{I} O \mathrm{O}}$. Les travaux ont de fait nécessité une dépense totale légèrement supérieure à 40000 livres, ce qui représentait près de trente fois le budget annuellement alloué à la bibliothèque pour son fonctionnement. Hormis la modification de la voûte, un nouvel éclairage lié à l'ouverture des trois croisées occidentales et le surhaussement du balustre de ferronnerie, l'intervention qui marqua le plus ostensiblement le décor fut l'extension des menuiseries en partie haute. Elles accueillirent un décor de pilastres, réalisé par l'un des frères Slodtz. Franklin avait lu "Sloods " dans les archives du collège, et Pierre Gasnault a évoqué sans plus de précision "le sculpteur ornemaniste Slodtz ${ }^{\mathrm{I} 4 \mathrm{I}}$ ". Il ne s'agit assurément pas de Michel-Ange (I705-I764), cadet des trois frères et le plus brillant : pensionnaire à l'Académie de France à Rome en I728, il ne rentrera à Paris qu'en 1747 . L'aîné, Sébastien (I695-I754), dont la postérité n’a pas conservé le nom, est un candidat plus

I39. AN, M/176-56 et M/I76-I2. Les deux dessins sont exécutés sur le même papier, dont l'usage est attesté dans le royaume à partir de 1734 (filigrane au motif de cœur et au nom du papetier, Chabrier, localisé à Riom, $c f$. R. Gaudriault, Filigranes et autres caractéristiques du papier fabriqué en France aux XVII ${ }^{\mathrm{e}}$ et XVIII ${ }^{\mathrm{e}}$ siècles, Paris, CNRS, 1995, p. I85). I40. AN, H/2832. I4I. A. Franklin, Histoire de la bibliothèque Mazarine..., ouvr. cité, p. 222 ; P. Gasnault, " Collège des QuatreNations... ", art. cit., 2002, p. 88. I I42. Quittance du Io septembre I740, AN, H/2832. La Mazarine ne figure pas dans le catalogue de l'œuvre des Slodtz dressé par François Souchal, Les Slodtz, sculpteurs et décorateurs du Roi (1685-1764), Paris, De Boccard, 1967, p. 613, 617-618 I43. Marché passé le 4 août I740, quittance du 4 octobre. AN, H/2832. Guinard n'est pas identifié par Stanislas Lami, Dictionnaire des sculpteurs de l'école française au dix-huitième siècle, Paris, Champion, I9IO-I9II. II44. 29500 clous ont été dorés, ce qui correspond à la fixation des passementeries de l'ensemble des deux galeries ; un tapissier est par ailleurs intervenu en 1740 et $\mathrm{I} 74 \mathrm{I}$ pour un total de I I23 livres, AN, H/2832. Tous ces éléments (clous, franges et bavolets de drap vert), implantés en 1672 , rétablis, restaurés, ou partiellement restitués en 1740-174I, ont disparu à la faveur de la campagne de restauration de 1968-1974. I45. Le 4 mai 1740, le menuisier Jacques Delcourt s'engage a déposer tout le parquet de la bibliothèque et de l'antichambre, reposer les lambourdes de niveau et le parquet neuf, fournir les clous ; le grand maître du collège fournit de son côté " les feuilles de parquet ", $\mathrm{AN}, \mathrm{H} / 2845$. I46. P. Michel, Mazarin, prince des collectionneurs..., ouvr. cité, 1999, p. 333. I47. Une lettre du directeur de la bibliothèque Jacques Renoult à l'architecte du Palais de l'Institut signalait le 4 octobre 1957 l'urgence de procéder à quelques réparations au parquet avant une réfection générale ; une lettre du Directeur généra des bibliothèques de France au Directeur général de l'Architecture, le 26 juin I96I, relayait une lettre de Renoult en signalant l'aggravation de l'état du plafond de la salle. Les travaux, pour lesquels des crédits ont été ouverts dès I966, furent précédés en décembre I968 de l'aménagement d'une salle de lecture provisoire à l'extérieur du bâtiment, et du déplacement en interne, achevé le 3 janvier 1969, des 40 ooo volumes manuscrits et imprimés alors conservés dans les armoires des deux galeries. Archives de la BM, inventaire en cours. I48. L'exigence de vraisemblance était grand, car nous avons retrouvé un devis de mars I972 qui proposait de réaliser le dos des faux livres en maroquin, veau et parchemin ; la peinture en trompe-l'œil fut finalement préférée, Archives de la BM, inventaire en cours. I49. Rien ne fut conservé de l'équipement antérieur, qui datait de 1672 et avait été partiellement renouvelé en 1740-174I. Un rapport du I5 juin 1970 présenté par l'architecte en chef qui conduisait les travaux de restauration, JeanLouis Humbaire, déclarait hors d'usage la basane collée qui recouvrait les tablettes, comme les bavolets de drap vert bordés de passementeries et cloutés de cuivre. La commande de tapisserie-passementerie du 26 avril 1974 comprenait $300 \mathrm{~m}$ de feutre, I $200 \mathrm{~m}$ de galon de laine, I $050 \mathrm{~m}$ de frange de laine de $45 \mathrm{~mm}$, et 30 ooo clous dorés. I I5O. Le rapport de l'architecte de juin 1970 laisse entendre que les panneaux grillagés qui figurent sur les dessins de Copenhague ne correspondaient pas à ceux alors en place, moins hauts, lesquels auraient remplacé les grillages primitifs à une date indéterminée. Quoi qu'il en soit la décision de ne pas les réinstaller fut prise avant le 2I mai 1973, date de la demande de crédit pour la fabrication des barres de protection encore en place aujourd'hui. 
vraisemblable. Sculpteur sur bois, pierre et marbre, en association avec son frère PaulAmbroise (1702-1758), il a notamment travaillé pour les Menus Plaisirs du roi, donnant en I730 un cadre en bois pour la Chasse de Louis $X V$ peinte par Oudry (qui décorait la chambre du Roi dans le pavillon royal de Marly), exécuté plusieurs décors de théâtre et livré à partir de 1737 les éléments de menuiserie du chœur de Chaalis, aujourd'hui partiellement remontés dans l'église de Baron (Oise) : on y retrouve des pilastres dont le décor vertical est constitué d'une chute d'éléments végétaux accrochés à une palmette, motif également retenu pour les pilastres de la galerie haute de la Mazarine ${ }^{\mathrm{I} 42}$.

Mais d'autres interventions liées à ces importants travaux eurent des conséquences moins visibles, que seules documentent les archives, puisque le souci d'intervenir à l'identique a guidé l'essentiel des opérations. Un certain Guinard, également sculpteur, se vit confier en août 1740 le « retablissement et ajustement des 53 pilastres [sic pour 54 colonnes] » et le soin de « rétabli $[\mathrm{r}]$ l'ancienne sculpture des chapiteaux ${ }^{\mathrm{T} 43}$ ". L'opération ne fut pas anodine; les seules dépose et remise en place de ces éléments principaux du décor originel ont représenté près du double de la prestation qui fut payée à Slodtz (70o livres contre 384). L'intervention sur les chapiteaux, achevée avant février 174I, explique les nombreuses variations qu'une observation fine des profils de volutes et de feuilles d'acanthe permet aujourd'hui de constater, et nous laisse entendre que l'état du remarquable ordre composite qui décore la Mazarine date autant des années I647-I648 que des restaurations pratiquées au XVIII ${ }^{e}$ siècle. Pour le reste, on suppose que les éléments tapissiers qui ornaient et protégeaient les tablettes ont été déposés puis rétablis ${ }^{\mathrm{I} 44}$. On sait, enfin, que l'ensemble du parquet a été renouvelé ${ }^{145}$.

Nous n'évoquerons pas ici les transformations, d'importance, que connurent depuis la fin du XVIII ${ }^{e}$ siècle les autres parties de la bibliothèque (atrium, escalier, combles, espaces de conservation). Les deux galeries en L furent complétées d'éléments mobilier au début du $\mathrm{XIX}^{\mathrm{e}}$ siècle, notamment d'imposants lustres de bronze, ainsi que d'une collection de bustes antiques et modernes (dont deux avaient figuré dans les collections du palais Mazarin avant 1664$)^{146}$. La plupart d'entre eux prirent alors place, sur des socles de marbre, au devant de chacune des 54 colonnes, chargeant quelque peu la perspective conçue en I647-I648, et respectée jusqu'alors.

Enfin, l'ample programme de restauration de la salle de lecture et de restructuration des espaces internes, entrepris entre 1968 et 1974 mais préparé depuis les années $1950^{147}$, introduisit dans les deux galeries les modifications suivantes :

- création ou réaménagement des passages à usage interne entre les magasins et les galeries, trois au niveau de la salle de lecture, deux sur le balcon, tous dissimulés par des portes décorées de dos de livres factices, à la hauteur des tablettes correspondantes ${ }^{\mathrm{I} 48}$;

- renouvellement complet de la tapisserie-passementerie et de la couvrure des tablettes. La basane qui recouvrait les tablettes fut alors remplacée par du feutre ${ }^{\mathrm{I} 49}$;

- suppression des "portillons grillés », qui avaient été placés au devant des armoires du palais Mazarin entre I662 et I664, et transférés en I668 ${ }^{\text {I50 }}$;

- remplacement intégral du parquet de "Versailles ", après constat de l'impossibilité d'en conserver certaines sections. 
La salle de lecture de la Bibliothèque Mazarine doit son décor à l'ensemble des intervenants qui depuis I646 l'ont conçu et mis en œuvre, ou ont contribué par la suite à ses transfert, réajustement et préservation. Cette galerie de portraits, qui comprend architectes, artisans, exécuteurs testamentaires et bibliothécaires, comporte bien quelques figures anonymes ou non confirmées, comme l'auteur véritable du dessin des colonnes, chapiteaux et boiseries sculptées. Mais le réexamen de cette histoire révèle finalement que la transmission du décor qui fait la singularité de la Mazarine aujourd'hui, n'est pas toujours allée de soi. Depuis le XvII ${ }^{\mathrm{e}}$ siècle, la conservation de ce cadre originel a été menacée, par les contraintes architecturales, les accidents politiques, les nécessités bibliothéconomiques, les ambitions de renouvellement, et, à partir du $\mathrm{Xx}^{\mathrm{e}}$ siècle, paradoxalement, par les intentions " patrimoniales ».

1652. La Fronde

En janvier et février 1652, on le sait, les livres et manuscrits de la première bibliothèque parisienne de Mazarin, quelle que fût leur localisation (grande galerie et ses annexes et anciennes salles du palais de Chevry-Tubeuf) furent dispersés en vente publique. Il faillit en être de même du décor, soit que le Parlement ou les Princes y aient vu la possibilité d'accroître ainsi les revenus de la vente, soit que des convoitises particulières aient été formulées parmi les acquéreurs. C'est ce que nous révèle une lettre de Naudé à Mazarin du 3I janvier : " ainsy toutte cette bibliothecque aura esté vendue un mois durant et pacquet a pacquet, sans que l'on ayt envoyé le moindre ordre de la cour pour l'empecher, et comme ils se vantent maintenant de vendre les tablettes, les plafonds et statues, je croy qu'ils en viendront a bout si l'on n'y veut apporter quelque remede ${ }^{\mathrm{ISI}} »$.

\section{Menace d'effondrement}

En 1653, pas même six ans après la livraison de la galerie, une expertise conduite par l'architecte Jacques Lemercier sur le comble de la bibliothèque conclut à un "péril imminent ». Louis Le Vau conduisit vraisemblablement les interventions de reprise qui s’imposaient sur la charpente ${ }^{\mathrm{IS} 2}$.

n. I5I. Kathryn Willis Wolfe et Philip J. Wolfe, Considérations politiques sur la Fronde..., ouvr. cité, p. II7. I I52. Lettre de Colbert à Mazarin du 19 juillet 1653 (BnF, ms. Baluze 216, f. 23I) ; le profil corrigé par Le Vau, daté du 22 juin I654, conservé aux Archives nationales, $\mathrm{Z} / \mathrm{ij} / 277$, a été retrouvé par A. Cojannot, "Le cardinal Mazarin et l'architecture française ", Mazarin, les lettres et les arts..., 2006, p. 97 et p. 437 , n. I4. I53. AN, MM/46I, f. 40. On notera que s'il est exact que le collège devait être agrégé à l'université de Paris, le testament de Mazarin avait laissé toute latitude en matière d'implantation à ses exécuteurs : «l'establissement dudict college auquel la biblioteque est jointe et de l'academie sera faict soubz le bon plaisir du Roy en la ville cité ou université ou aux fauxbourgs de Paris et en mesme ou divers lieux le tout selon que les executeurs de la presente fondation cy apres nommés le trouveront plus a propos " (copie dans AN, MM/462, f. 4). La proposition de Bellinzani n'était donc pas irrecevable à l'aune des intentions du fondateur. I54. AN, MM/46I, f. 320Vº-32I (délibération du II janvier I666). 
Parmi les lieux proposés en I66I et I662 pour accueillir le collège des Quatre-Nations et la Bibliothèque Mazarine (bâtiments du collège du Cardinal-Lemoine, Jardin des Plantes, hôtel d'Orléans...), il en est un qui est resté inaperçu de tous les historiens. La suggestion consistait tout simplement à établir la fondation du cardinal dans le palais Mazarin. La Bibliothèque Mazarine serait ainsi restée dans la galerie conçue par Le Muet et Valperga pour la bibliothèque de Mazarin. L'idée fut avancée en juin I662 par Francesco Bellinzani (I6I9-I684), discret conseiller du cardinal passé au service de Colbert, et qui était alors associé aux délibérations du conseil de fondation, avec le duc de Mazarin, Le Vau, Colbert et l'avocat Gomont. Elle apparaît furtivement au détour du compte rendu de la séance du 29 juin : «Monseigneur Belinzani a fait la proposition du Palais Mazarini pour y establir le college laquelle n’a pas esté recüe a cause de la situation dudit palais hors de l'Université ${ }^{153}$ ". On ne sait pas si le duc de Nevers, à qui la partie occidentale du palais était attribuée depuis le partage de juillet I66I, fut informé de cette hypothèse rapidement écartée. Les conséquences de ce choix sur l'histoire non seulement de la Mazarine mais de la Bibliothèque nationale auraient été considérables.

\section{I666. De l'inconvénient des colonnes}

Au mois de janvier I666, alors que le conseil d'exécution de la fondation commençait à se préoccuper du transport des livres et de la menuiserie, le sort des colonnes fut remis en question. Le contenu des échanges qui nous ont été conservés témoigne bien du caractère singulier de cet élément, qui frappait les visiteurs par sa monumentalité. Comme on l'a dit, il ne s'agissait pas dans la galerie de la rue de Richelieu d'un simple élément ornant le chant vertical des armoires, mais d'un régime à l'apparence architectonique, au caractère imposant. Citons le verbatim de cette séance. L'avocat Gomont rappelle que

son eminence n'avoit pas seulement donné les livres de sa biblioteque mais la menuiserie pour celle du college laquelle à la verité estoit magnifique et ornée d'un bout à l'autre d'un tres bel ordre de colonnes et de pillastres [il s'agit des pilastres de bois de la galerie haute, visibles sur le dessin de Copenhague, et non conservés dans le transfert] à la corinthienne, mais que les colonnes ne sembloient pas propres ny convenables a la disposition d'une biblioteque qui veult qu'en entrant par un bout on puisse decouvrir des livres de par \& d'autre sans empeschemens, \& que les colonnes \& pillastres pour leur saillie font un effect tout contraire par ce qu'elles cachent tellemen les livres en entrant qu'on ne peut presque voir que ceux qui sont a l'endroit ou on est, qu'il estimoit qu'il seroit beaucoup mieux de n'en point mettre du tout en la biblioteque du college, et ce servir d'icelles-là pour orner les salles des arts \& autres lieux ou elles pouvoient servir ${ }^{154}$.

Quelques jours plus tard, le 20 janvier, Gomont réitère ses réserves :

Monsieur de Gomont a faict remarquer d'abord et dès l'entrée du lieu a cette compagnie la beauté et l'ornemen que donne la disposition de ce grand nombre de colonnes de menuiserie 
qu'il y a dans tout le pourtour de cette magnifique biblioteque, mais d'ailleurs aussy les mauvais effects qu'elles faisoient par leurs saillies et advancées qui outre qu'elles diminuent notablement de la longueur du lieu elles ostoient encore à la veue le moyen de voir plainement \& sans interruption les deux costés de la biblioteque a la suitte des guichets ou sont les livres qui en decorent les facades, la Compagnie est demeurée d'accord que les colonnes ne convenoient pas au lieu ou elles estoient et que comme les livres sont les plus beaux ornemens des biblioteques il faut aussy que rien ne fasse obstacle pour les veoir et les decouvrir de l'entrée d'un bout à l'autre, ensuite de cela on a mis en question de scavoir si le colidor qui regne au hault de cette biblioteque en tout son pourtout y estoit utille, et propre en quelque chose, la Compagnie a jugé que non, mais il y avoit du danger de s'en servir ${ }^{155}$.

On regrette que Le Vau, qui ce jour-là a du se rendre à Versailles, n'ait pu participer au débat et nous laisser le point de vue qui était le sien. Si fort heureusement la position de Gomont, partisan de l'économie - il est responsable de la bonne exécution budgétaire de la fondation -, n'a pas été retenue, ses arguments ne sont pas si éloignés des principes qui ont prévalu pour la conception de la bibliothèque de Mazarin : sobriété, disposition fonctionnelle, espace continu et unifié sous le regard du visiteur, mise en valeur de la masse des livres. Il eut en revanche gain de cause (au moins jusqu'en 1739) pour le « colidor », remplacé par un simple balustre établi sur l'entablement.

\section{Les prétentions du duc de Nevers}

Nous avons noté l'impatience que Philippe Mancini manifestait depuis février 1667 à prendre effectivement possession de l'ensemble des bâtiments qui lui revenaient d'après le partage de I66I. En mai I668 cependant, il effectua un revirement surprenant : alors que la bibliothèque avait été vidée de ses livres, que les tablettes de l'attique avaient été entièrement démontées et que le menuisier entreprenait de démonter celles de la partie basse, le duc fit interrompre les travaux et proposa d'acquérir toute la menuiserie encore en place pour la somme de 3 ooo livres. On ignore l'intention qui était la sienne, car il ne possédait pas de bibliothèque personnelle qui exigeât un tel cadre. Mais la doxa du conseil de la fondation était fixée depuis I666, et on arrêta que " pour estre les intentions de feu S E les tablettes qui estoient au palais Mazarin dans lesquelles estoient les livres de la bibliotecque, seront transportées et placées en la bibliotecque du college Mazarin en la mesme manière qu'elles estoient au palais Mazarin, eu esgard a la convenance du lieu ${ }^{156}$ ". On observera que, si le conseil de la fondation, par fidélité à la mémoire de Mazarin, a refusé l’offre du Nivernais, la même année il cédait à la Bibliothèque du Roi une partie de la collection des livres du cardinal, comprenant tous ses manuscrits ${ }^{157}$.

I55. Ibid., f. $322 \mathrm{v}^{\mathrm{0}}-323$. I56. AN, MM/462, f. 293 (délibération du 20 mai I668). II57. Requête formuée par Colbert le 20 décembre 1667, entérinée par un arrêt du conseil du Roi le I2 janvier I668. II58. Les Premiers Travaux de la commission des monuments historiques, 1837 I848 : Procès-verbaux et relevés d'architectes, éd. Françoise Bercé, Paris, Picard, 1979, p. 96, 99-I00. I I59. Registre des délibérations du conseil de conservation de la Bibliothèque Mazarine (1850-1909), p. 79 (séance du 6 juin 1860). Archives de la BM, inventaire en cours. I60. Le projet ressurgit plusieurs fois, et ne paraît définitivement abandonné qu’à la veille de la Seconde Guerre mondiale, J.-P. Babelon, Le Palais de l'Institut..., ouvr. cité, p. 97-IOI. = I6I. La taille attendue du fichier n'autorise cependant pas à penser que tous les entrecolonnements aient été concernés. Archives de la BM, inventaire en cours. 
À plusieurs reprises des projets urbanistiques de l'État ou de la ville de Paris ont menacé le pavillon de la Bibliothèque Mazarine, voire l'ensemble des bâtiments du collège Mazarin, affectés à l'Institut de France depuis I805. En I840, le Préfet de la Seine et le conseil municipal, afin d'élargir les voies de circulation, envisagèrent de reculer la façade sur le quai en supprimant la première arcade, ce qui aurait imposé un nouveau déménagement de la bibliothèque ${ }^{158}$.

Sous le Second Empire, d'après le schéma général de planification des axes de circulation parisiens défini par le baron Haussmann en I853, un boulevard continu devait relier la gare Montparnasse à la gare du Nord, qui aurait traversé la Seine sur un pont établi au sud de l'île de la Cité. Le premier segment - la rue de Rennes, dont le percement est achevé en I870devait être prolongé au-delà du boulevard Saint-Germain, et rejoindre le quai en traversant le Palais de l'Institut. Différents tracés ont été successivement envisagés, dont l'un, discuté au début de l’année i860, supposait la démolition de l'essentiel de la façade édifiée par Le Vau face au Louvre, pavillon de la bibliothèque compris. Le projet inquiète alors aussi bien l'Institut de France que le personnel de la Bibliothèque Mazarine. Il semble que la décision de préserver les pavillons - celui de la bibliothèque et son pendant, celui " des arts " - ait été prise par l'Empereur suite à une visite du palais effectuée le 8 mai I $860{ }^{\mathrm{I}}{ }^{59}$. En effet, les différents partis ultérieurement proposés préservent la bibliothèque : la rue de Rennes prolongée vers le Nord, quel qu'eût été le détail de son tracé, aurait certes coupé le palais, mais à l’angle sud-est de l'aile de la bibliothèque ${ }^{\mathrm{I} 60}$.

\section{Supprimer les pupitres?}

En août 1954, le directeur de la bibliothèque, Jacques Renoult, envisagea de transformer la partie basse des menuiseries des deux galeries, en en retirant les livres, en supprimant les pupitres intégrés entre les colonnes et en aménageant sur le pourtour de la salle une rangée de tiroirs à fiches, qui aurait été malgré tout " assez bien étudiée pour ne pas déparer le décor ${ }^{16 \mathrm{I}}$ ". Le projet est né de l'abandon du catalogue sur registres (affectant la forme du codex, ils étaient parfaitement compatibles avec les menuiseries de la salle), et de la croissance du fichier au format dit « international ». On observera que la dématérialisation en cours, étape successive dans l'évolution de la matérialité des catalogues, prémunit toute incidence du développement catalographique sur le décor de la bibliothèque.

\section{6-1972. Peindre les boiseries?}

La campagne de restauration des années 1968 à 1974 donna lieu à un vif débat sur le traitement à appliquer aux boiseries, qui apparaissaient alors plus sombres qu'elles ne sont aujourd'hui la couleur « chocolat " est récurrente dans les rapports du temps. La question de leur couleur originelle fut incontestablement le point le plus délicat des travaux. Le débat fut porté sur la place publique, Le Monde du 2I février 1970 s'en faisant l'écho à l'occasion d'une visite du chantier par le ministre de l'Éducation nationale Olivier Guichard. 
Les interrogations naquirent de la redécouverte des dessins de Copenhague, publiés en 1965 et accompagnés d'une description de la mise en couleur dont ils avaient fait l'objet au $\mathrm{XVII}^{\mathrm{e}}$ siècle, les rayonnages apparaissant gris clair, les colonnes blanches et dorées, le balustre et les cadres de serrurerie dorés, et les grilles brunes ${ }^{162}$. Orientées cette fois par un souci de fidélité au parti originel, imposé non pas tant par une révérence au fondateur, que par les principes de restauration et de restitution patrimoniales, elles furent formulées dès 1966, au moment où se préparait le volet " restauration » du chantier. Sollicité par Renoult, André Masson, historien du décor des bibliothèques, s'était appuyé sans hésitation sur les examens de Knud Bøgh, et avait préconisé une mise en peinture conforme à ce que les dessins de Copenhague laissaient supposer de l'apparence des boiseries dans le palais Mazarin ${ }^{\mathrm{I} 63}$. En 1969, l'avancement du chantier exigeait qu'une décision soit prise. Dubitatif, l'architecte en chef des bâtiments civils et nationaux en charge de l'Institut, André Gutton, confia au laboratoire du Louvre l'analyse de prélèvements. Connus en mai 1969, les résultats renforcèrent son scepticisme : parmi les différentes couches qui empâtaient alors uniformément le décor, au-dessus d'un premier enduit directement posé sur le chêne et de la couleur du bois naturel, seule une couche au carbonate de calcium, d'apparence blanche, fut repérée, mais qui était vraisemblablement destinée à recevoir les couches supérieures. Une réunion du 23 janvier 1970 vit le débat se cristalliser autour de deux propositions contradictoires : le directeur de la bibliothèque et la direction des bibliothèques, appuyés sur les dessins de Copenhague et l'avis de Masson ${ }^{164}$, préconisaient une mise en peinture, tandis que Gutton recommandait un décapage et une restitution du bois naturel, qui serait par la suite très légèrement teinté. On s'en remit à l'avis de la Commission supérieure des Monuments historiques; réunie un mois plus tard, le 23 février, elle opta pour une mise en peinture blanc et or afin de restituer ce qu'on estimait être le " décor d'origine ". Cependant, une fois la décision arrêtée et les décapages préalables entrepris, Jean-Louis Humbaire, l'architecte en chef qui venait de remplacer Gutton, signala que nulle part on n'avait trouvé trace de peinture blanche. On fit en I97I une maquette d'une travée de la salle de lecture ; on reprit l'examen des dessins de Copenhague ; Maurice Piquard, qui venait de remplacer Renoult à la direction de la bibliothèque, envisagea de se rendre à la Kongelige Bibliotek, mais on fit finalement faire aux dessins originaux le voyage de Paris, où ils furent examinés au début de l'année 1972. La commission supérieure des Monuments historiques se réunit à nouveau le 3I janvier 1972, sur place. La valeur documentaire des dessins de Copenhague fut pour la première fois relativisée : on attira l'attention sur le fait qu'il s'agissait de dessins d'architecte, indifférents au décor comme à l'aménagement, susceptibles de convoquer la couleur pour souligner la courbe d'une voûte ou la profondeur d'un relief. De nouveaux sondages, qui révélèrent la présence par endroits de cinq à neuf couches de

- I62. K. Bøgh, "Kardinal Mazarin og Frederik IIIs Bibliotekssal... ”, art. cit., 1965. 1 I63. Lettre à Renoult du 23 septembre 1966, Archives de la BM. I64. Masson achevait alors son ouvrage sur le Décor des bibliothèques, publié en 1972, dans lequel il soutiendra, s’appuyant sur les seuls dessins de Copenhague, que les boiseries de la Mazarine étaient peintes : « il régnait donc une harmonie de teintes claires rehaussées d'or analogue à celle qui fait aujourd'hui le charme de la bibliothèque d'Admont, en Autriche, par exemple, et cette découverte arrive à point au moment où l'État engage des crédits importants pour la restauration de la Bibliothèque Mazarine ", ouvr. cité, p. 99. L'insistance de Masson s'explique par l'âpreté des débats et le caractère emblématique du chantier. 165. Louis Hautecoeur, Histoire de l'architecture en France, tome 2 : Le règne de Louis XIV, Paris, 1948, p. 358. I66. Le projet a fait l'objet d'une esquisse au I/100 ${ }^{\mathrm{e}}$, conservée par les héritiers de Georges Mathieu, et reproduite dans Mathieu : 50 ans de création, Paris, Hervas, 2003, p. 182. Je remercie Lydia Harambourg ne m'avoir mis sur la piste de ce document. 
peinture foncée et de vernis, confirmèrent l'absence de peinture claire et d'or sur l'ensemble du décor sculpté. Si les boiseries de la rue de Richelieu avaient été peintes en blanc et or, des traces en auraient forcément été retrouvées, même à supposer que le décor ait subi, en 1668 ou en 1739-174I, un décapage que les sources du reste ne documentent pas. La restauration de 1968-1974 confirma donc et, préserva, la couleur « au naturel » du décor de la Mazarine. Cette neutralité originelle servait l'intention de sobriété et de fonctionnalité du décor de la bibliothèque de Mazarin. De fait elle tranchait avec les standards de la décoration en France au milieu du XviI ${ }^{e}$ siècle : le grand historien de l'art Louis Hautecoeur l'avait dit, qui eut justement à se prononcer en 1972 en tant que membre de la Commission des Monuments historiques, les contemporains de Mazarin et Mazarin lui-même étaient habitués aux décors intérieurs où, par le recours à la peinture, tout était fiction : le bois devenait marbre, la peinture tapisserie et la tapisserie peinture, les grisailles imitaient le bas-reliefs et les camaïeux simulaient le bronze ${ }^{\mathrm{I} 65}$.

1968. Peindre le plafond? Restituer une voûte?

En 1968, une approche jusqu'au-boutiste de la restauration a sans doute influencé les personnalités qui programmaient les travaux pour que la perspective de restitution d'une voûte soit évoquée, qui aurait ainsi rétabli la situation antérieure à 1739 , et rapproché la bibliothèque de la configuration qui était la sienne dans le palais Mazarin. Le directeur, Renoult, y était alors assez favorable, qui envisagea de supprimer l'essentiel des tablettes de la galerie haute, et de refouler 15 ooo volumes, soit 417 m de rayonnage. Dans le même temps Jacques Rueff, chancelier de l'Institut, exprimait le désir de faire décorer le plafond de la Mazarine par le peintre Georges Mathieu (I92I-20I2), fondateur de l'abstraction lyrique. La Commission supérieure des Monuments historiques eut à se prononcer sur ces projets le 25 octobre 1968. Elle les écarta tous les deux : les échanges firent valoir que l'horizontalité d'un plafond peint serait écrasante, et que seule une voûte pourrait servir de support à un effet pictural; mais celle-ci, en réduisant l'attique de quatre niveaux, imposerait une démolition des pilastres sculptés du XVIII ${ }^{e}$ siècle, devenus partie intégrante du patrimoine décoratif de la Mazarine ${ }^{166}$.

\section{Transformer la bibliothèque en musée?}

Avant que les grands travaux des années 1968-1974 ne soient programmés dans le détail, un projet de restauration avait été esquissé, qui passait par l'abandon de la fonction bibliothécaire des galeries de la Mazarine. L'hypothèse à laquelle Jacques Renoult commença de songer peu de temps après son arrivée à la tête de la bibliothèque (1945), consistait à transférer l'essentiel des fonctions bibliothécaires et bibliothéconomiques (accueil des lecteurs, communication et consultation des collections, manutention, magasins) dans un nouveau bâtiment, implanté à l'est du palais de Le Vau, à la place d'un bâti existant encore privatif [ill. I2] Plusieurs esquisses, tracées sur des plans du quartier après 1952, permettent de constater que dans ce schéma la salle historique de la Mazarine [ill. 13] aurait été tout entière dévolue à un « Musée du livre ». 


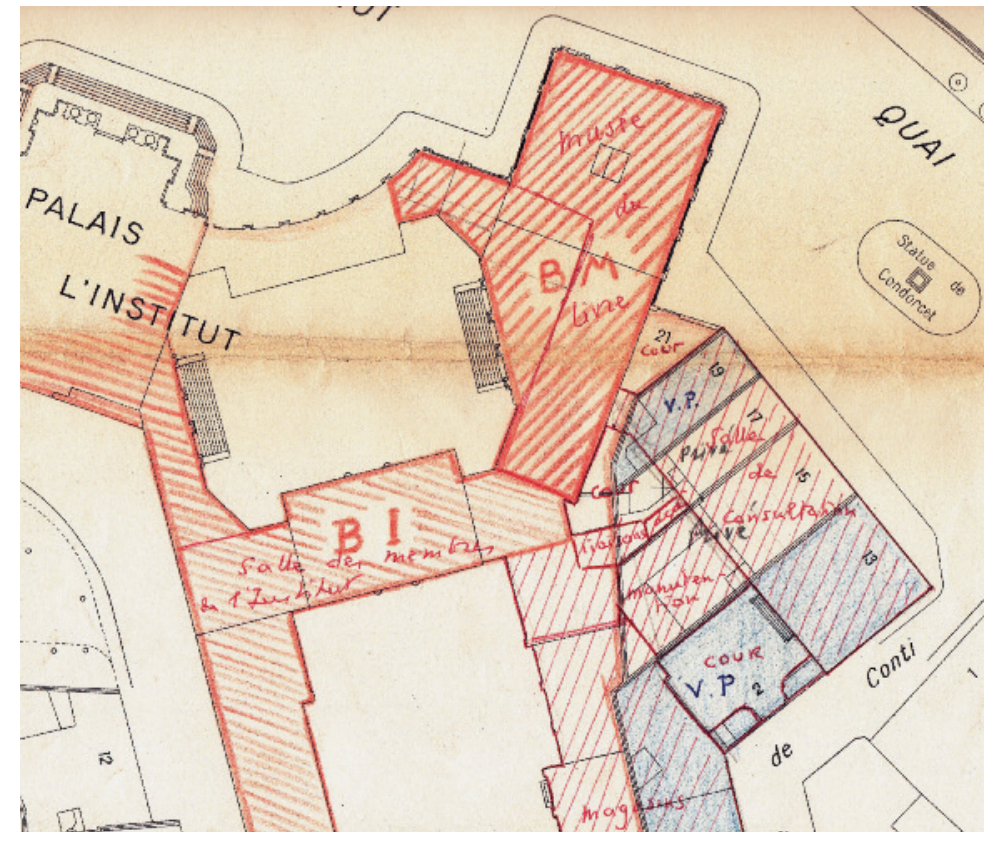

I2. Transformation de la Bibliothèque Mazarine projetée par Jacques Renoult, vers i960.

Il semble que ce projet ait habité Renoult pendant l'essentiel de la durée de son administration, alors même qu'il préparait les chantiers que son successeur, Maurice Piquard, allait poursuivre à partir de 1970. Dans un rapport sur les travaux en cours adressé au chancelier Rueff le 3 janvier 1969, à quelques mois de la retraite, il écrit :

Un jour viendra où, par la force des choses, le Palais de l'Institut s'étendra sur les terrains qui le séparent de l'Hôtel des Monnaies. Sans détruire un paysage urbain qui vaut d'être respecté, derrière les façades des maisons, une opération de curetage comme il s'en pratique tant permettra d'édifier de grands blocs de magasins à livres et une salle de travail de plusieurs centaines de places. Cette nouvelle bibliothèque pourrait vivre sur les collections de la Mazarine et celles de la bibliothèque de l'Institut [...]. Quant à la noble galerie de la Bibliothèque Mazarine, débarrassée [sic] de ses fichiers, de ses tables, de ses chaises, convenablement équipée de vitrines, elle offrirait un cadre idéal au musée du livre qui n'existe pas encore à Paris ${ }^{167}$.

Ce dessein, en retirant à la galerie sa fonction première, était sans doute censé servir la restitution et la mise en valeur du décor original, conformément à une certaine orthodoxie patrimoniale. Mais, paradoxalement, pour paraphraser Mersenne, il défaisait le projet Mazarino Naudaeum, qui interdisait de penser l'architecture et le décor du lieu sans sa fonction bibliothécaire. Il ôtait à la galerie la vocation particulière qui lui avait été conférée en I646-I648, pour la rendre à la généralité d'un espace de déambulation, de représentation et de collection. Un espace certes ouvert, "voué au public " pour reprendre le mot de Naudé, que les pas comme la vue permettraient d'appréhender dans sa totalité, mais qui ne serait plus bibliothèque, seulement témoignage et représentation de bibliothèque. 
Les transformations ou destructions auxquelles la galerie de la Mazarine a échappé depuis le $\mathrm{XvII}^{\mathrm{e}}$ siècle, montrent a contrario que le décor des bibliothèques peut être plus vulnérable que les livres qu'il contient. Elles montrent aussi que tour à tour, parfois contradictoirement et souvent in extremis, l'ont préservée la révérence au fondateur, le souci d'économie, les principes " patrimoniaux », mais également le fonctionnement bibliothécaire.

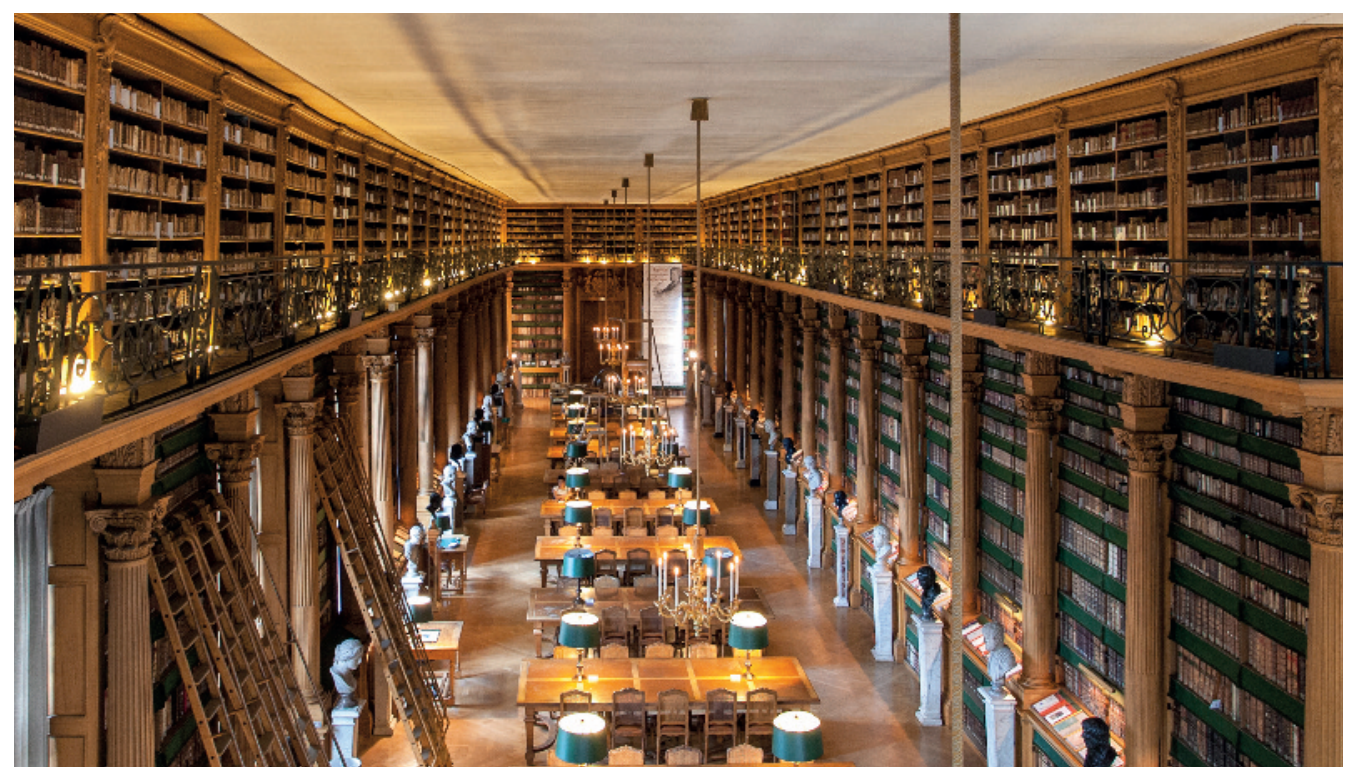

13. Bibliothèque Mazarine (cliché Guillaume De Smedt, 2013). 


\section{TABLE DES MATIÈRES \\ INHALTSVERZEICHNIS}

SOMMARIO

FréDÉRIC BARBIER, Bibliothèques, décors, XVII ${ }^{e}-\mathrm{XXI}{ }^{e}$ siècle

FrÉDÉRIC BARbIER

Illustrer, persuader, servir : le décor des bibliothèques, I627-I85I

Elmar Mittler

Kunst oder Propaganda?

Bibliothekarische Ausstattungsprogramme als Spiegel kultureller Entwicklungen und Kontroversen in Renaissance, Gegenreformation, Aufklärung und Klassizismus

Hans Petschar

Der Prunksaal der Österreichischen Nationalbibliothek.

Zur Semiotik eines barocken Denkraumes

Andreas Gamerith

Klosterbibliotheken des Wiener Umlands - Alte und neue Motive

Michaela ŠEFERISOVÁ LoudovÁ

Ikonographie der Klosterbibliotheken in Tschechien I770-I790

Szabolcs SerföZŐ

Barocke Deckenmalereien in Klosterbibliotheken des Paulinerordens in Mitteleuropa

ANNA JÁvor

Bücher und Fresken

Die künstlerische Ausstattung von Barockbibliotheken in Ungarn

JÁNOS JeRnYei-Kiss

Die Welt der Bücher auf einem Deckenbild

Franz Sigrists Darstellung der Wissenschaften im Festsaal des Lyzeums in Erlau

Doina Hendre Bíró

Le décor de la Bibliothèque et de l'Observatoire astronomique

fondés par le comte Ignác Batthyány, évêque de Transylvanie, à la fin du XVIII siècle 
YANn SoRdet

D'un palais (I643) l'autre (I668). Les bibliothèques Mazarine(s) et leur décor

FiammetTa SABba

I saloni librari Borrominiani fra architettura e decoro

Andrea De Pasquale

249

L'histoire du livre dans le décor des bibliothèques d'Italie au XIXe siècle

Jean-Michel Leniaud

L'invention du programme d'une bibliothèque (I780-1930)

Alfredo Serrai

I vasi o saloni librari

Ermeneutica della iconografia bibliotecaria

Index locorum et nominum

283

Les auteurs

299

Crédits photographiques

303

ISBN : 978-2-86742-254-6 